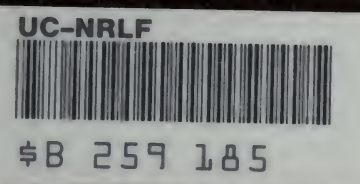

\title{
TROUT FISHING
}

II. C. CUTCLIFFE, FR.C.S. 
Gifford Patch, Jr.

East_Lansing Michigan

B ER RETEY

GENERAL

LIBRARY

UNIVERSITY OF

\section{CALIFORNIA}

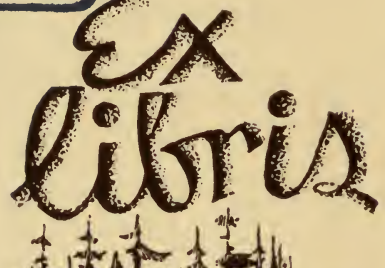

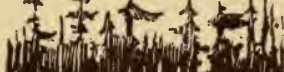
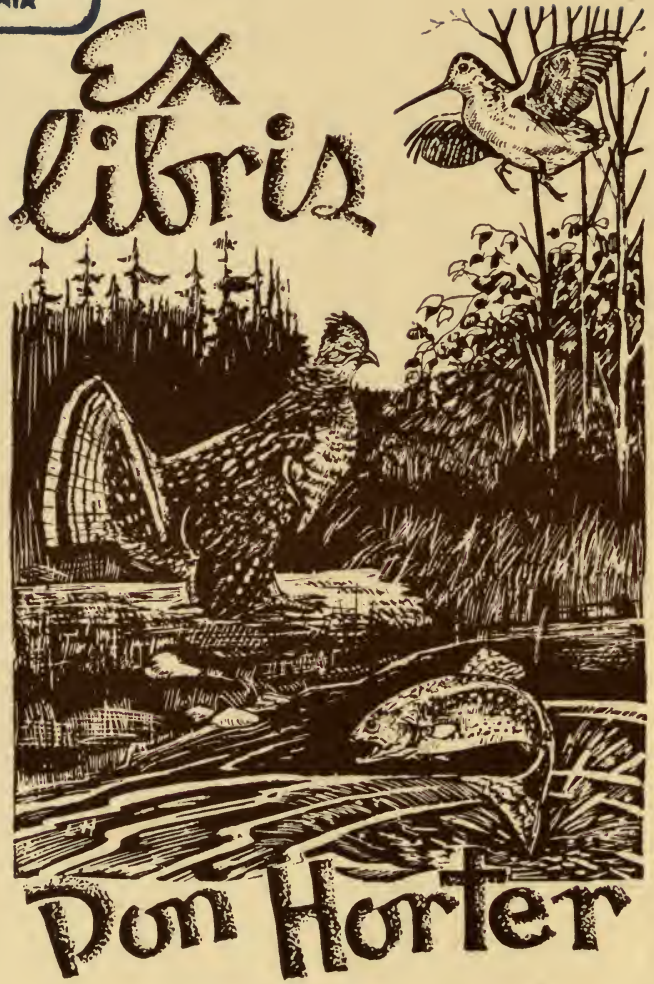

Digitized by the Internet Archive in 2007 with funding from Microsoft Corporation 


\section{THE ART OF \\ TROUT FISHING ON \\ RAPID STREAMS : \\ COMPRISIYG \\ A COMPLETE SYSTEM OF FISHING TIIE \\ f2orth 还evon Streams, \\ AND THBIR LIKE:}

WITH DETAILED INSTRUCTIONS IN THE ART OF FISHING WITH THE ARTIFICIAL FLY, THE NATURAL FLY, THE FERN WEB, BEETLE, MAGGOT, WORM, AND MINNOW, BOTH NATURAL AND ARTIFICIAL.

BY

H. C. CUTCLIFFE, F.R.C.S.

\section{LONDON}

SAMPSON IOW, MARSTON, SEARLE, \& RIVINGTON Limited

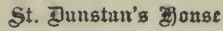

Fetter Lane, Fleet Street, E.r.

[All rights reserved] 


\section{BOOKS FOR ANGLERS.}

SECOND EDITION, NOW READY.

\section{DRY-FLY FISHING IN THEORY AND PRACTICE.}

By FREDERIC M. HALFORD, F.L.S.

ROYAL OCTAVO EDITION. Price, in cloth extra, 25.

** Fully Illustrated by Woodcuts, Chromo-Lithographs, and Coloured Steel Plates. Prospectus on application.

Floating Flies and How to Dress them. By FrEDERIC M. HALFORD. With full lllustrated Directions, and containing Ninety Hand-Coloured Engravings of the most Killing Patterns, together with a few Hints to Dry-Fly Fishermen. Second Edition. Demy 8vo, cloth, 158.

Near and Far: an Angler's Sketches of Home Sport and Colonial Life. By WM. SkrIor "Red Spiuner"), Angling Editor of The Field, Author of "Waterside Sketches," \&c. Crown 8vo, cloth, 6s.

Waterside Sketches. By "Red Spinner" (Wy. Senior). Imp. 32mo, boards, 18.

The Sporting Fish of Great Britain. By H. ChоцmondelexPEN NELL. Illustrated by Sixteen Lithographs of Fish in Gold, Silver, and Colours. First Edition. Demy 8 vo, 158.

Modern Improvements in Fishing Tackle and Fish Hooks. By H. CholMONDELEY-PENNell. With Two Hundred Illustrations. Crown 8 vo, cloth, $\underline{2}_{8}$.

North Country Trout Flies. By T. E. Partr. With Coloured Plates of all the best Flies. Second Edition. Demy 8vo, cloth, 108, 6d.

The American Salmon Fisherman. By HeNRY P. Wels. Illustrated. 116 pages. Smalı post 8 vo, cloth, $6 s$.

Fly Rods and Fly Tackle. Suggestions for Amatenrs as to their Yanufucture and Use. By HENRX P. WELLS. Illustrated. Small 4to, 361 pages, cloth extra, 108 6 $d$.

Recollections of Fly-Fishing for Salmon, Trout, and Grayling. By EDWaRD HAMrtox, M.D., F.L.S., \&c. Illustrated. Small post svo, (clo:h extra, 6s.

An Amateur Angler's Days in Dovedale. Being un Account of my Three Weeks' Holiday in July and August, 1884. Imp. 32mo, fancy boards, 18 , limp leather-cloth, gilt euges, 18,6d.

Fresh Woods and Pastures New. By the Author of "An Amateur Angler's Days in Dovedale," "Frank's Ranche," \&c. Large fcap.8vo, cloth, 18.6d.

A Book of the Running Brook : and of Still Waters. By LADY COLIN CAMPBELL. 12mo, handsomely bound in grey linen, lettered in gold, with gilt top, 58 .

How and Where to Fish in Ireland. By Hr REGAN. With Map and uumerous Text Illustrations. Second Edition. Crown 8ro, 3s. $6 d$.

Notes on Fish and Fishing. By J. J. Manlex, M.A. With Illustrations. Crown 8 vo, cloth extra, 363 pages, leatherette binding, reduced from 118. $6 d$, to $6 s$.

The Art of Trout Fishing on Rapid Streams. By H. C. CuтCLIFFE, F.R.C.S. Small post 8vo, cloth, $3 s .6 d$.

Float Fishing and Spinning in the Nottingham Style. By J. W. MARTiN, the "Trent Oiter." Coloured boards, Illustrated, crown 850, $28,6 d$. New, Revised, and Enlarged Edition.

The Book of the Roach. By the late J. Grevilhe FenNeli. In cloth, 28.

Ast Any of the above Works will be sent post free (on receipt of remittance to cover the price) by the Publishers-

SAMPSON LOW, MARSTON, SEARLE \& RIVINGTON, LD., ST. DUNSTAN'S HOUSE, FETTER LANE, LONDON, E.C. 


\section{SH 687 \\ C 88 \\ 1889 \\ MAN}

\section{PREFACE.}

I HAVE been induced to publish a little work on trout fishing on rapid streams, such as those in the North of Devon, by the following reasons.

The style I practised in the North of Devon was one not commonly worked out, if known, in all its details, by the fisherman in that county.

The success which resulted from the practice of my System of fishing was more than ordinary.

The inquiries which were constantly made of me, when I was in England, led me to think that an exposition of my views of the art of trout fishing would prove acceptable and useful to my old friends at homs.

The last has been really my chief motive in the attempt, as I fully believe, and sincerely hope that 
I may be of some assistance by my writing, to those I have had the pleasure of knowing at home, as well as to many other brother fishermen.

For my incompetency for the execution of my desires, for the many errors in expression, and haste with which the type has been allowed to appear, I claim the leniency of my readers in their criticism, and trust that as I have set about my task with the utmost desire to exercise my feeble powers, to the furtherance of the sport of North Devonians, so they in kindly feeling, acknowledging the intention of the author, will less consider the rhetorical construction of sentences, than the practical matter contained within the work.

I may be allowed to explain that I commenced this work many years ago, and used to write a few sheets at a time, during a period I was prosecuting severe studies in London. Want of opportunity prevented my completing my design till I had been some time in India, but my duties there were of such an absorbing nature as to prevent my giving up the time and attention necessary to complete the work to my entire satisfaction. Indeed I found, on reading over the manuscript, 
that the early sheets had been so written, that in order to work up the whole to a good or complete arrangement, I should have had to re-write them from beginning to end. In England this would have been no difficulty, but in India, where English writers are not for such purposes to be obtained, I had either to give up the idea of publishing, or to send to the press the manuscript as it was. Convinced that I had embodied in some form or other in the book all the knowledge I possessed that could be of any assistance to a fisherman, I determined to offer it to my friends in the hope that they would make kindly allowances for defects.

I feel sure that in perusing the work some will think me tediously prolix in one part, whilst others will consider me unsatisfactorily brief in another. The artificial fly fisher will think I have not written enough on his branch of the art, whilst the minnow fisher will complain that I have spun out worm-fishing and cut down minnow-fishing to an inadequate conciseness. To each and all I apologize, but at the same time beg them to understand that I have been eu- 
deavouring to expose a System of fishing, founded on certain known principles, of which the different modes of fishing, when considered collectively, constitute the practical art. Each subdivision of this art has been by no means written of as a separate and distinct treatise on the special subject; on the contrary, it has been only so dealt with as its relative importance and special significance, or distinct characteristics, have seemed to require. The whole taken collectively forms the System which I have practised; and I believe that if what I have written be carefully studied in all its details, tediously minute though they may at first appear, and my directions closely followed by the scholar, he will very soon fall into a style of fishing which will yield him unprecedented success. But I caution the beginner to be careful rightly to understand my expressions, or he will fall into sad disappointments. He must attend as much to the style of working the bait (for example) as the bait itself. Take the case of the gaudy artificial flies for upstream fishing: if he simply follows my instructions as to the manufacture of the flies, and tbinks he can kill fish with them in any other 
way than that I teach, he will find out too late his mistake. Let him learn the principles, then the mode of using the bait, and then the bait itself, and he will find my method the most reasonable, as it will be the most destructive to the trout.

I cannot conclude my prefatory remarks without a passing tribute of respect to the memory of an old and highly esteemed friend, the late Dr. Thorne, of South Molton; of his virtues generally, it would ill become me here to write-they deserve a higher eulogium in a more appropriate place, than I can give them, and will ever remain most highly respected in the memory of all who knew him. As a fisher of small, rapid streams, I never met his equal-his keen love of sport, his close observation of every minute detail in any way affecting fishing-his constant and earnest reflection on every circumstance connected with the art-his open candour of communication-and his persevering industry in carrying out his ideas, placed him, in my opinion, a King-fisher of small, rapid streams. From him did I glean my elementary knowledge of up- 
stream fishing. It was from his instructions I began to see things as related to the rapid streams in a new light, and from these I was. set a-thinking on the subject, and though in after years my views progressed and enlarged, and indeed in many respects differed from my early tutor, I yet am now sensible and gratefully so, that I owe my powers of enjoyment with the rod and line, mainly to the early lessons kindly given me by the late Dr. Thorne.

Should any reader desire a practical lesson in the art of worm-fishing in bright water, I recommend him to put himself under the guidance of one David BaLe, now I think a letter-carrier, residing at High Bray. $\mathrm{He}$ is the best worm fisher I ever saw, and, moreover, is a most civil, indeed I may say polite man, truthful and honest, and will be found a most respectable and wellinformed companion to the fisherman, who, I trust, will not forget to well acknowledge the merits of honest old David, now, I fancy, not over well provided with the good things of this life. 


\section{CONTENTS.}

\section{CHAPTTER I.}

Preliminary remarks .

\section{CHAPTER II.}

Habits of the trout in dull deep rivers contrasted with those inhabiting the rapid lively brookTrout in rapid streams almost always feeding: their different kinds of food-Localities selected by the trout for feeding-The best fish if feeding in the place most conducive to his obtaining food-The particular retreats of individual fish -Their constant appetite-The natural rapacity and tyranny of the trout

\section{CHAPTER III.}

Our resources for his allurement-The advantages of acting on his rapacity-The principles on which different baits are to be worked-The necessity of self-concealment-The directions 
in which trout see best-Circumstances which assist or oppose our efforts: how best used to our own advantage-All adversities may be overcome and fish always caught in rapid water

\section{CHAPTER IV.}

Artificial fly-fishing-The commencement of the season-Habits of trout early in the yearLarger streams preferable at this season to brooks, which afford most sport in autumnal fishing-The box of fly-making materialsFurs, hackles, and various materials necessary for fly-making-To breed fowls for hacklesFisherman urged to make his own flies-Instructions for so doing-Winged flies objectionable-The colours of flies - The flies commonly used by the author on North Devon streamsThe gut and collar: its length-Lines, reels, rods: their varieties, modes of action, length required, and how to make them-The different joints-Woods to be used-Boots for wadingCutting crooks for saving flies hitched in trees, \&c.-The principles of fishing on large streams

\section{CHAPTER V.}

Fly-fishing on small and rapid streams in bright weather-Rod to be used: how to make it: its action and advantages-Flies which are the author's favourites-Collar-Precepts for beginners-Practice to be adopted in fishing with the artificial fly 


\section{CHAPTER VI}

\section{NATURAL BAITS.}

The natural fly-Dapping-The fern web and the beetle compared: their relative advantagesThe mode of using both-Their powers as a bait-The waters best suited to th
CHAPTER VII.

The maggot-Alone or on a fly-The advantages of the maggot-The way in which it is to be used, and the particular time at which it is most serviceable $\cdot \cdot \cdot \cdot$
CHAPTER VIII.

The worm considered as a bait, and full directions as to the practice to be adopted to render it powerfully destructive on rapid streams in low and bright water $\cdot \cdot \cdot$
CHAPTER IX.

Fishing with the minnow-Artificial and natural - The two compared-Instructions in their use-Particular points to be observed . . 188

\section{CH.IPTER X.}

Concluding remarks on flies-Receipts for making artiticial flies-Table to indicate the most reliable flies to be used on North Devon streams throughout the year 



\section{TROUT FISHING ON RAPID STREAMS.}

CHAPTER I.

THE Fisherman has much to urge in favour of his sport, but as I am writing for those only who may be supposed to be already preconvinced that pleasure is to be found in prosecuting the art of Fishing, I shall dwell no more on the delights incidental to the art, than to remark that it is conducive to numerous collateral amusements and pursuits, and to urge the young beginner to recollect that in his piscatorial rambles he will be placed most opportunely for the study of all natural phenomena, and to advise him to take up some branch or branches of natural science as a study at home, so that in his walks he may practically apply and enlarge his book-learnt knowledge. Botany, Natural History, and Geology are especially connected with his art, and let me add, attention to these subjects, schools and disciplines the mind well for a fiture adept in piscatorial art. The study of these 
natural sciences tends to make the mind observe closely; and I will here state that no faculty assists so much in making a man a successful fisherman as that of observation does, and one may pretty safely infer that the youth who observes accurately and well, will, if he perseveres, become speedily skilful in his art: indeed it must be on the development of this faculty that he must chiefly confide for ultimate distinction.

The tastes of fishermen, as of other men, are very various. Some will condescend to fish for nothing but the largest trout; some will only fish quiet, almost still streams; and others only rapid ones. Many are influenced more by necessity than choice in the waters they fish, depending on the special locality they may be in. But each stream has its own peculiar and distinct charms. Upon the stream and its country is the fisherman dependent for many of the secondary pleasures. derivable from the prosecution of his sport. Should he prefer the deep, muddy stream, having: but little fall, and of sluggish monotonous course - the country for him to admire will probably be Hat, its outlines sober, and in accordance with the dark, gloomy, sluggish stream he wanders by; his movements too in fishing will be slow and quiet; he has time to observe the natural scenery, whose character and the nature of his occupation will conduce to grave and reflective thoughts. The very fish harmonize with his sombre mood. There they will be lazily basking in luxurious idleness-their bloated sides exposed to the 
genial warmth of the summer sun-stupidly sleeping out an indolent existence. To watch their gills in slow movement induces a yawn-in fact as is whole there is a perceptible want of animation, variety, and stimulus. Should chance lead him to the stream of greater speed rolling along with rapidity, now and then impeded at lengthened intervals by accumulations of stones or other artificial or natural barriers, sinuous in course, of clear aspect, flowing through luxuriant valleys, flanked by hills of gentle slope, adorned by woods succeeding the rich pasture land of its banks, indulging itself here and there in the calm repose of a large pool, shaded with overhanging bushes, where indeed fishermen delight and love to watch the tempting waters, with the busy populace of flies hovering over them, and the fat large-sized trout on all sides greedily feeding on the lively insect now bathing in, now hovering over the sides of the eddies, or perbaps just burst its chrysalis cell and dropping from the bough of an overhanging tree in innocence to trust its ephemeral body to instinctively attractive water, little knowing that in close proximity is the watchful trout, which presently opens wide his jaws, and on a sudden the poor insect is extinct, and added to the numbers now partially digested in the gullet of the dainty fish, here indeed his occupation and his thoughts will be more cheerful than when on the sluggish stream; but if with this he is always content, I pity him, for assuredly he has never felt the mirth-giving gaiety of the bubbling B 2 
brook. He has, I will grant, on these large streams fine opportunities for sport; and perhaps, at the end of the day, a handsome dish of large trout for his friends-but in his walk he has not enjoyed the variety of scene and sport, the wildness of nature, the bold unbroken outline of country, which so much enchants the frequenter of the moor streams, wandering for hours, altogether undisturbed by man, in full and unlimited enjoyment of some of the most magnificent country England can boast of, and called by his art to traverse a much greater extent of it than he possibly could do were he engaged on a greater breadth of water. The little merry stream itself, bubbling and splashing, sporting and bounding along, is at one time bursting through the narrow charnel left it by opposing rocks to precipitate itself hastily, and then angrily escape its narrow bounds to swell out again as though to assert its own freedom and determination of course; then again is it nestling into the bosom of a tranquil pool, to the delight of the old fish, thither retreating in advancing years, to end their days in comparative ease and luxury. But the stream sleeps not, for, lo! again is it spreading itself out widely over the shingly bottom, sparkling in the sun, and undulating onwards, till meeting an opposing bank it deviates from a straight course, and darts now again with greater declension hastily to one side, to form again another course; thus falling and collecting, twisting and turning, then smiling, now threatening, again placid and yet again 
enraged,-coquette as it is, constancy is only applicable to its variations of character; at every turn we see some new feature, and no five yards are alike. It presents in itself every variety of stream, and all connected with it is variety, excitement, and quickness, and tends to arouse the enthusiasm of the sportsman.

One might perhaps carry the consideration of the subject yet further, and dilate much on the peculiar effects of different kinds of streams in influencing one's whole frame of thought and idea; but my object is to deal with reality, and this chapter will be concluded with the shortest allusions to the pleasures of fishing, which are attractive to the young and old-to the young most especially as beginners', for they have all their limbs and senses in vigour, are more enthusiastic, and though less patient will yet be persevering when the probability, nay, certainty of success is held out to them; and to them, as a recreation from study, it is of all sports most desirable, since it is innocent in itself, obtainable by all from the little expense attending it, is most conducive to health, assists mental as well as corporal development, calls forth the young mind to observe for itself accurately and independently, . and conduces to the acquisition of most pleasing subjects for reflection in after years. Boybood is the proper time to commence fishing, in order to study and master the Art; but to the old it is highly agreeable, the quiet and peaceful retirement of the country, and the simplicity of the 
Art itself, contrasting sweetly with the anxieties and cares, the strife and contentions of society: and actual business of this life; tending to prolong a present existence, and by withdrawing the aged mind from its natural vice, happily favouring the preparation for a future, as it elevates the mind from worldliness, and conduces to the blissful consideration of a beneficence which has ordained so fair a world for man's reception, and induces a right and proper consideration of such blessings, and the change his body, in common with all around him, so shortly must undergo. This again is a subject apart from my intention, but a passing commentary on the healthful tendency and mental peacefulness begotten from the sport could not be avoided, inadequate though the remarks are to convey the convictions which experience and habitual devotion to the subject have stamped on the minds of veterans in the Art. 
ON RAPID STREAHS.

\section{CHAPTER II.}

WE must now proceed to the immediate intention of the work, and consider fishing as an Art as it has seemed best adapted.to small rapid streams such as are found in the North of Devon in all parts, on Exmoor, or in the South of Devon, and on Dartmoor. These streams will afford a suffcient type of the class of streams to which $\mathrm{my}$ remarks are most particularly applicable; such streams indeed may be found elsewhere in Wales, Scotland, and England, but taking my old favourite haunts as the seat of operations, I shall be able to write more practically, and make my remarks apply more forcibly, than if I were not so to keep the very water I am fishing before my eyes, even whilst occupied with pen and ink instead of the actual rod and line; at the same time, after selecting my type of streams, and thus excluding such as are not of their kind, it will be necessary to do no more in the way of particularity, and it is not intended to append special remarks on any peculiar mode to be adopted on any one stream or another, but rather to generalize the subject thus previously curtailed, classifying only 
those streams left us so far as may relate to the rapidity and depth of their course.

There are certain principles which regulate the Art of fishing, as they do every other Art, and these principles in themselves have appeared to me to be simple enough when rightly understood. We shall by-and-by be occupied in the simplification of these principles, endeavouring to reduce them to a few truths, and render them intelligible to the veriest tyro that ever handled a rod.

I doubt not there are many who would much desire to fish, if they could do so with sufficient success to be entertaining, but who, being engaged the greater part of their time in business occupations, are unable to adapt their business to their pleasure, and learning that sport with the trout is only to be obtained on special occasions and particularly favourable days, are timid to hazard their brief leisure time, and try their skill in such commonly called precarious and variable sport, and from fear of being disappointed in their endeavours are altogether debarred the pleasure of many delightful rambles by the sides of streams which would lead them to country beauties, and afford them delight to be obtained by all at the expense of a little patience and perseverance. Indeed the strongest, though perhaps most common argument, it would seem that is adduced against fishing for trout is, that it is uncertain and requires a very large amount of time to understand the details of the system, and more especially, as is usually urged, the 
precise fly to be selected on any particular day or hour. As to this point of selection of the fancied fly, it appears the common belief that the trout are so extremely dainty in the choice of their viands, that for each particular meal, occurring at regular intervals of the day, they are expectant of, and searching for, some peculiarity in their food; such distinctive discrimination urging them to the necessity of selecting, at one time a fly which a little later in the day would be rejected, basing or at least connecting their views of the trout's choice of flies, with the different varieties of insects at one time or another to be observed in most abundance on the surface of the water, rendering them thereby the more plausible, inasmuch as they are set down as being consistent with the natural habits of the trout, which all admit must be carefully studied ere we can expect a mastery over a fish apparently so sly and cunning; - -well, this view may, nay, I know full well does, apply in some degree to the Art of flyfishing, or deceiving trout by flies in ponds, or any such deep and still water; but as a principle to rely upon for success when our endeavours are directed to rapid streams, it is utterly fallacious, and the result of an imaginative theory, rather than the correct deduction from observed facts.

The trout in the pond, as an extreme example, or in deep sluggish rivers, is a fish whose habits are retiring, whose feeding is at intervals, and to whom rest succeeds a hearty and satisfactory meal; - he has little labour to perform, the pond or 
river offers him no resistance from force of water, he has merely to paddle himself at his leisure, and when not requiring food, to retire to some quiet deep hole for more perfect rest and slumber ; and again when his appetite calls him forth to seek food, he does it quietly and deliberately, knowing that as the resistance of the water is but slight to him, it can be but slow in removing his prey from his reach; and should a fly attract his gaze from his deep haunts, he has a considerable space to swim through in a direct line ere he can catch it, and consequently has much time to observe the insect and perhaps be pleased or displeased with its kind or exact form, and should the attraction be but artificial, of course with much consideration, he is well able to discern the deception, and ultimately refuse it altogether; moreover in these deep and sluggish waters, trout feed extensively on grubs, small fish, and such food as is generated usually in abundance by the sides of such streams; they are not therefore so much induced to be constantly snatching at every little silly fly that may come within their grasp, which after all the trouble requisite to catch him, is in truth but a small morsel. In these kinds of streams too, the number of the trout actually present is proportionally small as compared with the amount of food to be obtained, they have therefore less pressure of the necessity to race for every mouthful; they grow too, usually to a large size, since they live more summers than the little fellows in the small streams ordinarily do, and being less per- 
secuted by the poacher, and having plenty of food are fat and handsome:-to capture such trout we must make our baits as natural as possible, select such days as are most favourable to our deception, imitate the exact fly we have just perhaps seen one monster swallow, and be after all content with the size of the few captured at the end of the day, rather than the agility, activity, quickness, and strength displayed by a larger number of smaller fish. I remember having read in some book on fishing by a great authority, that when the wind is southerly, the waters of proper colour and quantity, the sky cloudy, the air warm, and the season suitable, we may select our best flies, go forth and hope for success in sport with trout, then and then only; but unfortunately every one desiring sport may not be able on such special occasions to withdraw himself from ordinary avocations on a sudden without preparation, and take his rod and fly book in immediate exchange for other books on the chance of success. If such views as these were in all cases correct, and so restricted, very few would be able to participate in the pleasures of fly-fishing; as most of us would care only to make fishing the recreation and not the business of life, we should desire to know how we could render our amusement suitable to our own convenience of time, and be able whenever we wished it to take a day's holiday and be tolerably certain of a day's sport. To this, I am sorry to say, in its universal application, I must admit that there is a great obstacle, namely, in the locality or situa- 
tion in which we may be placed; for if we can only command the deep, slow, and sluggish streams, I fear we cannot be absolutely sure always of the result of our labours, though even on these streams we may be far more so than is generally admitted, yet it cannot be denied that we are in great measure dependent on the river, the wind, and the weather, and not wholly and entirely on our own skill and exertions for success.

Now, having admitted this of the deep sluggish stream, we can do no more, asserted though I well know it is, that the same reasons and principles apply to the small and rapid, as well as the large deep streams-this I cannot allow, as I know from experience that such principles lead to very uncertain results, and attendant disappointments; so here let the barrier be drawn between the two kinds of water, that speaking of the rapid we may not be thought to include the slow, for the habits of the fish frequenting the rapid are as different from those inhabiting the slow, as must be our mode and practice of alluring the one and deceiving the other.

From the habits of fish in small and rapid streams will we deduce our principles for founding our ideas of fishing these streams, and the more fully we comprehend this portion of our subject the more correct will our reasonings be, and the more fruitful our labours prove.-Let us endeavour then early to form sound and correct opinions of our subject; let us not be guided or governed by the dogmatical statements of one person or 
another, as to what method is most suitable to our field of operations; let us not be biassed or limited in our attempts by the authoritative and often too positive assertions of others, but rather having formed our own notions on correct and just grounds, let us bring them early into practice and strive to steer a course as free and independent as the right knowledge of a subject demands ; we shall then be better able to judge of what others say, to refute their errors, and profit by their experience and statements when they have been justly and reasonably considered. A determination to comprehend fully the habits of the trout, to observe for himself and reason from his observations independently of all rules and dictatorial assertions of others, will inspire the young fisherman with an interest and ardour, patience and perseverance, which must inevitably make him speedily celebrated in his Art;-but to go to the water's edge full in his mind of what others say of the manner in which a fly must be cast (for example) the time for its being put on, the length of line, collar, and rod, and I know not how many other particularities, without any idea of the reason why such must be, will inevitably ere many hours have passed bring disappointment to his hopes and disgust at the want of success which he so soon complains of; he takes his rod in hand for the purpose of trying in practice what others have stated concerning the subject, but we well know the impossibility of any one, however well versed in rhetoric, conveying to the mind of those 
unskilled in the Art he treats of, all the miunte details of his practice, which often form the most important parts of his own skill and knowledge: his rough ideas of the subject he may give, and they will be perhaps remembered, ay and by the scholar thought all-sufficient and infallible, till sad experience disproves his notions and scatters his treasure nostrums; should he even partially succeed in his application of the crude ideas of others, the only reason he can give to his inquiring mind why he succeeds, js, that some one told him by such means he would do so, or because some one who did likewise, succeeded; the novelty of experiment will soon wear off, and variety of means being deficient carelessness will soon overtake the disciple, his shallow knowledge will be speedily exhausted, and an idea or feeling of tameness will attach itself to the subject which in no long time will be altogether abandoned, or if awhile pursued, more numerous trials will not effect a corresponding change or increase in success, which would assuredly have resulted, had the fisherman in the first instance learned to think for himself, instead of implicitly relying on the statements and dogmas of other people.

Of all the various modes of fishing, artificial fly-fishing is beyond compare the most exciting; it is that which beyond all others is sport; now although we feel confident of our assertion, we may yet obtain much amusement and profitable knowledge in learning and prosecuting other modes of fishing, indeed the less we limit our 
early ideas of the means we possess, the more ample in practice shall we find our resources and the fewer will be the days known to us so often alluded to by others when the fish will not sport, an idle excuse, begotten of ignorance and adopted to conceal the cause of want of success, which more candidly and truthfully had better have been at once confessed to be owing to want of skill; blame should have been admitted by the fisherman as due to himself, and not cast so absurdly on the fish, but we well know how loath we all are to confess our own ignorance and bear the taunts of others, and how fond we are of finding excuses to save our own reputation. We shall in course recur to the detail of various modes of fishing; -in the mean while let us briefly take a glimpse of the trout himself.

Any one who has observed a trout in the midst of a rapid, well knows that he is constantly plying his fins to maintain his position against the force of the falling water, and that if he did not do so he must as any other inert object obey the force of the water and partake in its rapidity of course. The exertion the fish has to undergo to maintain his position will be proportionally great as the force of the strcam acting against him; the greater the fall of water and force thereby acquired, the greater power or muscular exertion must the fish perform to maintain his position ; - again as the fish has constantly almost to be darting across or even swim directly up or against the opposing current to secure his food, it 
follows that in order to feed, he has a labour to perform proportionate to the resistance of the stream he is in. We see but few places in rapid streams of rocky bottoms to which the fish can retreat to evade the powerful current, or these so small, that a single stroke of his tail brings him into the current necessitating increased labour, so that in short by far the greater part of fish inhabiting these precipitous streams are incessantly performing great muscular exertion ; it is evident then that as the muscles moving their bodies and fins are constantly exercised, and that no muscular contraction can take place without wear and tear of tissue, the trout must either very speedily suffer from exhaustion, or supply his body with materials for fresh blood for the new formation of changing parts, and this supply must be proportionate to his laboursand in the same ratio as the frequency of repetition of his labours. He cannot take a large meal and quietly retire to rest for its digestion, since in obtaining each portion of that meal, and a prolonged one too, he is in violent exertion, is wearing away and reforming his tissues, and at the same time hastening the digestion of the hardearued meal, and moreover, when satiated, if so he could be, he has literally no place to retreat to where he could be free from labour, though perhaps lessened in some degree in some spots it might be. Now this is quite the case witb by far the majority of trout in small rapid streams; constantly working, constantly feeding, sometimes more, sometimes less, now feeding on one insect 
nr grub, now on another, still labouring and still feeding, there is no rest for them:-but a few there are even in these rapid streams who, mature in years and excessive in timidity, partake somewhat of the habits of those trout inhabiting the larger and slower stream, and find out what few quiet holes and hovers the stream may afford, and there enjoying comparative immunity from the necessity of constant toil, please themselves as to their time of feeding, and carry their own power of selection even to the kind of food they will eat, rejecting such as may not be quite agreeable, defying at the same time their smaller brethren to come within their domains or attempt to wrestle and contest with them for the dainty morsel their stomach desires: but those in , the North Devon streams are few, most lamentably few ; so many enemies there conspire together for the illegal and unfair destruction of the trout, that the number of those permitted to survive rnany summers is swall, most small indeed. Oh! that the gentlemen of North Devon would amalgamate in heart and action, and determine to preserve the trout they as Devonians ought most justly to be proud of, not limiting their field of operations to some few miles of water, but fencing their main and tributary streams, the nursery and the field from all intrusion of poachers, or those who would in any unsportsmanlike manner destroy a trouttruly their reward would be great; in no long time the North of Devon might boast not only of its natural beauties in outline and detail of hill 
and dale, but not the less of streams, more delightful to fishermen than almost any our own country can boast of;-no streams can be better formed by nature to afford sport to the fisherman, and there is but one thing wanted to make those streams well stocked with abundance of fish, and that is to preserve the waters by one regular and uniform system, extending from the estuary of the Taw to the fountain-head of every stream or brook which in any part contributes to it. Not only would the waters be speedily filled with large trout, but salmon would abound, and soon might the Devonians again realize the times, as of yore, when the farmer was bound by a special clause in his indentures with his apprentices, not to feed them on salmon more than three days a week. This is a traditional story in North Devon, and is commonly believed to be true; at any rate it is certain that salmon used to be very abundant in North Devon rivers, and that they are now very scarce, and any one who is familiar with the natural history of the salmon, and with the rivers of North Devon, the Taw and its tributary streams, must admit that there is no reason why salmon should not again abound to such an extent as to be a very considerable source of income to the owners of the water. With railroads at hand, the highest markets could be commanded, and without doubt, a vast supply in a few years would be annually sent from the Devon streams, if the streams and the salmon received due attention; the main points being: First.-To let the 
salmon up, which the structure of the weirs at present existing prevents. Second.-When the salmon has gone up, to preserve them till they have spawned; this would be necessary in great extent till a stock natural to the waters were bred. Third.-To let the fry and old fish back again, which the weirs also in a great measure prevent. The great obstacle to the salmon is the forbidding structure of the weirs; these might readily be so altered as to answer every useful purpose as regards the turning off of the water, whilst at the same time to permit salmon to get up and pass back again. The landowners are indeed shortsighted when they can only recognize the value of water to their land, and not comprehend the importance of salmon in their rivers. - I have gone astray, I know, from my subject; my inclinations would almost induce me to write a chapter on the subject of preserving the salmon and trout, but it is irrelevant to the purpose of this undertaking and I must forbear, at any rate for the present; I may be tempted perhaps hereafter to send home some remarks on the subject, but I now hasten back to the trout.

The majority of trout then in rapid streams are by a natural necessity impelled to be constantly feeding.-Now doubtless, the stomach of the trout, like the stomach of other animals, requires change of food; it is demanded by the body and suggested by the appetite. All the requisite constituents of the trout's body could not probably be found in any one particular kind of food, or such food could 
not at all times and in sufficient quantity be obtained, and consequently he at one time eats one kind, and at another time another kind of food, making up in the whole what in any particular part was deficient;-such a change and variety of diet is positively necessary in order to maintain the fish in a state of health. As a man, kept solely on animal diet, would ere long become ill, or on vegetable diet debilitated, so would the trout if long restricted to any one class of food be enfeebled. Kind nature to man, over and beyond that appetite arising from the body's appreciated requirement of food, added reason for selection and guidance in his choice, nor has she left the trout more unprovided for,-in them the same appetite calls for what instinct directs.

'The different kinds of food the trout lives on depends on locality; he eats almost everything that is nutritious to his body, but the classes of nutriment are in some streams very limited, in others more general, in all somewhat various, and yet a universal similarity to a certain extent prevails-a little consideration of the land, the sides of the stream, its bottom, \&c., will usually settle the point sufficiently for all practical purposesand as we must allude again to the subject, just now we will only remark that simple as this subject is, the places in which the trout take their food is one of the highest importance to the fisherman. I feel that it is absulutely impossible to describe accurately the precise spots trout may be found in; this can alone be learnt by personal 
experience and observation, but we may assist most materially our learning on this subject, by a little consideration. If we were now considering trout fishing on some river of sluggish and monotonous course, or one whose course and speed varied only at long intervals, it would be most easy to pronounce the most favourable localities, as weirs, eddies, \&c., \&c.: but to attempt to enumerate the many different places a trout will lie in, where we have to do with rapid streams, varying in their character every five yardsnay, whose very breadth at once shows variety in appearance, and choice feeding spots here and there at intervals - to describe or arrange systematically such confusion of water is, I say, impossible; and yet of all points to be attended to, none demands more exact knowledge than the precise spot every trout lies in ;-after all, a little common sense rightly directed will guide us very safely. Should we be fishing with the artificial fly, we, of course, are most likely to catch those fish which are mostly feeding on the natural $\mathrm{fl}_{\mathrm{y}}$, and consequently we should cast our fly in the most favourable manner, in such spots as we believe a trout would select for capturing his flies with the greatest ease to himself, where indeed he will find most flies on the water, and where he will not be foiled in his chase after the fly, when it has alighted on the water and is being hurried off by the stream, which he himself is swimming against. So we may find the trout lurking hy the sides of any little current, caused by the rush of 
water escaped the side of some prominent rock, stone, or sandbank, rather than in the current itself.

When the breadth of stream is much broken up into minor eddies, we do not throw our fly at once into the midst of the rapid, for should the fish see the fly from his lurking place by the side, he will most probably be unable to take it, or having taken the fly, we should be unable to capture him; should the stream in its whole breadth form one gently undulating pool, it is reasonable to suppose that the trout would be able to seize his fly in any part; yet even here, the sides beneath the banks if deep, or the shelving shallow edges if sandy, will be better suited to his feeding than the more central portions of the water, and often in very shallow water a good fish may be found, and with proper care caught; indeed, in little shallow sandy places the trout are fond of lying, they there rub themselves and procure grubs as well as flies; hence these peculiar little sloping edges of sand are good sporting places for any bait. On this head it will be only necessary further to mention that we have but to remember that the trout, when feeding on the fly, will be sure to be found where they can catch the greatest numbers-it requires no special knowledge, no peculiar judgment to discover thesespots, a little reflection will bring any one to a correct conclusion as regards the most of them at any rate.

Having then, after a proper survey of a spot, determined where the different trout are lying, the next point for consideration is how we are to cap- 
ture them, and this will require special notice hereafter, now only remarking, that frequently we may be led to suppose that no trout is lying in some little eddy or current we first thought likely to contain one, because after casting our fly we have not moved one, thus again reverting to the fisherman's plausible argument, that our want of success is due to the fish, and not to our own stupidity. Now having observed a spot, and determined that it is a favourable one for feeding, if we cannot succeed in at least moving a trout, without doubt it is our own fault and not that of the fish; for either we are fishing with the wrong bait, as the $\mathrm{fly}$, when the worm would be better, or we are not using the bait in a manner attractive to the trout, or we have in some way actually frightened the fish, who often sees the fisherman, lorig ere the fisherman sees him, so that he is too timid to feed. We have, I grant, great difficulties, sometimes insurmountable difficulties to contend with, but I am sure that if the fisherman will only bear in mind that any want of success in capturing a fish from a feeding spot he believes to contain one, is due solely to his want of skill, he will be shortly rejoiced to contradict the assertion so often made that the fish would not sport, in other words, would not eat, had given their stomachs a holiday and had gone to sleep, a statement so absurd that common sense must at once justly declare the party to be blamed in the affair of fishermen versus fish. Let us repeat then most assuredly that trout in small and rapid streams are always to be found in 
the places best fitted to their feeding, and these are not always deep holes or large currents, or places having any air of grandeur about them, but often a very shallow spot, of insignificant appearance to any but the thoughtful fisherman, contains a - good trout, and all these places are to be discovered by the simple rule of their being favourable in affording food to the trout, and conducive to their seizing it.

Now on these rapid streams, minor streamlets, cascades, or eddies, formed by the splitting up and subdivision of the main stream, the manner in which the trout takes his food is peculiar, and forms almost a contrast to the feeding of those in deep and sluggish streams; in them the feeding fish may be seen lying near the surface of the water watching for the passing fly quietly and calmly, and any fly alighting near him is just gently propelled towards him, or perhaps rises again from the water after alighting to dap once more over his anxious eyes, to whom, silly insect as it is, it displays its beauty and calls forth perchance admiration from him, examining its form and symmetry and scrutinizing its very condition and plumpness of body, till now the ephemeral beauty being within easy reach, the trout, fully satisfied with his leisurable inspection, gives one stroke with his tail and secures his prey. How widely different is the course pursued by the trout on the rapid stream, for here he well knows that as soon as the fly has alighted on the water it will be instantly carried away by the current, and if missed 
by him in his attempt at capture will be washed into the jaws of his neighbour only a very short distance, perhaps a few inches below-he a smaller fish not daring or presuming to occupy the best place in the pool or eddy, but humbly and submissively contenting himself with a spot lower in locality and less propitious in feeding, pleased to partake of the chance insect his superior has allowed to pass, voluntarily or not, and never venturing beyond the precincts permitted him by his elders, well knowing that any infringement on their rights of property. would be followed by instantaneous punishment amounting in all probability even to death itself.

Thus may we see that the trout in their society maintain their own rights; and since the law ruling them is one solely of force, and amongst them power holds the place of justice with men, we shall find the largest and strongest fish securing to themselves the best feeding ground, and the most convenient retreats for security against foes not of their own kind-a wise provision of nature, since of course their requirements are in proportion to their size. These strongholds and favourite spots of trout are retained by them for a long time, as they seem fond of old haunts and do not readily forsake them, very. seldom, I believe, excepting in particular migrating times. I have known a trout of peculiar appearance remain behind a certain stone for several months, his identity I could be sure of, and at different times I have made him show out, till at last I have 
succeeded in his destruction; no smaller fish dared, and no larger one cared, to turn this fellow out, and so he held his own retreat, which after his removal was speedily occupied by another.-This rule of particular retreats of trout applies of course most forcibly to the very small streams, or to such portions of the larger ones as are from their subdivisions of the main current allied to them; to keep in mind the rule on any river however will be of much importance, since it will teach us to pick out, as it were, the very fish we particularly desire, rather than leave our fly to the many who may pursue it, and all of whom often from over-eagerness in the chase will fail in catching it.

I believe we may safely assert that when a fly, worm, grub, or no matter what attractive article of food is cast into a pool, where many trout in different parts of it are lying, all take a look at it, and if it prove sufficiently attractive to him, the largest trout will seize it; if he declines the offer, the next trout in size and power is permitted his refusal of it, and so on till some young green-horn starts off, and in case of the baited hook, discovers his mistake too late. This is often seen when one is fishing with the worm or artificial minnow, the latter especially as being more exciting, - a bright piece of metal is drawn swiftly through a pool, and in an instant all the fish seem in movement, and if the master of the pool is inclined to take so large a mouthful, he at once mingles in the race, and immediately the small fish in fear will be 
seen running off in a contrary direction; should however the big one not take it, and at the same time the lesser ones be not too much frightened, some of them will rush away at the minnow and try to eat a body often half as big as themselves. The rapacity of the trout is truly astounding ; often a trout's gullet and stomach will contain a fish one-fourth or one-sixth as large as his whole body, and in large streams, where the trout preys much on his smaller brethren, we may conceive this gorging tendency a further reason for their being less constantly on the feed, than those trout are which we are more directly attending to. I have often caught a trout with the fly, whose gullet has contained a fish large enough apparently to satisfy his hunger for a whole day, and yet he could not resist the temptation my artificial fly afforded him. If their labour is constant, their digestion is very rapid, and the whole amount of food a trout would consume in a day, if it could obtain it, would be something enormous. I should much like to have an opportunity of making an experiment as to the amount of daily consumption by trout; a general idea of the extent or amount of their eating may be formed, by opening the stomachs of trout feeding greedily on flies, at such times as they are most abundant on the water, when though every stomach seems distended with food, yet all are busily engaged in eating flies as fast as they can. Sometimes if we watch a number of trout on the feed and where food abounds, we may see that one will refuse 
some particular fly or perhaps several successively, and yet another presenting itself within reach is swallowed with avidity; this remark applies to large streams, and its practical application to them is limited, as we shall see by-and- by that on the little streams we do not work on the principle of temptation by inherent qualities of attraction. No doubt some taste or appreciation of difference of flies as food is possessed by the trout, and perhaps a memory of some peculiar fly before familiar to him may induce him to take a similar one subsequently when able, but assuredly the trout is not guided in his feeding by judgment of what is most delightful to his palate; he seems rather to be stimulated to eat by the presence of food, acting as a direct and general force, and excited by what presents itself, in proportion to its power of acting on his habits and natural qualities of rapacity and tyranny. The desire or requirement of food prompts trout to eat, but often their tyrannical disposition will direct them in their object of prey. We may see a number of minnows swimming quietly and peacefully about in enjoyment of sportive play, close by the haunts of a large trout, who takes but little notice of them, on which account they are not afraid of his presence; now catch one of those minnows so familiar to the eyes of the trout, put him on a hook and make him spin through the water, make him an object amongst the others pre-eminently conspicuous, and the large trout will not brook such insolence from an inferior, he will immediately dart at the presumptuous little 
fish, and if he can, kill him. Again catch one of a number of flies playing over some quiet pool, put him on a hook and dap with him, make him more gay and sportive, more conspicuous and more audacious than his brethren, and the trout will select this inviting one in preference to all others.-It would seem that the trout think of such an unusually taunting insect, "Little rascal, what do you mean by insulting me with such boldness? I'll punish you for your insolence," and sure enough poor foolish fly speedily pays the penalty of his hazardous proceedings.

And thus shall we see that the most conspicuous object is often the most attractive, even with artificial baits, provided the trout has not the means of discovering such, proffered bait to be unlike what he naturally is accustomed to, or believes what is presented to him to be edible.

Now the trout are fierce, bold, rapacious, and tyrannical over all their own kind smaller than themselves, and all other smaller fish and insects ; but they are excessively timid of the presence of other animals. An otter, by natural instinct, they shun, so also water-rats, and even birds; cows, 'tis true, they will come close to, if they are in the water, being attracted by the grubs washing down from the dung of the animals, but these they come up to by slow degrees, and the sudden approach of a cow will intimidate them. But of man particularly, and beyond all other animals, do they dread the presence; generally, as soon as they discover one, they rush off, but this is not always the case, they may remain stationary, 
watching him, if he be quiet, but the slightest movement on his part will make them retreat hastily; and though after having seen a man they may remain stationary, they nevertheless seem awed by his presence, they cease feeding-or should they feed, they are yet evidently discomposed, shy, and timid;-impressed as it were with fear, they are doubtful in all their movements, and appear instinctively to feel the necessity of caution; sometimes when so affected, the sudden appearance of an insect within their reach will so arouse them for a moment, that in their eagerness for prey, they may have their attention so far absorbed as to forget the presence of a stranger, and make a start as if to capture the insect; whilst on their course, however, they are reminded that an enemy is near, and instead of capturing the insect, turn short of it, refusing indeed to feed. We believe this is often the case, that they are either so terrified by the presence of man, that they rush off to a hiding place, or frightened as to remain quite stationary, even food presenting; or just alarmed as to make an attempt at the capture of a prey with suspicion, and ultimately to decline taking it all. This is a subject of great moment to the fisherman, and the young piscator will employ some time very protitably in trying for himself some experiments in proof of what we have stated respecting the voracity of the trout, and the influence any strange object, or even any unaccustomed movement of a familiar object will have on his natural boldness in seizing prey. 
ON RAPID STREAMS.

\section{CHAPTER III.}

IN our last chapter we took a hasty view of the disposition of the trout, noticing only some such characters as immediately. affect us as fishermen, and of those only such as most especially demand the earnest attention and consideration of all desiring to obtain sport with the trout. Many more characteristics of the fish might of course have been enumerated, and altogether very much more have been said on the subject; but the desire has been and will be to state such leading points only as must be carefully remembered and earnestly applied, that we may not confuse the mind of a young beginner with rules and dogmas, but rather lead him reasonably to consider his art, and assist him to deduce from simple facts correct and decided opinions of his own, and instruct him in the best mode of practically applying the knowledge he may acquire from others, or from his own observation by the river side.

Having stated that the trout in small rapid streams are generally feeding, and that their food is various, it will behove us well to consider our best means of taking advantage of the trout's 
voracity, and of accommodating our resources to the variable desires of the fish, in order that we may not only always select the bait which by preference he may be taking in most abundance at any particular time, but also that we may employ that which will assist us most materially in attracting him and favour our own seclusion and deception.

As to the resources we have of varying our allurements, we have only to remember that the trout feeds on all fish smaller than himself, on all insects found on and near the water, or such as in passing over may fall into the water, as well as worms, grubs of all sorts, and the spawn of other fish. Having then so large an assortment for our selection, it will be well for us as early as possible to understand why at one time one bait should be adopted, and another at another time, before attempting to learn the mode of using each particular bait. And as a preliminary point let us briefly consider which of all these articles of food is best adapted for deceiving the fish. And perhaps to one not practically acquainted with our art, the solution of the question may seem obvious, and to depend simply on the fondness of the trout for any one article in particular, which of all others would therefore appear to be most advantageous to the fisherman as a bait. This has in part been alluded to before, and we mentioned that the voracious trout is not solely and at all times guided by simple appetite or peculiar inclination and love of any article of 
food; but that he may be excited to feed by the particular manner of his prey, tempting him by greater attraction or conspicuity, so that one of many small flies or fish will often be especially selected, not from any apparent superiority in condition or appearance in form, but simply from arousing the trout's belligerent passions, or awakening him from indifference by extraordinary provocation. Hence, in our determination of a bait, we must find one that will not only be agreeable to the fish as a viand, but one which of all others will be most exciting to him; nor is this all, for inasmuch as a third party is to be introduced,-namely, the fisherman himself,-no Jittle attention must be given to the importance of his share in the proceeding; consequently, the bait must not only be of all others the most alluring in every way, but of all others be such as is best adapted to the process and use the fisherman will adopt, besides being favourable to his own convenience.

If we turn our attention to the natural fly, it would appear from what we have remarked, that it would best answer the purposes required as far as the fish is concerned (and this is true of it as an enticement); but we should find the living fly very troublesome to use on rapid streams, from its delicate structure giving much annoyance in constantly necessitating a change of bait; every fish that touches it, independently of the action of the water itself, taking it off, besides being inconvenient to obtain at all times 
in sufficient numbers. We want, then, that which will be as attractive and enticing as the natural fly, and be more convenient to the fisherman. Next would suggest itself fern webs, and some beetles, and in them many objections are done away with, and certainly a most excellent bait is before us, but these cannot be obtained at all times, and the trout will only take them at particular seasons. But as we intend to remark specially on each particular bait, we now proceed with the flies, and finding inconvenience in the natural delicacy of the living fly, call art to our assistance, and imitate the insect we should otherwise use,-imitate with precision when we wish and are obliged to rely solely on our deceptive power, as in slow water, or deep and still streams; but where we wish rather to take advantage of the natural infirmity of the trouttheir voracity-and are able to do so without exposing too much our deception, as in rapid streams, we so far imitate nature in general appearance and colour, as to lead the trout to imagine an insect, or at least something eatable is before him, but rely more upon our bait as an attraction, than an actual deception of a particular fly, and its manner of employment, as an excitement to the fish, which from his habits we judge he cannot resist. And taking still water, and shallow rapid streams or cascades, as two extremes, we would say with regard to artificial flies, that in still water we should rely upon the deceptive power of the fly, and judge of the 
value of flies by their representation and exactness of similitude to the natural insect. Whereas in rapid streamlets, we should rely mainly on our mode of using the artificial fly, whose good qualities would consist in the greatest conspicuity, provided such did not so far exceed the likeness of anything natural and edible as to frighten the trout. And as in rivers we find every gradation of distinction between the still water and rapid brook, so shall we bereafter observe every degree of difference between the gaudy, conspicuous, and insulting bait for the rapid-and the sober, quiet, deceptive, artificial fly, for the still water.

Again, as regards baits, we have worms, slugs, and small fish, - as minnows; which are usually such stimulants to the gustatory and predatory dispositions of the trout as few, even the oldest and most cunning, can resist. And every fisherman ambitious of capturing large trout, ought to be made acquainted with the use of these baits, -as for bottom fishing no legitimate means of capture is equal to the minnow or worm. $\mathrm{He}$ would advise every student in the art of fishing to make himself well acquainted with the best methods of using the natural, the artificial fly, the worm, and the minnow; with such resources as these, provided there be rapidity of stream, and plenty of trout, a good day's sport may at any time with certainty be relied on.

In using each and all of these baits, we have one constant difficulty to overcome, with some greater than with others, but more or less still 
ever to be contended with, never to be forgotten, and this is to avoid alarming the trout. We shall find so far as our bait alone is concerned that the trout is not by any means easily frightened; but we must ever remember that the trout, most mercifully to him, is endowed with a wonderfully acute sense, viz. that of vision. To what extent trout hear or smell we do not pretend to decide; these senses, however much or little developed, will not either assist or oppose us in our practice; but the wonderful acuteness of the sight of trout will be found the greatest difficulty we have to contend with, and most especially careful must we always be to prevent the trout seeing us, not only our whole body but not even a hair of our head, and to avoid causing any unnatural movements of familiar objects within his range of vision, as well as to avoid frightening any other trout below where the fish we want to catch is lying; lest he should start off and in his terror tell his brethren something is moving, a stranger is in proximity.

In order to prevent the trout seeing us in our approach, which must be for subsequent success as near to him as possible, the simple precaution of fishing whenever we can, up, or against the stream, will be of the greatest assistance to us. The position of the trout's eye in his head, and the mechanical arrangements of muscles for moving the globe of the eye, are such as to be best adapted for observing objects immediately above, or above and in front of, the head; he 
sees indeed upwards and forwards, but cannot direct his eye to take in rays of light falling from behind forwards, or only to a very limited extent; consequently the lower in height we are, and the more immediately behind the trout we are placed, the less able will he be to see us. We must then have recourse to every stratagem to obtain such a position, and in advancing, for example, to any spot we believe to contain a trout; we should place ourselves as nearly on the level of the water as possible, below it if we can, and proceed if even obliged to crawl on the ground from below, upwards, or as regards the direction of the fish, from kehind, forwards. Should a high bank border the stream, rather than stand high above the eye of the trout and far off, we had better get down to the water's edge below where he is lying, and then cautiously make our advance, and in so doing keep the rod out of view. A thousand points in detail of means of secluding ourselves might be enumerated, such as getting behind trees, stones, rocks, into ditches or deep gutters, of our most appropriate dress, \&c., all of which common sense sufficiently indicates, and which will be attended to and adopted, provided the principle of always avoiding the sharp and watchful eye of the trout be remembered.

Now in this our grand obstacle, viz. the quick watchfulness of the eye of the trout, guarding him from our near approach, it is quite evident that the water in which he swims will affect materially our own seclusion, as well as our bait 
as a deception. If the water be very clear and shallow, the bottom stony, the polished surfaces of the stones reflecting light in all directions, and if the movement of the water be little or none, so that its surface is quite undisturbed, the trout would be able to see the smallest insect that might come within range of vision, with perfect clearness, and form an immediate and correct opinion of its appearance; he would, too, of course, see surrounding bodies with corresponding accuracy and ease; and as, too, he in this quiet water is little necessitated to labour, he is cool and methodical in his mode of taking his prey. The degree of power in his vision will be affected too by the intensity of light :-in a bright sunny day he sees best, in dull cloudy weather he discerns less distinctly, and in shades of evening least of all. Should the water too be coloured, as after rain, ruffled on its surface by wind, or broken and uneven by reason of its rugged course, his power of minute discrimination is lessened, and it will be so in direct proportion to the degree of each, or combination of any or all of them. And it is just these accidental circumstances which will prevent or aid us in our endeavours to capture the trout, either with the natural or the artificial bait.

If a trout be lying in very shallow, clear, still water on a bright summer's day, it is evident that the difficulties we have to contend against are so great as to be almost insurmountable, quite so indeed, had we not variety of allurements; we 
could scarce hope to obtain an artificial fly so well made and precisely similar in appearance to the living insect that the trout under such circumstances could not perceive the deception, and would imagine the artificial representation a natural reality; and even if we could obtain so precise a similitude of the insect, we should not be able to use it in a perfectly natural manner, so as in every way to resemble a living fly, without either exposing ourselves, or the rod or line, or even the gut to which the fly would be tied, and so frightening the fisb. A trout then, in shallow, still, clear water, with a bright sun shining on him, is almost past the bounds of possibility of capture by artificial baits, or at any rate, if some be so captured, they are but few, and we want to consider how and when to catch the many. 'To take a fish so situated it will be necessary to use the natural insect itself with the most delicate tackle possible, and keep ourselves perfectly secluded, or assuredly be our bait ever so tempting we shall not coax the trout to take it; consequently in such places, under such circumstances, we obtain but little sport; we may take some fish, but not nearly so many as we should do under more favourable circumstances -which would be coloured water, or surface movement by wind, obscurity of sun, \&c.; and when these conditions favour, we may in such places have good sport; when not so, after much labour, we shall reap but small rewardbence, when coming to such places at unfavour; 
able times, on small streams, mindful of the small chance we have, we should not delay, but hasten on in search of a better field for our exertions.

Now it is by no means necessary that all circumstances should be favourable to our seclusion; on the contrary, one condition alone being present, viz. rapidity of water in its descent, is sufficient to ensure success, in spite of all others, powerfully though they may act against us. We urge then, that provided we have a rapidity of water, with a consequently broken surface and splitting up of the main channel into numerous little rapids, we ought to be sure of success. These little rapids and secondary currents differ greatly from one another; some will appear in miniature the trout pool as found in large streams, some only a little cascade, others peculiar, but all certain to yield sport if we know how properly to seek for it. At some seasons the rapidity of the water is too great, so that the trout is unable to catch our fly, in its violent passage ; at others so slight, as to be insufficient to afford us the protection and aid we require; this is too often the case, and most frequently at the very time we most require the water to be rapid, viz. in the bright hot months of June, July, and August; at these times, when the waters are very low, we have a greater distance

- to travel before we come upon each favourable spot; all the minor rapids and pools we knew sometime before, are now dried up, or converted 
into still, clear, shallow water, and we find the ordinarily larger and more extensive rapids now so diminished as to just afford us the aid we want, these alone reminding us of what our favourite stream had once been, now so changed and altered as to be with difficulty recognized: and whereas when of average height we could not move five yards without meeting some, ay many pleasing spots wherein to cast our fly, we, now that there is so little water in the bed of the river, have to wander meadow after meadow and meet with disappointment in our search after some nice little rippling pool that our knowledge tells us is sure to yield sport. Thus do we at these unlucky times vainly wander for miles, led by delusive hope, picturing to ourselves in our imaginations these spots of fortune, till weary limbs and exhausted frame bring reality and deliberate judgment to convince us of the absurdity of our visionary pursuit.

We repeat then, that though the water be very low and the weather very bright, we shall obtain sport in those kinds of places which we should select at ordinary times, in fact in the feeding places before spoken of; but inasmuch as these places are, by the diminution of the water, lessened in number, we shall not catch so many fish in very low water as when it is of an average summer height; not that the fish at these times are sporting the less, but that our difficulties of catching them are the more; neither must it be thought that at such times we cannot 
catch any, or even a good dish of trout, but it will be found that we shall not catch so many. There are some streams which seldom or never become so diminished in amount of water as to lose their little rapids and bubbling falls; the declension of their course is so great, and the impediments to their progress so numerous, that they always present variety of appearance, have always sufficient force and disturbance to aid the fisherman; and in these (and they include most North Devon streams) sport may universally be obtained.

The wind often assists the fisherman on deep or slow streams, but we regard high wind-wind high enough to effect the rippling of the surface of the water-as an obstacle rather than an auxiliary in fishing in bright water, in hot weather, on rapid streams of small size.

The colour of the streams is of much importance at certain seasons of the year, its degree of tone of colour often suggesting the most appropriate bait to be employed; as when after a sudden rain the water quickly rises in height and becomes foul-of a dirty colour-in some streams red, in others, as on the moor, of a porter colour. In the extreme discoloration we had better use the worm because the fly could not be well seen, and, because the fish accustomed to these changes in their element, are aware of the effect of increase of bulk and consequent washing of ground by the sides, which for some time has been dry, and are looking out for worms and grubs which must 
necessarily be carried away with the earth and mud of the banks, and eager for change of food after being so long restricted from the lowness of water to one kind of food, refuse now their common diet the fly, sink deep in water to look for worms, and retire to such places as would best favour their capture of them. Knowing then these natural results of increase of water and deepening of colour, we do not use the fly at such times, so unsuitable both to the river itself and the situation and expectations of the trout, but employ the worm, which at once places us in a right position to compete with the trout.

Again, with reference to the condition of the water, we may observe that trout seldom sport at any kind of bait when the river is increasing in bulk and force; a temporary panic seems to prevail amongst the trout, and they retire to such places as may afford them protection against the force of the expected torrent, wisely so urged by a protective instinct; for otherwise, did they remain out in the stream, their strength would be insufficient to prevent their being washed away by a too powerful current.

From these cursory remarks it may be seen that we insist that trout in any well-stocked stream, which has rapidity of course, are always to be caught, and sport under these conditions certain to be obtained, but that at certain times our difficulties are greater than at others, to meet which, we urge the necessity of learning to vary our resources, so that at any time we may select 
that bait or means of capture which is of all others most conducive to our sport. Obstacles, though great, and difficulties apparently insurmountable, may be overcome, provided we compete with an energy and determination to conquer; and when nearly every circumstance is against us, when we have to put forth all our ingenuity and bring all our knowledge to the test, the trial will be the more exciting, and success sweeter when obtained, since it is attended with the satisfaction to the mind, which surely follows a mastery over extreme opposition. 


\section{CHAPTER IV.}

Is the foregoing pages, our remarks have been generally directed to certain points which affect each particular mode of fishing, almost equally,and having thus taken a hasty view of our subject as an Art, it will be necessary to retrace our extended steps, and, by pausing on such parts of our subject as require more particular explanations, to dilate on the details of each style of practice of our craft. Such points of detail will alone be dwelt on as experience suggests, to aid the novice, or stimulate the fisherman whose knowledge of fishing depends on observations acquired on large and quiet streams, and not on rapid brooks and streamlets. I trust our time will not be unprofitably occupied in considering separately the mode of using the different baits before alluded to, and going so far into the minutiæ of the subject as seems to be practically beneficial, and in so doing, we will endeavour to keep our minds on the river, to sum up the actual experience of work, and enumerate special difficulties which practical acquaintance with the rod and line can alone afford. The results of labour thus given may, 
it is hoped, prevent disappointments, enrich the mind of the novice with serviceable precepts, and teach him to make use of every favourable circumstance with best advantage to himself; and a right knowledge of the principles will ensure the exercise of his reason and ingenuity, and, if we add but a little personal familiarity with the Art itself, we can confidently promise certain and speedy success to his labours.

Whichever of the various modes of fishing we select for especial discourse, we must direct attention to the bait itself, our mode of using it, and the rivers on which it is to be employed. As of all styles of fishing, artificial fly-fishing is the most general favourite and most universally applicable to rapid streams, I prefer choosing this for our present subject; but, before proceeding further, I must again remind the reader, that we are about to treat of fly-fishing on small and rapid, or rapid and much divided streams; and I trust that what may be said will not be too hastily judged, or condemned without careful trial, lest such views as will be brought forward be deemed incorrect, because standing in some points at variance, in others in direct contrast, with what is ordinarily written concerning artificial fly-fishing; but with the assurance that nothing either of principle or practice shall be advanced, but what I have personally practised, and that nothing shall be dwelt on, respecting this practice, but what is deemed to be absolutely necessary to be attended to, studying to avoid all theoretical expositions, and en- 
deavouring to adhere as closely as possible to important facts, obtained by personal observation, I beseech the reader to reflect and make trial ere he criticizes; and if my descriptive powers are insufficient to make the Art comprehensible to all, I have to plead as my excuse, that my desire is rather to give what is practically advantageous and instructive to the fisherman, than by more careful attention to the writing itself, to render this little book pleasing and attractive by relieving the piscatorial treatise with the description of country scenes and pastoral pleasures, with their romantic and imaginative tendencies.

Fly-fishing on large streams, such as are mostly frequented by fishermen, has been very ably discussed by many authors, and I have very little to add to their accounts, or differ from their opinions in the general sense. The precise period when we should commence fly-fishing, is as soon as the trout are in condition for the table, for when they are so, they will be found in sporting condition. 'This depends on the breeding time of the trout, which in some rivers is much earlier than in others : the Exe, for example, is one of the earliest rivers in Devonshire, and Exe fish being comparatively earlier than most streams in the North of Devon, it is probable that their spawning season begins earlier, on which account the trout come into good condition, assume a healthy state, and in course, are more active and powerful in their movements, earlier in the commencement of the year than those frequenting streams in which 
they spawn later, and consequently do not get over the sickly condition which naturally ensues during and after the breeding time. In these later streams, although the fish is not in a healthy condition for sport, and in good plight of body for the table so early in the year, he yet is pleasing to the sportsman and agreeable to the gourmand proportionally later in the season. Trout, as autumn approaches (and in North Devon streams, about the months of August and September), begin to prepare for the propagation of their species, and in order to obtain places best adapted for hatching their spawn, where, indeed, it is least disturbed, and most likely to obtain the requisite supply of natural elements, run away from their old feeding grounds in the larger streams, and repair to the smaller branches;' here they remain some time, till the necessity for depositing their spawn induces them, usually in October, to seek the narrowest brooks and streamlets, and here they remain watching their spawn and young till the following spring, when they gradually descend again to larger waters; as yet enfeebled by the late demands on their bodies, unable to resist the powerful rapid, they prefer the more still and quiet places, where, with the least

1 This assertion may seem to require proof. The best I can advance, and from which I draw the conclusion, is the gradual emptying of the bigger and at the same time proportional filling of the lesser streams in the Autumn. The rule of migration is believed to be generally true, but not universally necessary to trout, as is the case for example with salmon. 
possible exertion, they may obtain sufficiency of food; in such places they may be caught in January, and the early part of February, lying in almost still water, by the sides of the stickles, at the tails of pools, under overhanging banks, \&c.; but not in the bubbling, gushing torrent, or so near it as that they would be obliged to swim against it in their pursuit of prey ; and here too, at such times, they prefer to feed on ground baits rather than sport with the lively fly.

Spring however, returning with her genial warmth, conduces to the health of the trout, who with increasing strength and bodily power will soon attempt more rapid waters, at first seeking the tails of long pools, where they may with tolerable exertion catch the flies now becoming gradually more numerous, and on whom they desire the more to feed, and may moreover rub themselves in the sand to free themselves from the slime which is always found adherent to the scales of sickly fish, and rid themselves too of insects, often numerous and sources of great trouble to the emaciated trout; thus improving the condition of their integuments, they stimulate their body to vigour of growth, and feeding more abundantly, they soon become strong and healthy, fat and fair, their scales bright and lustrous, and their beantiful spots conspicuously ornamental to their sides; and having rubbed their coats and freed themselves of slime, new scales develop themselves, their bodies acquire plumpness, their muscles power, and their systems vigour, old desires and habits return, 
and having regained rude health, seek the rapid current, delighting in its very opposition, and gambolling amidst its turbulent waves in perfect enjoyment of life. The precise time when these changes in localities, in habits, and in health occur, varies, I believe, in almost every stream; some, as I have said, being earlier, and some later than others; but speaking in a general rule, I may say that the trout in North Devon are in good condition in the end of February, or beginning of March, and remain in a healthy state till the end of August; so that fly-fishing may be legitimately pursued from February till the end of August. All the trout will not, in February, be found in perfect condition, but many will; and, if the season be warm, good sport may be expected in the end of February. Late fish when captured should always be thrown in again, as they are wholly unfit for table, and disgrace a fisherman's basket.

In the spring of the year, as in February, the brooks are, from rain and snow, usually very high; the water seems to come lashing and dashing along in one determined, unbroken, and most violent course; the inequalities of the bottom, from rocks, \&c., are as yet, with so large a volumè of water, insufficient to divide, pond back, or retard the impetuous stream : and though its surface is thrown into waves, and its body forms whirlpools, the insignificant opposition of presumptuous stones but increases its raging and turbulence, aud, bounding as it were from trifling hindrances, 
it continues its wild career. In such waters as these, the trout to be able, even if willing, to take our fly as we are obliged to use it, need be very strong and active, and this so early in the season we know they are not; consequently we could not reasonably expect much sport early in the year, on brooks or streams whose volume is great, and fall precipitous-we should rather turn our attention to the broader and quieter streams, in which the convalescent trout can gently sport, and in which he will be able to seize our fly, when offered to him in the proper manner. The peculiar kind of weather we generally have too in the earlier months, is adverse to fly-fishing on small and rapid streams, inasmuch as high winds usually prevail, and these prevent our throwing our fly with that amount of precision requisite for success in the little lively brook-it also favours most inconveniently the entanglement of our flies and collar, and the hitching of our flies in the bushes, which are almost constantly found by brooks, and always in the way to bother us. Now this high wind (my detestation on small streamlets) will ofteu be found of the greatest possible assistance when we are on the broader and quieter river; and will, often from its particular direction, whether blowing up or down, or across the stream, make very considerable difference in the weight of our basket after a day's exertion. If then we wish to commence fly-fishing in February or the end even of January, we evidently should select some 
stream where we may find quiet pools, still water, or gentle undulations, such as will be suitable to the enervated frame of the trout and its requirements at this period; and we may continue our preference to large streams even so late as April ; for though on chance occasions good sport might be procured before April, on small, yet we know we are more certain of it, on large; and, as the time of year when we can so say of large streams is but short, it is advisable for the fisherman to make the best use of his time, and fish the large streams early, when successfully he can, lest later, when he would, he be disappointed in sport on them,-whereas he would be certain of sport on the small. And again, from what we have said, it would follow that in late or autumn fishing we should seek sport and obtain it on the small, rather than large streams: we shall then expect a greater number of fish, and these, too, better inclined to sport, as they are yet active and lively, and pleased with the fly; and the water being suitable, as it often is in July and August, we are certain of capturing a great many in a day; indeed, I think if I had to name one month in the year, in which over many year's' fishing I have captured on an average the greatest number of trout, I should name August. Often in June or July the bed of the small rivers and brooks is almost dry; it is, in fact, no longer a stream in which we could at all expect sport, and the fish from their great exposure and being constantly worried and frightened by poachers, groping and 
netting, and fishermen whipping the crystal water, become excessively timid, rush off on the slightest appearance of a strange object, to stones and hovers, and are, from reasons which we have before considered, with great difficulty deceived by artificial baits. If after a long drought at this time of the year a heavy rain succeeds and increases the size of the stream, converts the extended shallow clear water into a series of rapids, deeper in breadth and heightened in colour, we may be sure, as soon as the mud has settled so as to allow the fly to be seen, of fine sport. All the trout seem full of activity and animation; they run up from larger streams and take the fly most greedily, and no season or period of the year is equal to autumnal fishing, on water in good condition, after a long drought;-one wonders where all the trout come from, for so lately the river seemed unoccupied, and now it looks quite alive with them; a new supply indeed has come up from larger streams, which in their turn are now proportionally becoming deficient.

We will now begin, if you please, the season. Winter with snow and frost is ceasing; the sun begins to show our nearer proximity to him; the marshes over which so recently we wandered, frozen, and perhaps white with snow, in search of the swift-flying, twisting snipe, are now assuming a drier and greener appearance; the coverts through which we have toiled for the woodcock-to the sportsman, the grand and supreme attraction in covert shooting-are now 
becoming lively and animated by the presence and voice of woodlark and other innumerable small birds of merry, cheerful voice, though less musical perhaps in note. We have lost the cold blast of winter, and a deliciously soothing, refreshing, gentle breeze sighs through the branches of the trees, and as it passes, and we hear it higher in the dale; we are reminded that tempestuous winter is disappearing, and exhilarating spring is again returning-stimulating our hopes of enjoyment of a yet future summer, and leading us to look forward to pleasures and happiness we hope to realize in the yet untried future: we look back on the past as irrecoverable: troubles, cares, disappointments, and sadness are forgotten in our anxious anticipation of a coming seasonthe idea of its novelty, the knowledge of its uncertainty, the hopes of its joys act together on our expectant minds. We mercifully are denied the certainty of a prospective view of future events -we are delighted with present blessings, and hope still for future enjoyment, and seductive contemplations, forced upon us by the natural appearance of objects surrounding us, yield to us the greatest possible delight-nature herself seems to be awakening from cold reserve, and throwing aside the chilly slumber of winter, is now preparing with genial freshness for assisting in the necessitous duties of animal life, and conducing to the growth and fructification of vegetable life. The commencing season warns the sportsman that a change is taking place-the 
woodcocks have nearly, or quite left us, and foxhunting is ended. We must nowlay asideourguns and spurs, and seek some other source of amusement, and having packed away our gun, we shall do well to take down all our rods and overhaul them most carefully, try every splice, examine every ferrule, scrutinize every ring, so as to leave not an inch unexplored; and put all in the very best order, and prepare for constant employment; - this careful overlooking of our rods and tackle will save us much vexation; as often after having been put aside for some time, splices will start and ferrules and brass fittings get loose, and we must have everything in proper order and ready for active service. And now being satisfied that all is right with the rods, let us take a peep at the old box of fly-making materials. Open the lid, oh! what an enthusiasm arises in the breast of the young piscator, emulated by the enchanting odour of the preservative spices which have now quite scented the box, there placed to prevent the attack of the intrusive insects. - To turn out our old materials in the commencement, or even in anticipation of a future fishing season affords a gratification to the sportsman, only equalled by meeting an old friend after long and complete separation, with an interval of wintry times. It is the stirring up of old memories. Oh, what pleasures rush upon the mind! What excitemeut is experienced and what hopes are speculated in, of deeds to be attained and feats achieved with the rod and line! How we recollect our 
best days and forget our worst; and how we expect that every day of the coming year will bring us unprecedented success, and unparalleled pleasure. Now take out the books. Here is one with furs, -a squirrel's white-tipped tail peeps already at us; and hare's flax, rabbit's flax, and water-rat's we are sure cannot be far off. Here is another containing similar treasures; but now comes the most valuable, the highest treasured of all-the book with hackles, oh these precious beauties! Does one project beyond its especial case? Take it gently, handle it respectfully, and place it tenderly where no harm can reach it, where it may rest undisturbed; by the leaves turned over in search for some particular feather you know is placed in its proper and appropriate position, refresh your memory with another view of these rare feathers, and assort each and all carefully, that you may know where, at a thought, to put your hand on the very one of the exact shade you may require-yes, but the books are full, and of what-how do you know what furs and what feathers will be useful and necessary? Of the former, many - of the latter, a few. For furs, we cannot well do without, for general fishing, the hare's flax, and a word about this. Hares, everybody knows, have different colours in different parts of their bodies, and all hares are not of the same colour, and we must have the flax of many of various colours, each placed separately, in a convenient place by itself. Now first catch your hare, and let this one be an old Jack hare, 
at the end of the season-March hare if you can find one insane enough to be caught; brush or stroke his flax down very carefully over the back, and make it quite smooth, and then take a very sharp razor and shave him downwards, only over the back; you do not of course lather or even wet his hair, but shave him dry, and when you have removed all the cut hair, you will find the remaining stumps looking black, and below this the fur is light fawn colour, or almost white; you have indeed removed all that portion of the flax which gives the hare its peculiar colour which you are requiring, and have left the less desirable part or roots of the hair attached to the skin. Shave an old doe and a leveret, the younger the better; and you will find the younger flax more fawn colour, and not black or red; whilst the older flax is darker, interspersed with some blackish hairs, and has a red or rusty shade shot as it were throughout it-be particular to have an abundance and much variety of hares' flaxno other flax equals it; skin the ears and keep the ears entire ; take a pad, and cut out the forehead, the rest you do not want: get some fur from a fox's skin; the pate of some foxes makes a very rich body, the difficulty is to get a hackle to match it; and the entire skin of a very young cub. Water-rat-entire skins must be kept; be sure you get water and not house rat, or at least have both; some of the latter, which have fine and silky hair, are useful; the coarser reject. A mole's skin is useful; its fur is convenient to 
mix with others of brighter and more lively tint. Some rabbit skin, the same parts corresponding to the hare. Some squirrel skin, the darker over the back the better; these will be found redder, the lighter ones being carroty. A field mouse, a house mouse, and a little otter's fur, with some bullock's hair, of dark, almost purplish tint, which may be obtained by searching along the palings in paddocks where bullocks are kept, and you will find some little tufts appended to the numerous projecting points along the rails, rubbed off and carded as it were by the animals scratching their sides against the sharp points projecting from the timber; or, in old cob walls, often little delicate tufts of useful shade may be pulled out, having been doubtless changed in colour by the action of lime; but I prefer that which I take from the rails, as it is always finer, and therefore more easily used by itself, or mixed with other furs. These constitute the essential furs for general fishing for rapid and small streams. I could be quite contented with a restriction to the hare's and squirrel's flax. Sometimes furs are dyed, and it is useful to have a rabbit's and hare's skin dyed in one's box; this is usually done by soaking the fur for a day or two in turmeric-with a little alum. A new series of shades is given the fur; the roots of the hair are bright yellow; then comes some black; and the extreme points acquire a brighter hue of their former colour, from some hairs taking a yellowish tinge, thus as it were heightening the tone of the 
former shades. The ends must be shorn off as before directed, and will not lose their dye by washing in water. With these furs, we must have gold and silver twist, of various sizes and thickness, and some gold and silver tinsel flattened will be often serviceable. As regards feathers, we have for making winged flies (which I how('ver seldom or never use in small rapid streams) the woodcock, the starling, the wren, the pheasant wing, and tail of cock and hen, blackbird and thrush, snipe, partridge, lark, and the tail feathers of a peacock, a large supply of which should be obtained, as a great variation in colour may be observed in the feathers of this bird; some have a greenish tinge and are little used by me; some are copperish, and less frequently employed ; but others have a bright golden lustre, sobering down to a rich red black, and these of all others I prefer. Peacocks' feathers and woodcock's wing are the only necessary feathers here named; the others it is as well to have by one in case of our going on the large quiet river, but for rapid fishing, the winged fly is seldom required. Our supply of silk must be copious; of colours for fly-making, the yellow is most adapted, and the lighter shades of straw most required. For tying on hooks for worm-fishing, a quiet purple is applicable, but the yellow answers very well. For tying on hooks for dabbing, the purple alone will answer, as the yellow soon by the rubbing of the insects loses its wax, and forms a contrast in colour to the natural tinge of the beetle. Then 
of course we must have gut, and plenty of it, some very fine, some very stout, but all round, transparent, and strong: great attention should be paid in the purchase of gut; and the above terms express the necessary requirements in this article.

Hooks we should too, have, in abundance, and arranged separately in their different sizes. I have generally myself used hooks made by Messrs. Hutchinson and Co., of Kendal, Westmoreland, and the shape they designate the Kirby bend; I have myself been highly,pleased, after much trial, with them, and numerous fishermen of my acquaintance are as much delighted; these are forwarded by post, and consequently may be obtained with every facility to any amount, at a very low charge. For fly and worm fishing I prefer the shape and temper of these Kendal Kirby bend hooks; but for dabbing, the angular bent and prominent barb of the Limerick hook is more convenient, as there is less tendency of the beetle to come off when once placed on the shank of the Limerick hook than on the Kirby hook.

There is another article of the greatest importance to the fisherman, the wax as used by cobblers and saddlers. We ought to be very particular in procuring good wax. It should not be so hard as to be friable, nor so soft as when rolled into a ball and placed on a board to spread itself into a flattened mass, but just of sufficient consistency to maintain its rotundity and globu- 
lar form; and it should, moreover, stick well to the silk. Some little difference will be found in the varieties of silk, one colour or kind taking the wax better than another-the yellow I have usually found the best: if the silk be not nicely and well waxed before we commence tying our fly, we shall not get the body on well, or shall run a great risk of the gut slipping out of the splicing connecting it to the hook.

A pair of tweezers are convenient for attachment to our hackle when we are fastening off the end, but are not necessary; the back of a small penknife answers well, using the base of the blade when open to press upon the back spring of the handle of the knife,

And now we must speak of hackles, - which are very various in description and colour; and as of all the parts of a fly the hackle is the most important, much attention and care should be bestowed upon the selection and collection of these feathers. Many hackles may be obtained of good colour, but indifferent shape, or good shape and bad colour, or a colour which though good when out of the water is bad when immersed in it. A hackle then should be of brilliant lustre, reflecting and sparkling in the light, when moved about in the finger; if the colour of the shining part of the hackle be red, the root or that part nearest the insertion of the feather should be black or nearly so, and the under side of the feather should be dark; also, if blue (or what the fisherman calls blue, the natural 
living colour of such feathers), the root should be nearly black (a little down will always be found close to the root of the feather; this must always be pulled off, as it does not form a part of what the fisherman terms the hackle-it seems an appendage, or perhaps young and undeveloped fibres); in fact, in all feathers, excepting very light blues, the root should be the darkest part of the hackle. In dark hackles the tip and extreme edges of the fibres forming the feather, should be darker than the centre. All hackles should be plucked from a cock's neck; hens' hackles are worse than useless in rapid streams; they have no stiffness, cannot resist the force of the water washing on them, and consequently lie flat along the hook, lose all the little colour they have when dry, and make your fly hook more like a little oval black mass of dirt, than a living insect; few fish would attempt so uninviting a morsel as this represents. 'The shape of the feather should be an isosceles triangle, having its base at that end which is inserted into the skin, and its elongated apex slenderly, gradually, and evenly tapering off to a fine point-many will be found suddenly ending in a rounded extremity; these are not so good, but some of them if of fine colour may be retained. 'Then the hackle must be stiff and elastic, the fibres standing out independently and boldly from the midrib or stalk of the feather, like so many bristles set each at exactly the same angle. A common mode of trying or examining a 
hackle is, after pulling or stripping off the down at the root, to take it by the stem, and with the bright side upwards, place it on the sleeve of a coat, if black, or on any dark object, when the brilliant lustre of the feather will be displayed, and then by pressing the apex against the cloth, bend it, by which we judge of its shape, the regularity of tapering of the fibres, and its stiffness and elasticity in regaining its natural shape, after being impressed and bent in any direction.

The best of all fowls for hackles is the old English game-cock, which, however, is now very difficult to be obtained; no bird seems to have such lustrous, shining, stiff, and well-shaped feathers as this game fowl, such as was used in times of yore for cock-fighting; if these cannot be procured, any one wishing to keep a stock of fowls for feathers, will do well to purchase a blue hen from a farmyard, where most of the fowls are either blue or red and black, where indeed the breed seems especially of a blue-red or blackish colour, and mate this hen with a well-bred darkred or black-red bantam cock; the chicken will be of small size, but one of the cocks of dark colour (blue or red) should be mated with a hen similar to the parent hen, all the others being: destroyed, and from this generation we may perpetuate a class of fowls very similar to the old game fowl; the cross with the bantam fines down the feather, makes it more delicate, better shaped, and brighter in colour; and from this 
stock of fowls, reds, blues, and blacks will alone be born. By choosing a red bantam we shall ensure a richness of tinge in our hackle, and procure more rusty blues and reds than plain and sober-coloured feathers. These rusty feathers are by far the most rare, and by far the best when obtained; they combine several colours, and shot as it were over the surface of a rich glossy grounding in blue and red, and on scrutinizing their surface carefully we perceive the exact similarity in tints of shading to the natural colour of various furs, as the ends of hare's flax, water-rat, and mouse and fox fur, pulled out and mixed well together. There is a class of fowls generally red, of the Indian breed, which are decidedly objectionable for fly-fishing; the feathers look very well and pleasing when dry, but after they have been soaked in water some time, they become soft, flabby, and of a dull hue, as though they had been dusted over with brown sand; these fowls have a white ear, and any cross with them will show the characteristic ear, which in itself is sufficient to make one reject at once any offer of their feathers. I generally pluck my fowls twice in the year; in the spring as soon as the bird has assumed his gay summer dress, and again, late in the autumn, before moulting season, when I find many hackles, which in the spring I would not take, because too small, now however grown of proper size : but the best time for plucking fowls depends on the condition of their bodies; often in some adjoining yards one cock is 
in condition for taking his feathers long before another; we must then from time to time catch our birds and observe the condition of their feathers, their colour and maturity of growth; and when they are most bright and regularly tapered in shape, pluck out as many as are of proper size, remembering that those which are too small nearest the head usually will grow, and if we patiently wait our time, we shall be able to take them of proper size and shape. As soon as plucked they should be placed in regular order, one overlying another, and subjected for a time to gentle pressure, which will flatten and straighten them, and prevent their coiling up, which they have a constant tendency to do ; they are thus better seen, and are less likely to get rumpled and creased, and are more easy to turn when we use them. Of the different varieties of feathers, as I have said, the rusty are the most valuable in all respects, and therefore we must seek to procure a good assortment of rusty blues; a series of shades in colour resembling exactly the hare's back, these feathers are beautifully spangled in yellow and gold, on a dark blue grounding, they are very scarce, and of all feathers the best for rapid stream fishing: also rusty reds-not forgetting the blood red, the black red, or a feather whose central rib, apex, and base are black, whose back or hinder surface is shining and dark, and all the intervening part dark blood-red colour; this of red feathers next to the rusty is the best: then come the browns, 
serviceable in the early months; and the blues, from the pale, sober blue of the heron's wing, to the dark rich spangled blue of the back of a waterrat, as seen when the entire fur is smoothed down. A few black, and a few white hackles, and our assortment is complete.

It is not advisable to have too many furs in one's box, they accumulate so fast as to become a nuisance; a few such as I have named are ample; and winged flies are of but little use on rapid streams; so we may dispense with many birds' wings, tails, \&c., which are cumbrous ; but of our stock of hackles, I should speak very differently -we cannot have too many of them, provided they are all good; if we have good and appropriate hackles, it is most easy to mix our furs so as to match them, but we cannot so easily match our furs with a limited supply of hackles.

Our box is now fully stocked with fly-making materials, such as every one pretending to the name of a fisherman must possess, for no good fisherman will use flies which are not tied by himself, and as the operation of making artificial flies is in itself most simple, I should hope every young piscator would make the attempt early, and he will find fly-making a very pretty amusement for any spare half-hour he may chance to have. For a variety of reasons it is desirable for

- all fishermen to tie their own flies. I have so often observed that those who use bought flies are impressed (doubtless by the vendor) with an 
idea that unless you have the right fly on, or the fly which, at each particular hour of any day in the season is mostly on the water, the chance of success is small, whereas, if you have really the similitude of the very fly, which you may see a trout swallow, your endeavours to secure him amount in result to a positive certainty. It is easy to conceive why the fly vendor pronounces so positively on this point; he being usually himself ignorant of fishing, and therefore probably not knowing his .error, naturally leans to a doctrine which mostly conduces to his own personal advantage, and therefore tempts the young gentleman who desires to have all his tackle complete to fill a large book with an innumerable supply of flies, he being speedily impressed with the belief that a great variety is essential, and that possessing this variety, he has but to use them, and sooner or later his success is certain: his brain full of this nonsense, he rushes to the rapid stream, tries one set of beautifully tied, and most neatly finished flies; these he soon thinks, from his early disappointment, that the trout are not taking just now; consequently he changes them all, and in their place a new series of equally carefully made flies are substituted; these fail to allure, and are in their turn taken off after much trouble and occupation of time; and so changing and shifting, hoping to hit the sporting flies, and as often failing, he wastes the most of his day over his flies, believing that the whole secret of catching trout consists in 
having the right fly on, and forgetting that if he found his first set of flies did not take, there might be some fault in his way of using them; that in truth the want of success depended, not on the improper fly, but on his improper and unnatural use of it, which if he had corrected, would have saved him much trouble, and more early brought him sport. I consider it a very great mistake to have a fly book filled with a host of flies; a few proper ones are all the fisherman will require; and having a paucity, and tying them for himself, he will learn the best of all lessons on rapid streams, namely, to rely on his own exertions for tempting the trout, rather than upon any peculiar and fanciful beauty in flies. A great annoyance constantly will befall the fisherman who uses bought flies on rapid streams, where he will be sure to catch many and hook more trout, which is the slipping of the gut from the hook, and the speedy wearing out of the bodies and untwisting of the hackles; this I have very generally obserred with flies purchased even of the most celebrated makers. If you are going to fish for chub or roach in the Thames with the fly, you may as well buy your flies as not; but if you are going into the North of Devonshire to fish the rapid streams, take my advice and tie them yourself.

Well now, how should we tie the fly? Many receipts are given, many tie them in different ways, and it matters very little how we proceed, so that we make a fly of proper colour, size, and 
sufficient strength to resist the wear and tear it will be subjected to in the mouth of the sharptoothed trout, and so spliced to the gut that it will never slip. Much has been written about making the fly so like what is natural that a cat will be as easily deceived by the imitation as the trout we desire to catch, about small bodies and small heads; this is all very well, perhaps in some measure true, where we have to rely on our fly solely as an imitation of the natural insect, as in slow rivers, but this does not hold good on rapid streams. I object to the winged fly on rapid streams, because the wings are so soon washed down upon the shank of the hook, and therefore lose the appearance which they have when dry, and because they are so soon worn out; and in themselves, even supposing they did in the water look precisely as they do out, they are not one jot superior in their power of exciting the trout, to the simple hackle fly. Upon broad streams and quiet water, I often use them, but even here I cannot assert, from experience, their superiority; there are however just a few periods in the year when they may beneficially be employed. In March, when the trout are universally feeding on the March brown fly, I generally keep one if I am on a broad stream, on my collar. Towards the end of April and in May, the class of flies known as the blue duns are best imitated by a wing fly, and these are the only flies I have ever been pleased with when made with a wing. The directions I am about to give for making flies are 
very simple and short, and I shall only say just so much as I have myself found from experience to be correct; and if I am too limited in my descriptions, the reason is, that I do not wish to limit by rules the beginner, but after explaining the path I have taken, induce him to take his own steps in such a way as he may suppose as good or better.

The grand point in making flies is to have every part of the correct shade; it is not that all the fly, the body and hackle, should be precisely the same colour, but there must be an harmonious blending of tints, and shading of colour; and in choice of our feathers we should strive to heighten the tones of shading above the fur of the body as much as possible, keeping within the limits of general harmony, and carefully avoiding anything: approaching a contrast of colours; there should be a richness, brilliancy, and variation in the aspect of our fly, so that when immersed in water, - vivid shades may spangle amongst duller hues.

I find it impossible to convey by language to the mind of the reader the different colours, shades, and tints of hackles; it will be more easy to speak of some particular fur, whose appearances we are familiar with, and then simply state that a hackle must be found to match it, by which we mean ore whose shades and tints harmonize with the different colours of the fur ; a good test for which is to place the hackle upon the fur we are going to use, and then observe carefully if our feather heightens in tone the shading of the natural fur. 
This is not the way I make flies myself; usually I select a good brilliant hackle, which I know is nearly allied to the fur I am about to use, and then if I find the fur deficient in any of the shades which the feather possesses, I mix some other fur which has the desired shade, in conspicuity above all other shades ; for example, I am about to tie a fly with the hare's flax, I select what I should call a killing hackle, a superbly attractive one, and then turn to my hare's flax; now, if I find the hackle has a reddish tinge in excess above the flax, I take a little cow's hair (if that agrees with the red shade on the feather), and mixing that with the flax in due proportion, comparing my flax and feather frequently, I at last arrive at the precise harmony of shading I desire, and then tie my fly. Sometimes a yellow or golden tinge is excessive in the feather; I then add some hare's flax which has been dyed yellow to the natural fur, and so obtain my proper colours. The greatest care must be paid to this assortment of colours; and though I speak of using a particular fur for a body and hackle to match it, the best rule in practice is to make the fur match the hackle-it is far better to be guided by this rule in tying flies, than to copy the prescribed receipts for making a body, and then trust to the indefinite terms of a blue or brown hackle for legs and wings; and though it may appear we are not adhering so closely in our general rule to the imitation of nature, depend on it if we have brilliancy of colour to stimulate the 
trout, and harmony of shades, in copy of nature, we shall, for rapid stream fishing, find our fly of the greatest practical utility.

We now are thinking about fishing, and it is the month of February, the weather is mild for the season, the water in the small brooks is swollen in size, and the colour of it is translucent ; we can see the light shining through it, and in so doing it displays mud, \&c., settling; it looks as if the smaller particles of the mud had first deposited and left the larger ones to give it a colour, but not deprive it of its translucency. We have seen that it is better to fish on a large or quiet, rather than a small and rapid stream at this season, and therefore we will turn our attention to preparing to fish on the gently flowing river, of moderate breadth, say for example thirty or forty feet loroad in its wider portions, and we will select as our part for trial that which is quiet, moderately deep, and has not a very violently rushing current; some part where the water flows along between its opposite banks of uniform appearance, slightly varied on the surface, 'tis true, by gentle undulations, but not disturbed by waves or frisking eadies; where the whole current trips along evenly, buoyantly, and quietly, its whole breadth presenting much the same aspect and depth nearly throughout, and this equality of course continuing for a hundred yards or so, and then perhaps gently subsiding into still water, or water whose passage is so undisturbed by impediments and declension as to deceive the eye into a con- 
ception of stillness. The wind is not boisterous and we expect a calm day, and now we turn out our box of materials and are going to tie some flies, for we have few in our book. Well then, we will, if you please, make a brown fly, a blue, and a red fly-and first the brown; turn to your fox's fur and pull out some from the back, turn to your darkest squirrel fur and pull out an equal quantity from the back also, and mix them with your fingers well together. Now take your hackles and find one that precisely coincides in colour with the mixture you have made, see that it be not too dark or too light, let it be rich in shades and bright in lustre, but not differing from the fur before you.

Now select your hook, which may be of the size corresponding to (if you have none of them) No. 6 or 7 Hutchinson; if the water is high and the wind boisterous, let it be 7 ; if quiet and calm, as we supposed, No. 6 will be best; but either will do, provided the hackle you have chosen is of the proper size for it, which you judge by measuring the fibres on one side of the hackle with the hook, and they should be just a slight degree longer than the hook from the end of the shank to the bend. Pluck off all the raggedlooking down from the larger end, or base of the hackle, till the fibres from the smaller to the larger end form by their margin or extreme points a triangle; now place the stem or midrib by which it grows in the fowl, between the fore-finger and thumb of your right hand, as low down as you can 
hold it in the division between the thumb and finger; keep the shining surface of the feather uppermost, having the thumb closely pressed against the fore-finger; take the apex of the hackle between your left fore-finger and thumb, and bend the feather and pull it between the thumb and fore-finger, held as before closely together, so as to subject the fibres to pressure, and on drawing the whole length of the feather through, you will find you have turned all the fibres to one side of the midrib. Now take your gut-let it be good strong round gut, not very large in circumference, but everywhere perfectly round and trarssparent; bite off the length you require, and you will find the bitten end flattened; put this between your teeth and impress it in three or four places, of a distance of half the length of your hook, from the extreme end; now your gut is jagged as it were and flattened, the silk will fit into the pits made, and will not allow the gut to slip; now take some strong fly-making silk, which is only a finer description of common silk, of yellow colour, wax this well, and cut off as much as you want, say ten inches. Your tweezers are by your side, and a pair of fine-pointed, wellcutting scissors; and first you take the hook in your left hand, between your fore-finger and thumb, with the hend of the hook pointing towards the hand which holds it, with the barbed point downwards, and the free extremity of the shank, on which will be formed the head of the fly, pointing to your opposite or right hand; now 
take your waxed silk in your right hand, and with the fore-finger and thumb bind it twice around the middle third of the shank of the bare hook; take now your gut, bitten as directed, and place it on the upper surface of the shank of the hook, and let the flattened end of the gut extend forwards as far as the point where the hook is first bent, and maintain it here, together with the hook, between the fore-finger and thumb of the left hand; now seize the silk, which is pendent from the shank of the hook, and .bringing it to within four-fifths of the extreme point of the shank, begin to wind it round the gut and the hook, carrying your left hand in a direction away from your person, and evenly, regularly, and firmly continue your winding towards your left hand, till you have in a perfect manner covered and concealed your gut completely. Your hook is now spliced on, and for a beginner it will be well for him to try if he can pull the gut out of the splicing, as all steps which will give firmness to the hold upon the hook are now completed; and this should be done with great caution and irresistible firmness. Now place your left fore-finger a little lower down on the shank of the hook than it was before, so as to include in its grasp the end of the silk attaching the hook to the gut. Take now a pinch of the fur you have mixed in the fore-finger and thumb of your right hand, and lay it on the silk, which is made tense the while by seizing the free end of it between the apex of the little finger and the ball of the thumb of your right hand; having 
laid on a bunch of fur upon the silk, and taken care that the ends of the fur are close up to the attachment of the silk to the hook, you carry your right fore-finger and thumb down over the bunch, and spread it, as it were, down over the waxed thread, and when this is properly done, you have a tapering roll of fur just adhering to your silk, the finer end nearest the attachment of the silk, and becoming thicker and more bulky as it approaches the free end this being done, and you being satisfied that the length of your furred portion of silk is sufficient, you place your forefinger and thumb of the right hand upon the thicker end, and twist it round, moving your thumb over your fore-finger, in a direction towards its point or tip, and rolling the fur between them, till, after several revolutions, the fur seems to be entwisted firmly, and is regularly tapered, and lies evenly, with its points tending towards the tail of the hook; you have now to bring the silk down to the free extremity, or head of the hook, and in so doing, you will make the body and splice on the hackle; continue then to wind your silk, now covered with fur, in the same direction as you began, but of course bringing it evenly downwards to your right hand, instead of upwards to your left; as soon as you have arrived at a point in the shank of the hook corresponding to the junction of the middle with the lower third, pass the silk down, so that you may hold it firmly between the little finger and palm of the left hand; this prevents your silk unwinding; and sets your 
right hand free to take up the hackle, which has been prepared as directed; seize, then, the hackle by its feathered and pointed extremity, and, with its root, or that portion by which it grows in the skin, lying towards the left, and its finer end towards the head of the hook, and its midrib or stem placed along the back of the hook, as you are still holding it; maintain it in this position with the fore-finger and thumb of the left hand still holding the hook, and having adjusted its length, so that the tip of the feather protrudes a little below the head of the hook, you again take up your silk from the left little finger, and continue your winding of the fur for the body, now including, together with the hook and gut, the end of the hackle as well. And now having arrived at that point, the lower four-fifths of the shank, where you first began to splice on the gut, pull off all the fur adhering to the silk, and wax it again thoroughly, and quite close up to the hook, and then wind it twice around the projecting small end of the hackle you have spliced on. Now pass the silk, as before, between the houk and the gut, that it may not slip, and just hang the long end of the silk over the gut, to keep it out of the way whilst you cut off the protruding little end of the hackle close to the silk; trim up the body by pulling out any fur that may be bushy, and arrange the hackle for winding it on; see that all the fibres stand off at a right angle to the stem, and do not intrude upon one another, but at equal distance project in their proper 
direction. Now being satisfied with the body of the fly which is completed, there but remains to wind on the hackle for legs and wings, and fasten the end that it may not slip, and in so doing we shall have made the head to our fly. Now, still holding our hook as at first and throughout the whole process, clasp the root of the hackle between your right fore-finger and thumb, and wind the hackle in the same direction that you passed your hand in forming the body, at first over the little fur which intervenes between the point of attachment of the hackle and the bare silk below ; make your turns at first more distant from one another than afterwards, but judge how close they should be by the length of your hackle, and the distance intervening between its point of attachment and the extreme end of the hook, remembering that you must leave a little of the hook at the head uncovered (about one-sixth of the whole length of the straight part of the shank). In winding on the hackle, you must be particularly careful not to allow one pass of the feather to rumple or overlap any portion of another; the fibres should incline outwards and a little downwards, towards the tail of the fly; and to obtain the proper direction of the fibres and prevent any overlaying of the turns of the feather, you may, by a halftwist of the stalk of the feather between your right fore-finger and thumb, cause each successive layer of feather to lie smoothly up over the preceding one, which will keep also the fibres out of your way, and allow you to see the precise position 
of the midrib or stalk of the hackle. Having now wound on all the feather you intend, and having brought the last turn near the free extremity of the shank of the hook, you may take the remaining bare stalk between the middle or ring finger, and compress it between its extremity and the first joint of the thumb, to prevent its becoming loose, and you must firmly hold and draw upon this, as the midrib of the feather is very stiff, and tends speedily to unwind itself when coiled up. If tweezers are at hand, you may attach them to the end of the root of the feather, or if not, you must proceed to fasten off the end, and form the head of the fly, which is done by taking the silk you left between the hook and the gut, and windingit in the one samedirection around the end of the hook and the stalk of the feather; having by three or four turns spliced the end of the feather to the shank of the hook, you now, keeping the silk tense with the fingers of your left hand pressing on the palm, smooth down all the prominent fibres of the hackle, and include all evenly in your grasp between the thumb and fore-finger of the left hand, and this being arranged smoothly, you take again the silk, and after bestowing a little more wax close to the attachment, make several half-hitches, which are simply formed by passing the silk around the hook loosely, so as to form a bow, through which you slip the end of the silk, and draw it tight; or instead of ending and forming your head by half-hitches, you may lay the end of the silk up- 
wards over the hackle, and grasp it with the hackle, and then taking the silk at a short distance from its attachment, splice the root of the feather to the end of the silk (now doubled back) and the gut altogether,-five or six turns will suffice, when, by drawing upon the end of the silk which you find passing through the splicing you have made, you can pull all the loop you left tight, and cut the silk off close to where it appears from beneath the turns below it. The fly is now complete, and you have only to overlook it, and arrange any irregularity in the position of the fibres of the hackle or the fur forming the body of the fly. I may here mention a mode of partially curling the hackle, by which we secure it a more precise regularity and order of lying: it is thus done-first, you take the fly in the left hand and hold it by the hook, having the bend inclining downwards; you now, with a pin or penknife, divide the fibres of the feather on either side, and press the fly between the fingers so as to make the feathers lie in the direction now given them, that is, one half standing up and the other downwards, in the direction of the bend of the hook; now, by stroking these fibres between the thumb and the edge of a penknife held obliquely towards them, and commencing from close to the roots, we shall give them a curve which sets off a fly, gives it a more finished appearance, and so divides the fibres of the hackle, as to assume the direction of the wings and legs of a natural fly, the uppermost representing the wings, and the 
lower ones the legs. Whether this is of any practical advantage, I leave the reader to judge, merely stating that I do not believe that it is, so far as the representation of the natural fly is concerned; but by placing the fibres so as to maintain only two directions, I think it gives them greater firmness to resist the action of rapid current washing upon them, than when they are permitted to stand out in a circle around the hook.

We have now tied a brown fly (an excellent one in January or February), but perhaps it will be as well to state how I make another brown fly for the early season. The body consists of the fur pulled out of the tails of the brown sable which ladies wear; it must have a decided brown shade at the roots, and the tips dark or nearly black; to this I put a brown hackle, on which a silvery speckled shade is observable; here the hackle is rather lighter than the body, as the body is of itself of a very sober tone; sometimes this fly may be ribbed with gold twist, which is very simply done by splicing on the gold twist with the gut to the hook, as in the first step for tying a plain fly; we leave the twist hanging from the tail of the fly till we have spliced on the hackle, and formed the body, when we wind it down over the body at regular intervals, and evenly; and then before winding around the hackle to form the wings and legs, we must secure the gold twist by some turns of the silk, then cut off the twist, and place the silk, as before directed, 
between the hook and the gut, whilst we wind the hackle round the hook, \&c.

Now the red flies for early fishing are-first, the black-red palmer, made with a peacock's feather for body ribbed with gold twist, and a black-red hackle for legs and wings, as they say ; to make this fly, you splice the fine end of the peacock's feather and the gold twist together with the gut to the hook, as before directed, as our first step; then having spliced as high as the gut on the hook, you place the peacock's feather along the waxed silk, and taking both between your right finger and thumb, you twist them tightly together, till you have lost sight of the silk now covered by the close revolutions of the peacock's feather; this you then wind down, as though you were making a fur-bodied fly, and the hackle being spliced on, you next bring down the gold twist regularly, and then secure both the silk and the peacock's feather by a turn or two of the silk, waxing it afresh; then having cut off both twist and peacock's feather, you may conclude your fly as above directed. The great advantage of putting on the peacock's feather in this manner is that it never wears out, an annoyance which will often be complained of, if it be merely by itself warped or wound down over the hook; the teeth of the trout catch in the coils of the feather, and pull it out, and speedily the fly is useless.

Use the same hackle; and as a body, cow's hair of a dark red or purple red, such as you may 
find in old cob walls, and rib with gold twist. This is an excellent fly on the broader streams, and may be used almost at any time of the year, particularly when the water is rather high. Obtaining some light-red bullock's hair (you may find it in wrens' nests), rib this with strarv silk for a body, and put on a hackle of a darkish. blue, very rusty colour. Take some of the lastnamed bullock's hair and mix with it nearly an equal quantity of the tipss of the fur from the back of a light squirrel, use this for a body, and then get a rusty blue hackle of the exact shade to match it. This fly may be used all the year round, and will, on the broad streams, seldom fail. The reddest part of a squirrel's fur alone makes an excellent body with a lightish rusty spangled hackle, or we may use a blood-red, or a rusty-red hackle to this body; each will form a separate fly, and by the addition of any fur to match any peculiar tint or shade which predominates either in the rusty-blue, to match which, a little of the back of the squirrel will answer; or in the bloodred, for which cows' hair is appropriate; or in the rusty-red, for which water-rat is best: thus we have a series of different flies, approaching very nearly, 'tis true, the blues, remembering that there should be no marked distinctions between the reds, browns, and blues, but inasmuch as we have rusty or reddish-blue hackles, so should we have reddish-blue bodies, and good killers they will be found too; and so we have reddish-brown and rusty, or brownish-red feathers, and therefore 
we must mix our red and brown furs, and our red and blue furs, to form reddish-brown and rusty-red bodies. There are extremely marked blues and reds, but there is every shade of difference till they gradually become, as it were, mixed together in one and the same fly.

I would here remark, before giving directions for tying blue flies, that I do not rely much upon them in January and February; - the red and brown flies I have given, I have never found to fail, but the blues are supplementary to your collar, and sometimes useful-of these, the rusty I have generally found the best; I might give an endless number of receipts for making all varieties of these, but, if the principle of matching the hackle by mixture of different furs is observed, no one will be at a loss to know how to make a rusty-blue fly.

Take some hare's flax dyed yellow, and some water-rat's flax of a natural colour, and of the roots of the fur of rabbit's flax as much as the two former together; mix well, and with this make your body; and for a hackle select rather a light blue smoky-tinged feather. This fly may be ribbed with straw-coioured silk. On looking at the body of this fly a greenish tint is seen with the light blue; this is gained by the addition of the dyed hare's flax; and much variety of shade and colour may be obtained for the bodies by mixing in different proportions the lighter, as olue rabbit's fur,-and the darker, as water-rat's, -with various parts of the dyed fur of a hare; 
and to match the difference in colour of the body a lighter or darker hackle must be used to correspond to the body. By taking the fur of a rabbit dyed yellow, we may pull out some hair about the skull and eyelid, and mix it with the dyed roots of the fur of the back, and form a good body, to which a spangled blue-rusty feather should be tied. The first or lighter of these greenish blues I have done most with in the early season; the darker, rather later in April and May, in which months the light, however, are excellent flies.

Take some water-rat alone and make a body, or some fur of the little shrew mouse, or some of the house mouse, and match each with their appropriate hackle; the little shrew mouse fly, I generally tie very small (No. 4). These are all that can be required, all I ever use, and such as I have, from my own observation, and the assurance of my friends, been induced to believe the best we can employ; and I am certain that if with these flies tied in any ordinary way, a fisherman cannot obtain sport in Devonshire, in February, March, or April (with an addition or two in the later months), he must look to his use of them, his mode of fishing as defective, and in that endeavour to improve, rather than lazily beguile his mind into the belief that because he has failed he is sure he has the wrong flies and it is useless to persevere with such, as he is confident the trout will not take them.

The collar of gut we are to use should be made 
of six or eight links, and three flies may be put on at intervals of two links apart, so that we shall have three or perhaps four links between the fly nearest the line, or as it is commonly called, the bob fly. But this should depend on the wind, for a long collar in a high wind is very inconvenient; and remember, it is a most simple thing to shorten a collar, by taking off the links nearest the line.' We should always soak the gut previously to attempting to tie the links together, so as to make a collar; and as every one knows, the largest and stoutest links should be nearest the end which is attached to the line; it should, indeed, taper off to a finer end from the line; this makes the collar pitch lighter in fine fishing, and in case of a hitch, and the necessity of a sacrifice of a portion of the collar by a hard pull, we are more likely to lose only the extreme end, than when the whole collar is of equal strength throughout: the only knot I am aware of which will never slip, is made by taking a link of gut, for example, in each hand, and placing the ends on one another a length of one inch and a half or two inches; then proceed as though you were going to make a single knot, but before tightening, pass again the one link and one end through the loop, so making a double knot; now draw gently, and see that the knot runs evenly and regularly, and pull away as hard as you can till it be quite tight, and cut off both ends close to the knot. I have never known this knot slip, and it is of greatimportance to have such a knot in fishing small streams, where 
a violent and sudden jerk is often given the collar, and will surely at some time or other try the knot much. The end fly, or stretcher, should be tied on the last link of the collar in this manner; and I always, if I am using the red fly with gold twist, put it on as a stretcher; it is a very conspicuous fly, a great temptation to the trout, is readily seen, and rarely (if thrown into any little hole, or under a stone, or by the side of the current) escapes the observation of the trout, who will dash off after it. It is very doubtful, too, what the trout imagines this red fly to be, probably some worm or grub, and if so, it would be more naturally used as an end fly, when it often or generally is under water, than bobbing and dapping about on the surface of the water, as the middle or bob fly must dc. I leave those fishermen who attach more importance to the exact imitation of natural flies than I do, to settle this question theoretically; practically, I know that the red-gold twist flies will always kill more fish when placed as stretcher and not simply from the end fly reaching the best places, for often I have changed, and then killed fewer fish with its substitute, till restoring the original red, I have again been strengthened in my opinion from former observations.

The middle fly is placed on the collar simply by making a loop in the gut to which it is tied, and hitching this above the second knot from the stretcher $\mathrm{Hy}$; I like my brown fly to come here, unless it be a March brown, which I always keep for my bob fly. The length of the gut to which 
the bob fly is attached should be longer than that to which the middle fly is tied, so that the collar gradually rising from the water, from the stretcher fly to the line, may just allow the middle fly to be seen, whilst we are bobbing the bob fly on the surface of the water. For the bob fly, then, select the blues-these are generally a lively class of flies; and so I suppose we may be acting more in conformity with the natural habits of the $\mathrm{fly}$ we represent, by making it dance and sport about on the surface of the water. I have certainly observed that some flies do better as bob flies than others; I mentioned the March brown-these flies may be observed to be strong on the wing; they dip themselves, and just when they please, rise from the water and dip again; they are not easily washed under water, as more delicate flies are; and have more power to direct their flight, and command the movements of their bodies.

Some use more than three flies, and if the wind is not high, you may put on as many as you can manage to throw properly; but more than four are sure to become a nuisance by entangling the collar, and hitching in just everything you do notwant them to do; and at most disagreeable times, as when playing a trout with a bob fly, your stretcher catches in a stake in the middle of a deep stickle; or just when, your fish being tired, you are about to lift him over some little bush, you find your numerous flies each hooked in the branches of a blackthorn, placed as if on purpose to molest you; if, therefore, you do not care to be 
constantly trying your patience, use never more than four flies, and remember, that you will kill as many trout with three as with four flies.

The most serviceable kind of line is made of hair and silk spun together; I think the colour of very little importance; every line before being: used should be first put to a severe trial, in all its length, by pulling hard upon different parts successively with the hands; and in order to have sufficient strength, it is better to have the line stouter in quality than such as are ordinarily recommended for fly-fishing. Some lines are tapered, -these I prefer, because the bulky part (which is seldom required) fills up the reel and makes it equivaleut to a multiplier; the tapered line is more easy to throw, and can be commanded with the greatest precision of direction in casting; and in case of a hitch and a pull for breakage upon the line, we save the greater portion, being the stronger; but I by no means imply, in speaking of preference for tapered lines, those little whimsical things ordinarily kept in shops, which, for example, in a line of thirty yards, begin a gradual tapering from the first to the last inch, the first of which is not one-half so stout as it should be; and from the length of its tapering, we lose its advantages, because, generally speaking, we have not more than six, eight, or ten yards out, and in this distance the tapering is so gradual and so slight, as to be inappreciable. The most useful line is made,- - say thirty yards, - the first ten not to taper at all, of a large size throughout, nearly 
twice as large as the stout end of such tapering lines as are sold in London shops; then, for the next ten, or fifteen, a gradual decrease of sizeshould take place, till at the last six yards, the tapering is sudden. We should have a line with all the advantages of lightness of a fine one, together with the strength and weight of a stout coarse line,one we can employ with equal ease in fine fishing in quiet water, in brook fishing, and in broad stream fishing, in windy weather.

Of reels, I prefer a stout brass one of large diameter, but narrow from side to side; the effect of this, of course, is, by enlarging the circle on which the line winds, to proportionally increase the rapidity of drawing in the line; the click is a very useful addition; the stop, of little service. The multiplying reel is so often getting out of order, that it is more plague in its annoyance, by getting the cogs fixed, than profit in quickness of getting in a long line.

We must now say something about rods,-and this something I shall shorten as much as possible so far as broad stream fishing is concerned. Every rod maker imagines his own rods superior to any others, and each has some peculiar, fanciful whim, in which he believes his excellence to consist; but, as the maker and the user of the rod are not often the same individual, I am afraid rods are looked upon too much as articles for sale, than for use-are manufactured often rather to make money than catch fish; and in being recommended a rod, the brass fittings, splicing, spare tops, and hollow butt, 
\&c., \&c., are set forth as the grand attractions to the purchaser, each adornment of brass, or neatly ornamented splicing of purple silk, adding a new feature of commendation, nor diminishing the price of the article, till at last a very superior specimen of ornamental workmanship is produced, which has as much brass, and as many coloured splicings, and as small rings as can delight the fanciful requirements of the mechanic in his workshop, or annoy the fisherman by the river side. I do not wish to decry the efforts of rod makers to produce a neat and well-finished rod,-far from it, by all means should their endeavours to this end be praised; but I have frequently observed that the minute detail of ornamental finish has been more attended to, than the elementary points ; the first, selection of wood for the construction of the parts, their proper adjustment and firm conjunctions - which form the essentials for use; the brass fittings, colouring, and varnishing being just so much as is superadded to please the eye, and in some measure minister to the convenience of the fisherman, though, after all, to be regarded as matters for secondary consideration. It is true, in some measure, that, inferring from probabilities, the man who could neatly execute these details of workmanship, and would take pains elegantly to finish off all the adjustments of fittings, \&c., would carefully endeavour to form a good basis for displaying his workmanship, would, in truth, endeavour to make his bare woodwork perfect as far as he could, before commencing the ornamental super- 
structure with his varnish and brass; this may make us incline favourably towards a well-finished rod, but we must not forget that the maker of the rod may, after all, have a very erroneous idea of what a rod should be. We would yield to his knowledge and superior judgment of an ordinary piece of furniture, the construction of a cabinet, or the choice of his various tools, but we must reserve our own opinion of his rod when completed; and acknowledging its elegance and general aspect, criticize carefully the article before us, as to its capability of fulfilling the duties which will be required of it, and its adaptation to the end for which it is by us intended.

Great variety may be found in rods, and different men in different parts extol different kinds of rods. We are considering fly-fishing in the early months on rapid streams, such as are found in the North of Devon; and for these rivers and their like, we must have a rod of great power in itself, of much strength, considerable stiffness, combined with appropriate weight and lightness; and as all do not care to possess a large assortment of rods, I will endeavour to give an idea of a rod which may be used in the early months, to the broad and narrow rivers, in windy and calm weather, in still and rapid water; one that will be generally applicable to all kinds of fishing, excepting bright water fishing in small streams, and the very broad streams, as the Taw, where greater length is more advantageous, though even on these broad streams such a rod as I am about 
to describe will be found very useful, and the same principles extended to one of greater length will constitute a rod to command almost any breadth of water.

I would say, then, a rod for the early months should not be shorter than twelve feet, nor longer than fourteen; this difference will allow a more correct adaptation of the rod to particular streams and different individuals; a medium length, however, as a general rule, will be the most useful. Of whatsoever woods we prefer to have our rods made, it is absolutely necessary that such woods be most carefully selected, and the slightest flaw, -a knot, an obliquely running grain, - that is to say, the fibres of the wood taking such a diverse or oblique direction that the wood could not be worked or split down parallel to it before planing; in short, if ever the least doubt from any cause arises respecting the condition or quality of our material, the mind must instantly incline to a decided rejection of the rod completed, or the rough material iutended to form a rod. Rods are made of different woods, and several woods generally contribute to each rod, selected according to their pliability, their lightness, toughness, and stiffness, to take that portion of the rod where their pre-eminent qualities will be most brought into play, and to fulfil purposes and requirements for which each is best adapted; for we must know that in a rod we desire not one simple end to be obtained-as in a bow, for example, where vibration is all that is requisite to affect the string for 
imparting motion to the arrow-but many functions have to be performed; not only must the rod bend and with elasticity regain its straight line, butit must bend in one particular manner; increasing in amount from the hand to the extreme point, it will be required to bend by force applied at either end,-and during its bending, or when it assumes the arc, it must maintain especial qualities of stiffness and elasticity, with proportionate degree of power from its finest end to its largest extremity. Again, it must be so tapered and balanced as to assist the fisherman, and not feel to him a dead weight dragging on the muscles of the arm, and constantly tiring him. Now, we shall find great difference in rods, both as to their stiffness, weight, balance, and the arc they assume when a weight is applied to the finest end (as a bunch of keys, for example, suspended to the end of the top joint), and this will constitute a point of the greatest importance. In examining a rod, not only should we carefully scrutinize and observe the amount of bending power the whole rod has,-whether it is, as is commonly said, a stiff rod or not,-but see clearly wherein and in what part the stiffness exists, - whether the whole length of the rod be too stiff or too limber, or whether it be too stiff or too limber in one part only; for we sometimes meet with a stiff rod too pliant in some spot, and a limber rod too stiff in one joint or a portion of it. If a rod is stiff, it must be proportionally stiff throughout; if limber, proportionally pliant throughout; and this proportional resistance in 
different parts of rods gives them the arc they assume when bent. Of course, a heavier weight will be required to bend a stiff than a limber rod in any part, and this forms a great difference between stiff and limber rods, that, independently of the greater weight required to bend a stiff rod at all, it forms when bent a different arc from that of the limber. Now, not only is there in rods this distinction to be observed, between the much curved pliant, and the partially and slightly curved stiff, - but in many rods which might be called stiff or pliant, the curve commences in different parts; in some slightly, but continuously from the larger end of the butt to the finer end of the top; in others, a curve can only be seen to commence in the second joint, and this curve may be sudden, gradual, great, or but slight, which varieties will afford totally different characters to the rod. To the former described we shall now more particularly have to refer; to the latter, which are better adapted to small streams, we must allude when in the later months. We are preparing to fish the small streams, - and although we may, with advantage, consider the numerous varieties of rods, and attempt to give some little advice on the subject, we must call upon the young piscator to view this portion of his subject in a general light, and attach only a due importance to the selection or purchase of rods, remembering that the good rod is not the essential point for insurance of sport, but only a better means of exhibiting his skillit a matter altogether of personal convenience; and 
to be impressed with an idea of the necessity of a perfect rod will produce discontent, weaken resolution, and withdraw our attention, in times of disappointment, from the real cause of error, which should be attributed to the workman, rather than his tools.

The rod we are now about to make use of is a rod generally useful on various streams ; one that a fisherman cannot well dispense with, and one that will serve him in all purposes, and all times or seasons,-excepting bright water fishing on small streams in low water, when a peculiar rod, hereafter to be described, will be required. This general rod then, we say, is about fourteen feet in length,-whether it consist of three or four parts is rather a point of fancy in the fisherman's mind than of real practical value. There are many heavy objections to a fly rod of fourteen feet being composed of more than four joints ; and three-jointed rods, of such a length, may be objected to, from the awkward length of each joint, rendering it inconvenient of carriage ; nevertheless, without doubt, the fewer the number of joints forming a rod, the better; indeed, if we desire to have a perfect rod, we must put up with the disagreeable awkwardness of fourteen feet of straight wood to carry, and have our rod made in one continuous piece. I do not mean to say of one and the same piece of wood, but the several portions selected to form different parts of the rod should all be spliced together, so as entirely to do away with the objectionable brass of a ferruled 
rod, and make the whole rod flexible throughout its whole length, in every part and particle proportionally and continuously, not interruptedly stiffened and at intervals broken in flexure by the intervention of the inelastic, inflexible brass.

The materials of which our rod is to be composed should be-for the butt, ash; and this an especially good piece, straight in the grain, having no knots, light and well-seasoned. Provided the wood be light, never fear having the spear end of the butt too large. It is very advantageous to have a large butt, that the tapering may be gradual throughout the whole rod. Many prefer hickory for the butt-it is usually lighter than ash, but it tends to make a rod too limber, and gives it too much action in the butt. Then, for the second part (if the rod is composed of only three parts), I think lancewood forms perhaps the best; and for the top (which from its great length will be found very difficult of construction), lancewood may form the lower fifth or fourth; and cane split, and in short pieces, the remainder. The lancewood employed in such a rod must be of a very superior quality, of pale colour, hard texture, and light in weight. Lancewood often is heavy and dark,- -and this will be found tough, but not so resilient as the light whiter wood, which should be very springy, easily bending, but às easily regaining a perfectly straight line. The rod we have now considered will be found very springy, rather stiff, but very commanding; having great power in the central parts, and in its action bend- 
ing with a long large arc; the top joint is the greatest point for attention, as unless it be very carefully made, the rod will be either top-heavy, or the action of the rod will not be proportionally and uniformly diffused over the entire length; a too heavy or too stiff top will throw too much action on the middle joint, and a too light and limber top will make the rod like one of those tandem whips, which have a long piece of whalebone at the finer end ; it will, indeed, be flicking about and partaking almost as much of the course and direction of the line as of the rod itself. But we have said that a four-jointed rod is most convenient, and on the whole, for general purposes, the most desirable; the butt of this rod may be either ash or hickory; I should prefer the former -and the same caution as to large size should be remembered in this as in the three-jointed rod. The second and third joints are usually formed both of hickory-and the top, cane. The greatest possible care should be exercised in selecting cane or bamboo for rod-making-some, or indeed most of the bamboo is so thin that when it is worked down and made round, the remaining wood for the joint will be found of unequal texture, in part hard, corresponding to the outer enamelled surface of the cane; and in part soft, corresponding to the inner or hollow portion of the wood; which, in endogenous woods, such as cane, nourished from the interior, is always porous, and consequently soft, and unfitted for the purposes we require of it. We must, then, always 
obtain cane of great thickness from the outer to the inner surface, so that, when split and rasped down, the remaining round piece may be of perfectly uniform dense texture.

The most common error I have met with in four-jointed rods is, that cornmencing from a butt of too small diameter the tapering of the rod is extended over too great a length about the middle, so that it is here weak, and consequently, when put in action, as in throwing the line, or made to wave, as it were, by alternately raising and depressing the top whilst holding the rod at the butt, a double action may be at once perceived; in other words, a series of arcs or vibrations will pass from the butt to about the centre, or weakest part; here they will be partially interrupted,-and, as though from a second point of . fixture, a new series of vibrations will pass forward to the extreme end ; these, too, seem to have partaken of the force first exerted by the first movement at the butt, together with the accumulated vibrations sent forward from the middle weak point of interruption. The consequence of this is obvious, for should we violently strike at a fish whilst we have any slack line between his mouth and our rod, the muscular movement we have made will generate a force, which though we suppose just sufficient to hook our fish, will be increased to such an amount that the mouth of the fish or our tackle will be endangered; we shall first cause, in the elevation of our arm, vibrations to pass along the rod to the centre- 
here they will be interrupted, but our movement continuing and fresh vibrations passing on, at last the accumulated force is transmitted to the top with a multiple of power beyond our calculation. Again, suppose the vibration or waves to have reached the extreme end of the rod, it by no means follows of necessity that the first movement given to the end is in an upward directionfrequently it is in a downward course-that is, the top dips before it rises; it dips, I say, and before it rises, of course, other vibrations have been succeeding-have now reached; and at last, with great force, the top flips up, suddenly pulling with an unintentioned jerk upon the line, and the fish, which will probably be lost. But again, we have only now considered the effect produced on the fish when thus powerfully struck, but let us retrace our steps, for having struck and having set a rod thus in vibrations, we have another effect produced, a new series of vibrations will be sent from the top downwards towards the butt; nor, as yet, has the first force exerted been lost on the butt; no-vibrations still continue from this direction, and as we now have two sets of vibrations set up at opposite ends, the only question which remains is-where will these meet? the answer will be, in practice, speedily discovered-it will be at that part of the rod which we called the point of interruption, where the second action commenced, owing to the too extended length of the part disproportionally with its tapering, and the effect of the concurrence, or 
meeting of the opposite forces will be similar to that produced by striking sharply a globe of glass, or of compact uniformly dense metal at any point, when the fracture of the globe will be found at a spot diametrically opposite to the point of concussion-where, indeed, the vibrations traversing in radii from the point struck will impinge on one another; here, then, will the force have so accumulated that the molecular disturbance of matter will be sufficient to separate its particles, and so cause a fracture of the globe. It seems to me, that this just explains the fracture of these rods, weak in the back, so to speak, causing an interruption of action-or, as I have called it, a double action, when fracture so frequently follows sharp striking-or even violent movements with a heavy line in windy weather, when forces exerted at the opposite ends of the rod will surely cause fracture of the rod at this point of meeting or concurring vibrations. It is true, that by pulling violently at either end of a rod with a sudden jerk, it will snap in its weakest point, as any common stick will snap when bent between the hands, but it is not thus that rods are commonly broken; it is not by the immediate direct force applied, but by waves of vibrations transmitted along the rod increasing and multiplying in their power during their progress, that the unfortunate disaster occurs; if the former were the common cause, we need not have so long considered the subject; it would have been obvious, and its remedy easy; but as it is by no 
means easy to remedy the effect, and the misfortune is a common one, it may well be inferred that the cause is not so well understood, nor has been so well considered as its importance demands. Importance, I repeat; for with such a rod on a small stream, where it is absolutely necessary to strike instantly and sharply, one may plainly see that our success will be doubtful, since we cannot correctly estimate, and so school our arms with the precise amount of force to be applied, as to avoid fracture of our tackle, or rupture of the fish's mouth, and be sure of bagging our fish. On large streams, 'tis true, in striking, it is of less importance; but in playing our fish we shall discover such a weak-backed rod a very serious inconvenience-it wabbles about and permits the fish in his struggles to command our hand and control the rod, as much as we should steady the latter and direct the former.

I cannot enter into all the detail of considerations respecting this subject, which is one of great moment, as far as the convenience of the fisherman is concerned. I hope I have pointed out the most common and most important errors which experience will disclose in rods ; the explanations given will be obvious enough to any one who will take the trouble of trying the effect of the action of rods, and having perceived them, he will be ableto satisfy himself more easily in purchasing rods from shops; and remembering that all rods should taper equally and with precise gradation from the larger to the smaller end, he will judge of their power; and 
reflecting that the amount of movement every part and portion of a rod possesses should be directly proportional to the size of bulk of wood at that spot, he will be able to form a proper opinion immediately on handling the rod, of its practicability and adaptation for service.

We have now summarily glanced over flies, collars, reel, line, and rod-and as we are about to fish the large streams, it will be advantageous to us to procure india-rubber boots reaching to the fork, in order that we may wade and fish in the water without getting our feet and legs wet, and endangering an acute attack of rheumatism-or of rendering our bodies susceptible of this horrible malady, with its multifarious complications and consequences, in after years. Any fisherman respective of hygiene (and disregard of it is folly) will not neglect the caution of wearing indiarubber boots if he intends to wade in the river. This wading gives us much advantage; not only does it allow us to reach our flies accidentally entangled in bushes on the side of the river opposite to us, but by allowing us in comfort to walk in the water, we can, where the sides of the river are bushy, fish in places which no one from the bank can reach; and in these places, the fish, unaccustomed to the sore mouth of the ordinarily much molested trout, takes his bait with avidity; and here, too, in avoidance of disturbance and intrusion, the larger fish resort, and may be readily caught with the hook. Again, in broad streams, even if both sides are free from bushes, 
and the whole current may be easily commanded from the banks, yet by walking into the water we lessen the height of our head from the surface of the water, and so render ourselves a less conspicuous object to the eager gaze of the trout, and consequently are enabled to approach without scaring him to a much nearer distance, which of course is a point much in our favour, as we have less line out, and can more quickly hook our fish. 'The boots $I$ refer to, are such as are sold at Cording's, near Temple Bar, and very probably, for aught I know, at many other places ; no fisherman should be without them; they will not only add to his comfort, but assuredly increase his sport. One caution I may add,-take care to have plenty of iron at the soles of your boots, so as to make them heavy, and see that the nails are not closely packed together; or, in case of light boots, the rapid current will wash you off your legs; or, when the nails are driven in so as to form one compact mass of smooth iron, you will slip up in walking over the rocks forming the beds of the rivers-and to get one's head under water in the month of February or March, is by no means agreeable, or conducive to temporary comfort and future health.

I have been in the habit of carrying in my pocket two small hooks, or crooks, for the purpose of cutting off any little bough or twig, rush bush, or thorn, in which myflies may accidentally become entangled. (I am indebted to my lamented piscatorial instructor and friend, the late Dr. Thorne, 
for these, as well as for many practical instructions.) The crooks are two-a larger and stronger, adapted for boughs of trees, \&c.; and a smaller and lighter one for rushes, brambles, and the like. The larger is formed of a curved piece of steel, sharpened on the inner border like a common sickle on a minute scale, having its point more incurvated or crooked instead of standing out as in the sickle; the iron piercing the handle of the sickle would correspond to a spill-like process descending from the thicker end of the curve, and through the point of juncture of the spill with the curve traverses a pin, to either end of which is attached the ends of a bent piece of wire, descending and turning round the free end of the spill; to this loop of wire is attached a strong piece of sash cord, which should be about five or six yards long. The crook is thus used-we suppose the flies entangled in the branch of a tree overhead, at a part where the wood is not more than half an inch or one inch thick-line being let out from the end, the top joint of the rod is taken off, and in the ferrule from which it came is placed the spill of the crook; the curve of wire with the cord being turned on the other side of the spill to that on which the free end of the curved crook projects, the crook is now simply placed over the bough which is desired to be cut, and by a little dexterity in mode of pulling made to cut its own way through, by the force exerted in traction on the cord ; a few attempts will readily instruct a novice in the use of this instrument. The smaller crook 
is in shape like the letter $\mathrm{v}$ inverted, having one arm made longer than the other, and from the end of the longer arm of the letter is continued a spill, perpendicularly downwards, for one and a half inch,- the shorter arm of the crook being one and a half inch, and the longer two inches; at the point from whence the spill commences is bored a hole, to which is tied about six yards of strong light cord. The opposing edges of the arms of the hook forming the angle must be well sharpened, and the material used must be good steel, the whole crook weighing not more than three-quarters of an ounce, or one ounce. This crook is intended to be used when the whole length of the rod is required to reach the object to which the fly is attached, and when the weight of the other crook would be objectionable; and it is thus employed-two common goose quills must be bound tightly together and their ends cut, so that the end of one quill can be passed over the extreme point of the top of the rod, whilst the slender spill of the crook is inserted into the open end of the other; thus, then, the crook can be placed where the rod can reach, or the top (in cases of necessity) may be lengthened by tying a pole to the butt, for the sake of greater length; and the angle of the crook speedily catches in the bough, bramble, or even rush, and cuts, by being pulled on through the medium of the cord, its own way through.

We commenced our discourse on fly-fishing with the beginning of the season, and advised a 
visit to the larger streams. We have mentioned a few flies suitable to the season, in order to bring the subject of fly-making before the younger students in fishing, and also to say a word or two about rods; ; but as large stream fishing is beyond the province of our present work, we are not going further with our considerations on this subject than cursorily to allude to a few points in the art of fly-fishing in early months, trusting that on the subject of small stream, fishing, we may be able to bring our views more conspicuously before the reader.

The style recommended for fly-fishing in rapid streams, in bright weather, is not wholly applicable to fishing the larger streams in the early months, as we have seen that trout early in the year have not the same habits or powers that they acquire later in the season. In the early months we cannot altogether disregard the principle of imitation; indeed, it is best to work on this principle, trusting to our flies as imitations of the natural insects, and using them in conformity to our ideas of the movements and appearance of the insect itself: thus adopting the more ordinarily practised system of fly-fishing. At the same time we urge the fisherman, whenever he has the opportunity, to work as we advise on small streams; the opportunity will be appreciated by general similitude to the small stream, and in approaching a spot which the fisherman perceives to resemble a sporting locality on a small rapid brook, he will do best to fish it just as he would on a small and rapid 
river; indeed, bearing the former precepts for small rapid streams in mind, he should, whenever practicable, no matter where he may be, apply them; the result will be, that on many occasions, when fishing, perhaps, with a good fisherman of larger streams, he will fill his basket, when his friend of more limited knowledge will kill scarce a fish. This has actually occurred, that two fishermen have been together on the same large stream (the Taw); one was for large stream fishing a better fisherman than the other, who however was greatly superior on small streams in bright weather. The big stream fisherman (an Exe man) could do nothing; the small stream man killed a large basketful. The reason was, that the weather and the stream brought the field of operations to a near similitude of the small stream, and consequently, far removed it from the type of large streams : the one fisherman could not accommodate his style to the conditions presentthe other could; the one therefore failed-the other was successful.

In fishing with the artificial fly, if we are on dull, slow, and deep water, we must consider our flies as pure imitations of the natural insect, and our practice must be adapted to our intention of deceiving the trout; if we are on rapid small streams, our principles are entirely different, and we no longer consider our fly in the light of a representation of some insect on the water. The two principles must be practically understood, and when we have thoroughly become conversant with 
them, we shall find no difficulty whatever in taking advantage of one or the other as circumstances may require; and when fishing, for example, on the larger streams, rapid and deep, we shall be able to apply our knowledge to the best possible advantage, deceiving the trout when deception alone can avail, but stimulating his predatory tendencies whenever we are able. We shall understand our means of stimulation as we advance, and consider the small streams, and the various methods to be practised on them. 


\section{CIIAPTER V.}

For fly-fishing, on small rapid streams, the best description of rod I have used is made in this way :- butt, of white or silvery spruce fir, light, well-seasoned, and strong; there must on no account be any flaw in the wood, or irregularity in the grain; the thicker part of the rod to be so large as the hand can grasp, or so big that the fore-finger and thumb can scarce span it-second part, lancewood, very light and elastic-top, made of best split cane, with a few inches of lancewond at its lower end. Entire length of rod, twelve feet; the butt, longer by an inch or two than the second part, the latter as much longer than the top. The splices in the cane to be so struck that, when the rod is put together, the extreme point of the rod will cock up a little. This is a very commanding rod, and extremely serviceable for fly, beetle, worm, minnow, or any other kind of fishing on small streams; but for finer work, with the artificial fly alone, I prefer a rod of ten feet only-certainly not more than eleven feet in length-butt, light spruce fir-second part, entirely of split cane, though in this a few inches of 
lancewood may be inserted at the lower endtop, entirely of split cane. This is an extremely light rod, and one easily broken, so that it is hardly adapted to any other kind of fishing than artificial fly-fishing. These rods are stiff and have no double action; to use them we must exert a sharp wrist movement, and not work them with the long arm swing required for the double-actioned rod; they cast the fly by a sudden jerk, with great force and proportional accuracy ; the line is always " taut," and when you strike at a fish, you are into him in a moment; but, above all, you may work with them through the most successful day's fishing, and your arm will not be fatigued; a point of no small importance, I can assure you.

The flies I hare had most reliance on, in small bright water fishing, are made of hare's flax, shorn off the back; they are made large, on a No. 6 or 7 Adlington hook ; their bodies are ribbed with gold twist to add to their conspicuity ; and the hackle of the brightest shades, to be obtained of the main or predominant colours of the hare's flax. I make the flax stick out from the body, so as to mingle with the fibres of the feather. In some kinds of the redder hare's flax I put a rusty-red hackle, with gold twist; to others more silvery, a gingerred hackle almost yellow. Then, again, for very low water, with very bright sun, I use a lot of stained flies, made with bodies of lamb's wool, such as ladies work with; some of the colour of an infantry soldier's coat, with ginger-red hackle and gold twist, on a No. 7 hook; and capital 
killers these soldier flies are-but in using them, one need be quick of movement, or they will scare and not catch trout. The various shades from crimson and yellow to red, all with fancycoloured hackles, answer well at these times-indeed, the only objection I know to them is, that they catch so many trout that their bodies wear out by the constant biting and tearing of the fish's teeth. I have commonly used two hare's flax flies-one of a reddish, the other a yellowish hue, and I rarely or never change them during the brighter months. I don't wish to limit the fisherman's resources in flies, but I state this fact, hat it may console him some day, when he may be fishing my old haunts and can obtain no sport. He may, too, if he remember my confession, think that there is some truth in what I have endeavoured to prove, viz. that there is more trust to be placed in the peculiar use of flies, than in the selection of any one particular fly. The collar should consist of four or five links of stout gut, and no more than two flies should ever be used in bright water.

From what has been previously stated concerning the difference between the sluggish deep stream and the merry, lively, boiling brook, it must not be expected that any or scarcely any similarity should be described in the manner of fishing the two-the former essentially requiring the wily temper to dissemble, and by false imitation deceive the cautious trout; the latter affording a scope for a new practice over and beyond 
that of simple imitation of natural food, and based on the principle of the character of the fish, and his boldness and tyranny; remembering the universal maxim, however, that the fisherman must be wholly concealed, which maxim, in the case of the clear swift-running brook, will be found difficult to carry out, and will cost some little labour and experience to perfectly accomplish.

And now, to the uninitiater, let me briefly recapitulate what may elsewhere be found in different parts in alluding to small rapid stonybottomed streams, or brooks. Remember that the trout are pretty constantly feeding, but that their food varies. They feed early in the morning, and seem especially fond of an early breakfast; therefore you cannot be too early by the river side. If a trout sees you, or any part of your dress or tackle, distinguishing it from local objects, you will not catch him, and probably will not catch his neighbours either. Conceal yourself, therefore, entirely, rod and all, by every means (and these are numerous) in your power. Regard a pool or river, or any portion of water you approach, with a most scrutinizing eye, and endeavour constantly to pick out the exact spot where every fish is lying; practise this, and you will soon catch every fish favourably situated. Give every rapid-running stream credit for a great number of fish, so every likely spot will be fished as though you were convinced a trout were there: this conviction firmly fixed, will make you fish at all times in the same determined but 
cautious manner, and your reward will encourage you. Note in your mind the exact spot from whence every fish you move proceeds, whether you kill him or not; observe the manner in which he took, lost, or refused your hook; and reflect on the way in which you worked for him, and the different circumstances influencing your sport at the time, as wind, weather, colour, and height of water; if successful, think for what rewarded -if unsuccessful, cast the blame on yourself manfully, and reason with yourself in what way you were wrong, and how in future you may be right. Never lose these practical lessons by saying to yourself that the fault was the trout's, but reflect at all times on your proceedings, and your reasoning will soon conduct you to more successful practice. Remember that in rapid streams, rapid movements are necessary on the part of the trout; his action is wonderfully rapid, so be quick in eye and hand; in the latter, the utmost rapidity with the least possible force is required: the trout has a force which may be either opposing or concurring with his movements, in the rapid course of the water, and the voluntary force he himself exerts may be towards or away from you in direction;-learn, then, to calculate instantaneously your advantages and his, when you strike him, for your fly must be into him instantly-nor neglect these forces, if you are obliged to play him out. Remember that a trout sees best upwards, forward, and on one sideless easily backwards and upwards-and but 
little, if at all, directly backwards. Keep behind his tail then, fish up stream, and keep your head as close to the level of the water as you can. Keep as short a line at all times as possible; creep and crawl-get down to the water's edge, or into the stream itself-use every artifice you can for concealment-throw up stream, but do not, if you can help it, let out line to reach a fish. Throw boldly and with exact precision ; and provided you are fishing rapid water, and throwing up stream, yourself being concealed, care less about your fly pitching very lightly, than its pitching in the right spot to an inch, and in the right manner for his taking it-you will soon catch plenty of trout, though you have made your fly euter the water with even a little splash, and will learn how to work your fly when it has pitched in the water, a matter next only in importance to the spot where it should pitch. Keep your line, from fly to reel, "taut."

The practice I recommend is, to be by the water very early - not later than six a.m., during the summer months. Don't be alarmed at the idea of turning out of bed at four a.m., for you may be assured, if you do so a few times, you will agree with me in saying, that a fisherman who comes to the river at nine or ten, loses a large portion of a day's pleasure. I reflect with the greatest pleasure on the many early walks I have taken up the Devonshire valleys to reach the spot I intended to commence my day's fishing; and most truly enjoyable and delightful is a walk 
before the sun is up to reach some beauteous valley, and there to witness the rays of the rising sun bursting through the morning haze and mist,

- clearing the atmosphere just now partially obsoured by the vapouring air, but now rarefied to allow a more extended scene. Pardon, reader, my hinting at the pleasure I remember, before getting to the water; - make the experiment yourself, and I shall have your forgiveness. Arrived at the water, my usual practice has been to commence with the worm, and continue with this bait until I find the fish are not taking it well; I then change for the artificial $\mathrm{fly}$, and with this I work away as long as I am confident I have the best advantage with it. Now, I may say, that for early, morning-perhaps from four a.m. to ten a.m., generally, the worm will beat the fly; supposing, in this statement, that they be each managed with equal skill by the fisherman. As a general rule, in a complete day's work, the fly will beat the worm in numbers, but the worm has the advantage in point of size. The worm is decidedly the more uncertain bait of the two, i.e. sometimes you can hardly kill a fish with it, at other times you may kill them rapidly; with the fly you may always kill some fish, but sometimes more than others; therefore, if they take the worm well, stick to it-if they do not take it well, waste no time, but change to the fly; to persist with the worm when they are taking badly, is, in my opinion, a waste of time. And as we must give a separate chapter to worm-fishing, we will say a 
little more about the fly. I prefer to use two flies only for up-stream fishing; you are better able to throw and to work two flies in the water, and can better command them with the rod-and, moreover, you can more keenly observe when a fish moves, than you could with three flies; a short collar of stout gut, which, however, must be round and clear-four or five links are quite enough-will be better managed than very fine gut, which, after soaking, becomes so limp that it is difficult to keep the collar "taut" in the water; the stouter gut is stiffer and more easily managed, and the objection to its being, seen more easily will be found practically of no importance in upstream fishing. Horsehair and silk form the best line, which should taper, but on no account be very light; and fifteen to twenty yards will be long enough for small streams. When you approach a part of the stream you are going to try, cast your eye well over it first (having taken care to be in a position where you cannot possibly be seen) ; and supposing it to be a rapid part, intersected by rocks and large stones, so as to be cut up as it were into numerous little eddies, select the spot which you can fish without disturbing the other parts, and try that first; now, this spot may perhaps be so small as a square foot, or less, but if it be a feeding spot, never mind its size; if the water is deep enough to cover the trout and sufficiently attractive to him for feeding, he will be there. Suppose it is just below a stone, with a little water gushing down on the side towards 
you, and a little quiet spot the other side to that on which you are standing, your cast must be as nearly up-stream as possible-it will be probably a little oblique-throw boldly, so that your end fly pitches close to the stone-say, touches it, then your bob fly will drop in, and by that time the current will begin to wash on the collar and carry it down; now, there is just a nicety of judgment required to measure the time you mustallow the end fly to remain in the quiet water on the side of the rapid; if you pull on the line by moving the rod too quickly, the fish will dash at the fly, but probably miss it, for as soon as you pull, the whole collar is in the rapid current, and moves so rapidly that the trout cannot catch it, as he and the fly are not moving in the same direction. The trout dashes directly at the fly in a straight line, but the fly sweeps round and the trout is left behind, and before he recovers himself, the fly is washed out of his view down the stream-but, if you leave it too long in the still water, the trout will not take your fly for anything living or eatable, and will be scared away. A little practice will docide the point for you, and generally, as soon as you have seen the fly clearly, you may raise your rod, so as to keep the bob fly on the surface, and this will be sufficient, for speedily the current will wash the collar towards you, and of course, to keep the line "taut" and the bob fly on the surface, you must move your hand and rod. If the spot you are going to fish is itself rapid water, allow for a mo- 
ment after pitching, the fly to be washed by the current; it will be carried under water a little, and if a fish takes it, you will see him turn; you must not expect to see your trout rise, you must keep your eyes open and watch for his turn in the water, and immediately strike. From your fishing up-stream, your fly will most often be a little under water, and there the tish takes it;-he may try to take it as soon as it drops on the water, and in that case would rise, but you must be very quick with your eyes, and watch for the turning of the trout. If the first cast does not succeed, try the same spot again, but remember that the first cast is the important one, and if it be properly made you will take a fish, if there be one there to be taken; but try again more carefully, for perhaps there was some fault in the manner of your first attempt, and you will be surprised often to discover how little a deviation from the right manner will make all the difference between success and disappointment. You cannot be too attentive to your casting or throwing the fly in the exact spot, for you should depend on your casting for sport. Many fish you will pick up in swimming your flies and working your bob fly, but these must be considered casual ones, and the casting the part essentially to be relied on. You must learn to pick every fish out of his particular hole, and not trust generally to any fish the flies be may washed over, and so I advise you to try first the spot you could best fish with least disturbance to other spots, and that completed, try another, and 
another, till all be thoroughly tried, and don't despise a little spot because it looks meagre or hardly grand enough to hold anything but a very small one. You will often find good large trout lying out in very shallow and insignificant-looking places; on the other hand, you will sometimes be disappointed to find only a little one in a place where a large one should have been; in this case probably the fault is yours-you have not fished it sufficiently well to attract a large one, and he has allowed some little imp to dart in and take what he was too wide awake to be gulled by. It is impossible to describe the variety of places you must fish, but generally whenever a stone in the water is large enough to interfere with the direction of the current, look out, throw so that your fly pitches close to the stone, at the very head of the turn. If it falls only in the middle, or at the end of the little eddy, you cannot expect success -you do not deserve it. In getting at these several little holes and currents, don't be afraid of your knees; keep down close to the mother earth; go on your knees or crawl on your stomach; remember the trout is there, and you can catch him if you work properly, and do not frighten him away. I must again impress the necessity of self-concealment; without it your best efforts will assuredly be unavailing: and in throwing with precision, I have found in my experience that a little splash in rapid water matters not at all. I advise a beginner, however, to learn to throw as lightly as possible, for in quiet water, un- 
doubtedly, you might as well throw your hat in as your fly with a splash. Light pitching has nothing objectionable, under any circumstances, but heavy pitching is only excusable under circumstances the beginner will not comprehend very readily. As a general rule, you will catch your trout by the sides of rapids rather than in them; so again I repeat the necessity of attending to the casting and pitching of the fly. The end or stretcher fly should be regarded as the depending one-the one you rely upon to exhibit your skill. The bob is a useful appendage to take stragglers, and work in just now and then when your stretcher cannot well be made to go. I use generally a red or brown for stretcher-the formel made with peacock body ribbed with gold twist, and a dark blood-red hackle, black towards the head and tips, and the latter made with hare's flax, ribbed with twist and a dark-red, or very rusty-red hackle. I like something very gaudy as a stretcher for up-stream fishing, and that is why I put on the twist. At one time I used to put on a piece of gold or silver twist, making a large staring shining tail of the metal to the fly, and found it answer very well; the additional trouble in making the fly was the only objection I had to it, and its superior attractive powers I found an advantage, and I was convinced thereby that in the way I fish, I kill the trout somewhat as a troller does with a kill-devil, by arousing his greediness, attracting him to make a run at the quick-moving deception, and giving him no time 
to discover his mistake till he has the hook in his mouth. The bob I generally make a quieter $\mathrm{fly}$ - this fly has to depend more on deception than attraction-his work more nearly approaches the duty of the fly on the quiet and large stream, viz. so to resemble a living insect as to deceive the trout into the belief that he is one, for the reason that his work is quieter, and he is kept floating on the top of the water, and often is used even on small brooks, just as a bob fly is used on a large stream, to go into little places under banks and under bushes where the stretcher cannot be worked as he should be worked to do his duty. Each fly, then, has a separate office to performthe stretcher to be cast almost into the mouth of the trout and tease him out, by attracting him to his impudence; the bob to act the more deceptive and quieter part; so I make the latter like one of the many flies every fisherman has plenty of, a blue dun, a hare's flax, cow-dung, any indeed which happen to be about the water at the time. We have noticed that fishermen write a great deal about imitating the natural fly; if they think that imitating the natural insect alone or principally is to be relied on for sport in rapid streams, I can only say a considerable experience is not in support of such an idea; and as to the stretcher fly, why mine is generally wholly unlike anything of insect life I have ever seen on the wing. Certainly, the nearest approach would be a large humble-bee with a smart military jacket; and moreover, the way in which he conducts himself in the water is 
very different to anything I have seen of insect life. I allude to this subject again, since I find so much spoken about the natural fly and its imitation, but little about the insect before arrived at its maturity. How seldom does one imitate the larva or pupa of the several insects! Many of them must necessarily be often washed into the water and devoured by the trout; and if looked into, these will be found more like some of the hackle flies I use than are any flies in their perfect state. I never have attempted to imitate them, trusting to my stretcher simply as something to rouse the fish and attract him, with some idea of its being eatable. I never use a winged fly on a rapid stream for a bob, excepting the March brown I have described, and this only in March. A winged fly washed by the water looks more like a little roll of the dung of a rat than a fly ; - for the force of the current washes the wings close round the hook. For a stretcher, as I have said, always select a smart gaudy hackle fly. The brighter the weather the more gaudy the stretcher fly; and in June or July, sometimes I use a fly made with a body of orange-coloured worsted, ribbed down with yellow silk, to make it last the longer, and a hackle of a light yellow red, such as one can only get from a smart little bantam cock. This fly I have found very destructive. In low and bright water, with these bright gaudy flies, I find one need be very quick with the rod in fishing; the sport becomes dashing, one must work the flies quickly in the water, for from their 
greater conspicuity, they are the more quickly seen, and will be the more quickly refused if one let them be stiil in the water. The instant they pitch they will be darted at, and as quickly must the fish be struck. It is just this dash that I so much like in bright water fishing-one never sees the trout so lively or quick and agile as they are in a hot bright day in July; and though this quickness or vivacity may be by some considered an obstacle to sport, it is, in truth, a very incentive to it; 'tis a condition on their part, which the fisherman should strive to turn to his own account, and by attention he will soon learn how to do it. If I may be allowed the comparison, this dash with the trout is to the fisherman what he and other sportsmen so highly prize with the foxhounds. 'Tis his highest charm, the fox-hunting of fishing.

Whilst I write, what thoughts flash back to my mind! how vividly do I picture the beautiful and homely English scenery on that type of small streams, the little Bray; bubbling, merry little fellow - he always seems joyous, and by his music, so sweet to the fisherman's ear, what a welcome does he whisper to your very heart! He lives in the midst of nature's beauties, selecting, when he has acquired the power, after his barren birthplace - fat meadows, screening himself by the overhanging bushes, the fragile alder, the knotty thorn, and drooping nut bushes; all made luxuriant and stimulated to healthy growth by his proximity; at one time coyishly meandering over smooth 
ground by the side of his brother woods (brothers they are by name and fellowship, how still more so by association in the minds of North Devonians); at another, grown impetuous by presumptuous obstacles, dashing and foaming with contemptuous indignation past and over rocks and pebbles, till having regained his wished-for course, he assumes the jolly, delightful aspect so characteristic of his pleasure-giving nature. How innocently he lulls himself down in yonder pool! How pleasing his richness of complexion, differing from the sickly-white transparency of inferior streams, as does the nutty cheek of the country damsel by his side from the unhealthy pallor of the daughter of cities! With his temporary placidity, how pleased is nature! See how the trees luxuriate in the tender and watchful care of him, as they gently bow over their protected one, nor permit the sun to break in on his slumbers but by stealthy beams playing here and there upon his surface: how delighted the choristers of the forest are; how they rejoice to tune their constant lays to his honour: and see the busy spider has actually spun her wondrous-wrought web from yon drooping branch over his bosom to the adjacent banks, sure token of undisturbed tranquillity. How numerous are the gaudy flies dancing along and sporting joyously on his surface; and oh, reader! if you can but get your end fly well under that spider's web, just where the beams of half-refracted rays are sportively playing on the water, giving the water itself, and a little air above, a 
warm golden hue, yourself concealed and in readiness - what a fine trout you will surely catch !

I know of no stream in the North of Devon which may be so surely relied on for affording sport with the rod and line, as the Bray; and though the trout in it are small, they are nevertheless most wonderfully active and strong. I believe that if this stream, together with the rivers below, which it joins, and the small brooks which contribute to it, were well preserved, in a few years there would be found abundance of fine trout in it.

The little stream, commonly called the Nymph, which crosses the Turnpike Road at Bish Mill, is a beautiful stream for sport in the early months, or in the autumn after rain, when it is of a more than ordinary size ; but for bright water fishing during the hot months of the year, with low water, it is not at all to be relied on for sport-at such times the conditions before mentioned as requisite for sport are not present, but, on the contrary, very little else than still water will be found in the bed of the river.

The upper part of the Mole, above South Molton, is admirably suited for bright water fishing; and I know of no water on which a beginner could better learn the art of up-stream fishing as I have practised it, and endeavoured to teach-it, than this little stream. Indeed that portion of it above and immediately below North Molton, will be found to be exactly the kind of water 1 have been so particularly writing of. 
ON RAPID STREAMS.

\section{CHAPTER VI.}

NATURAL BAITS.

Amongst natural baits, I shall first select for discussion such as are, in their mode of usage, most nearly allied to the artificial $\mathrm{fly}$, which consequently will be the natural fly, the fern web, and the cow-dung beetle. Of these, the first-named, viz. the natural fly, will not detain us long.

Of natural flies, any which you can catch near the rivers will be destructive to trout in the North Devon streams, some more than others, but all are good to the fish; and as far as their power of attraction is concerned, little can be said against them. I shall presently, however, say a good deal condemnatory of them.

The time of year when these flies are most in requisition is in May and the later months. I don't mean to say that in March, a March brown stuck on a hook will not kill trout in our streamsfar from it; but at that time any tyro can kill his fish with the artificial bait, which, being used with less trouble, is preferred. In May and the later months, the rivers are apt to get low, and what before was a rapid stream now becomes still water, 
with only here and there, at long intervals, anything approaching a current or eddy ; and these so difficult to get at, that they are of little service to the ordinary fisherman with the artificial fly; and for the most skilful, since these places are but few and far between, there really is great decrease of fishable water: hence his chances decrease with the fall of the water and loss of rapids. He has, in point of fact, lost one of the necessary conditions for certainty of sport, namely, rapid water; hence he taxes his ingenuity to make up by skill for the natural defect so powerfully acting against him. Well, there are certain kinds of flies to be caught in abundance, which, therefore, is a point of importance, as the fisherman requires a large stock of natural flies. Of these no fly perhaps beats the May fly, oak fly, or down-hill fly. I believe it is popularly known by each and all of these names. The last is descriptive of the character of the fly, which is a good-sized one, with speckled wings, white and brownish; these wings are flat, and stand out broadly from his body. You may see them on trees, principally oak trees, or railings near water, always with their heads down hill, i.e. dependent, and they are easily caught by the hand. The wood fly is another good one. Go into a wood, have some horse-dung thrown down in a small heap; it will soon be covered with these flies, which may conveniently be knocked down by the branch of a bush, when you can pick up the crippled ones, and put them into your box or bottle. The common house-fly, 
which much resembles the latter, and the blowing fly, will any of them kill. I may here also mention grasshoppers, of which trout are very fond, and eagerly snatch at them and the wood-louse. Now in the use of these natural flies, we must remember that we are limited to one principle only, and that is deception. Displaying the real fly to tempt the trout, we cautiously conceal the hook to which it is attached, the gut, line, rod, and its owner; this in still water is not always easy, but we are much assisted by banks and bushes, or trees.

To fish with these flies or grasshoppers, have a collar as long as your rod, and of the very finest gut you can obtain; let the rod be light in hand, with top active, and stiff towards the butt, its length fourteen feet. A double-actioned rod is a sad source of trouble. The size of the hook, No. 7 . The line should be very light. You can put on one or two flies; one is enough, just hitching him up by the back, with his legs downwards and wings free, that he may look as nearly natural as possible. You cannot conveniently throw over-hand, as by such movement your fly will be whisked off; but you must content yourself by stealing alongside the stream, and just dropping your fly in over any deep pit or hole, under any bush or by any stone, that will hold a large trout. Weir pools, where the water is still, and which have bushes by their sides amongst which you can conceál yourself, are perhaps the best places for this kind of work. Should a little air be stirring; you should take advantage of its direction, and 
allow it gently to waft your fly in such a way as you may desire it to go, and, when on the water, you may sometimes (particularly if you have only a short line out) dap it up and down, just making it rise and fall again into the water as an unfettered fly would do ; indeed, in all you do you have but to imitate what you can any day see the same kind of fly doing on the water, and at the same time remember that you must do your utmost at concealment of self and tackle. This is dapping with the natural fly. It is in almost any river a very destructive mode of working for fish ; but it does not come up to my ideas of sport. Its principle is toolimited. You are, in its application, too hampered-too restrained to particularities; there is no scope for diversity; and there is altogether about it somel hing so pottering and slow, and so bothering and fidgeting, in everlastingly putting on fresh flies, that I do not like it. I leave you, after what I have said, to please yourself, reader. I can assure you the method is simple enough, more simple than any, and certain, too, of taking large trout, but it is tame and uninteresting, uninstructive and unsatisfactory to your mind; and if the pot be what you wish to supply at the same time that you obtain your sport, bear with me awhile patiently, and I will assuredly' conduct you by a more pleasing course to your wished-for gratification.

Having summarily discussed all soft flies and grasshoppers, let me call your attention to the fern web and cow-dung beetle. I shall classify 
them together, as the mode of using them is precisely similar. I know but of one difference, and that is, that the fern web is a softer and more delicate bait-more easily whisked off than the beetle, and consequently requires more care in its usage ; in this respect being an intermediate step between the soft down-hill fly and the hard-cased beetle. The fern web I need scarcely pause to describe;-everybody knows the little insect, which, in the end of May and through June and July, may be found on the ferns; but the cowdung beetle is by no means so generally known; its name bespeaks something disagreeable,-and you need a boy to collect them for you. They soon cleanse themselves if put into a tin in good numbers, by rubbing against one another. The beetles are a little larger than fern webs; have their wing cases perfectly black and shining, dense and strong, and are thicker set, shorter and broader in figure than the fern web; their bellies and under surface beneath the wing and covers are perfectly black; they are found in recent cow-dung-that of about two to four days' exposure, usually lying beneath ihe dung on the ground, though often in the dung itself. Another beetle, something resembling it, is also found in the same dung; usually they are together-but this other beetle must be carefully discarded; he may be known by his being less dense and black in the cases of his wings, by his greater length of body, by his belly being reddish, and the parts under the wing light-coloured. I have 
always considered him a nuisance, as the boys who collect these beetles for me are constantly making mistakes, and putting the wrong ones into the tin. When you get them on your hook, or rather into the water, they look light-coloured, almost white-are so soft that their bodies break up, and they seem to be frightful rather than enticing to the trout. The most simple mode of carrying the cow-dung beetle I have found to be in a common half-pound gunpowder tin, the sides of which I perforate with a number of small holes. 'L'hey will live for many days, but should, if kept, be shaken out or put in some larger case, where they can get more air than they possibly can obtain when huddled together in a small space. Fern webs are difficult to keep alive any length of time: the best way of keeping them is to put them into a large open case with plenty of fresh green fern leaves, or leaves from nut bushes, frequently renewed, and cover them with a wellperforated tin plate. When dead neither of these insects are useful, as the head separates, on the least touch, from the body.

The rod I use for these baits is the same I recommend for artificial fly-fishing in the Bray and similar streams. It may be a degree or so stiffer and stronger, as it will have rough work to do, which a very delicate rod will not stand. The collar should be strong, and not shorter than six links of gut. The hook which is best adapted for these beetles is a Limerick, because, from its peculiar bend, the beetles lie on the shank of the 
hook, thereby not encroaching on the bend nor preventing the hook burying itself deeply in the trout's mouth when you strike; moreover, the shank being tapered off towards its extremity, allows the beetles freely to run up the gut when you strike, and come down on the hook again afterwards to their proper place, without tearing or breaking them. The best size for the hook is that which would correspond to a No. 9 or 10 Adlington. This seems, at first sight, a monstrous one, and very clumsy, and so it is ; and, moreover, I may here tell you the whole style is clumsy; it is nevertheless terribly destructive.

It is well to carry in your pocket a little silk on which cobblers' wax has been rubbed, as the hard cases of the beetles fret the silk so powerfully that a few hours' fishing will make the warping of the hook come undone, and you will perhaps go on with an unsafe hook till you get hold of a good large trout, when assuredly the gut will slip out and your fish be lost. This has occurred to me more than once. A good way of splicing on the hook is to end towards the extremities of the shank with eight or ten half-hitches, so that no sudden undoing of the silk can occur; and at the first warning of any of the hitches being loose or undone, and the end of the silk projecting, you should at once either resplice the same hook, or put on another already spliced to a link of gut; and this caution, trivial though it may appear, should be remembered in all kinds of fishing with natural baits. 
The way in which the fern web or beetle is to be put on the hook is simple enough. Hold one of them between the fore-finger and thumb of your left hand, with his belly towards you, and his head uppermost. Look over and behind his head, and in this position you will see a triangular-shaped piece of his case, which is situated below the head and above his wing cases; through the centre of this pass the point of the hook, carry it down the body and bring it out at the very bottom of his belly, thus almost entirely transfixing him from head to tail; pass him now up the shank of the hook, out of your way, till you have similarly treated a second; bring this last one fairly on the shank of the hook, leaving the bend free. Now, of both, with your finger, raise forcibly the wing cases; blow under them, and the wings will become extended, and must be made to remain so; you will now have two beetles on the shank of a large hook, whose entire bend is free and uncovered, and these beetles so placed that the heads of both are upwards, and the tail of the upper one in contact with the head of the lower one. And truly a great ugly-looking bait it is, and enough to frighten away all the trout in any river, you will say, when you first see it.

Sometimes, when fern webs or beetles are scarce, and economy is necessary, I have used a small hook, about No. 6 of Adlington's, and put on only one beetle or fern web; and on the whole, perhaps, it is a matter of no very great importance whether you use one with a small or two with a big hook. 
I prefer the large hook and two beetles, because one has less bother in constantly putting on fresh beetles; for one may, when one has two on, in killing a trout, perhaps lose the body of one beetle; in this case I work away with one complete one, and the head only of another; indeed, these heads go on increasing, and I have often counted no less than six on my hook at one time. A good big bunch seems rather the more attractive; again, the big hook gives one much advantage in hooking one's fish. I will push this no further; make trial for yourself; but, reader, beware of being led away by any primitive ideas about the splash and coarseness, the frightening the trout, and the old dapping story. Take my word for it, 'tis all humbug. I told you that in dapping with the natural fly, you were restricted to one principle only, and that deception. The principal restriction to the fern web and beetle is the peculiar uncertainty of the trout taking them. I have failed to account to myself for this; but sure is it, that the trout will do one of two things with regard to the taking the fern web and beetle-either gorge them greedily; splash, dash, throw it in as you will, or when you will, and they are at it, and before you can even strike have swallowed it deeply: or they will not have them at any price; do what you will, be as artful as you can, 'tis no go, Master Trout, will not look at them; and you will sadly waste time if you persist in working with them under such circumstances. I have so often convinced myself of the capricious nature of the trout with 
respect to the beetle or fern web, that I must strongly impress it on the mind of any one beginning this kind of fishing, otherwise much disappointment will result, and perhaps the real value of the bait never be understood, because the first few times it may be tried it may be found not to be killing; from which it will be inferred, after too limited an experience, that it is not a good bait, and that I have overrated its killing powers.

The season that I have usually done best with the fern web or beetle is when the weather is extremely hot, in June or July, and when the water happens to keep up, so that there are plenty of rapids, and therefore plenty of fishing, the state of the water being just that which is most favourable for all kinds of fishing. The most killing part of the day is the morning. You may begin with it in June at five or six a.m., and often find the trout take it at that time. I think I have killed more from nine to eleven or twelve than at any other period of the day, but this possibly may be accounted for by my practice of using always not that bait which simply is at any time killing, but that which in my opinion the trout are taking best, or with which I can kill most fish. Hence, occasionally, I may have used the worm the first thing in the morning, up to nine a.m., when, by means of the beetle, I could have done as well, or perhaps better before that hour than I did with it afterwards when I had changed to it from the worm. It certainly, as a general rule, is not so good a bait as others, when the sun is sinking 
behind the hills, and, generally speaking, I feel a preference in other modes of fishing after three p.m. The kind of day which seems best suited for it to display its excellence over other modes of fishing, is when the sun is very bright as well as hot. I have often, however, found it beat the fly, worm, and minnow of a dull hot cloudy day, and even when it has been raining hard. I have never known it beat the others.on a windy day; the trout in windy weather are sure to take it short; they rush and make a great fuss, which seldom means work; they rise short, or on one side; and though perhaps you may rise any amount of them, you will kill only a few, and these of small size: consequently, if you persist with the beetle, under such circumstances, you will not only do very little with it, but you will waste time and opportunity for more successful efforts in other ways. You do not want to see your fish rise and splash about with much demonstration; the trout that means to make sure of your beetle, as a rule, does not rise if he can help it; he takes your beetle while it is beneath the surface of the water, and to do so makes a sharp dart and a turn of the body, which displays him to your watchful eye, and before your wrist can respond to the sight, he has it greedily clutched in his mouth, and you will assuredly soon make him fast in your basket if you treat him as he should be treated. I take, then, my type of a day on which, as a general rule, it is superior to any other legitimate fishing you could adopt, to be a hot bright day in June, with a good 
amount of water in the river. I write somewhat guardedly respecting the time of using the beetle, because I have killed so many fish with it on all kinds of days, and even when the water has been extremely low; but I have endeavoured to convey to my reader the general impression I have, as to what circumstances are most conducive to its killing powers, that any one wishing to bẻgin to practise this mude of fishing, may do so under most favourable conditions, and become familiar with it before he tries its comparative merits with other baits; as well as to insure a certain amount of success, and avoid that disappointment which might befall him from thinking that, because it is said to be a most destructive bait, therefore he is sure of killing lots of trout with it under all circumstances. And I again remind the reader that I have found, sometimes under apparently the most favourable circumstances, that the trout have not taken the bait as I expected, nor as well as they would take other baits at the same time. This quality of caprice in the trout, however, under such circumstances, will not affect the tyro so much as the adept, as, of course, the former must expect to serve a hard and devoted apprenticeship to the various modes of fishing before he can reasonably suppose himself competent to decide on the relative merits, at any particular time, of any baits; or even determine whether he, in his means of using the bait, the particular bait itself, or the trout, is most obnoxious to his success.

Before coming to the river, we may just awhile 
a little more minutely compare the beetle and fern web. The former has the great advantage of being very much harder than the latter, and consequently lasts much longer on the hook; indeed, you may often catch four or five trout without putting on new beetles. Almost every trout you get hold of will take away your fern web; and with the beetle you can throw more boldly, and into places you might be afraid to cast with the fern web. This, in the beetle, is increase of utility, with economy of time and trouble. The beetle is a more universal insect than the fern web, and may, in the North of Devon, be obtained in abundance, when not a fern web is to be seen; and at all times they are more numerous. The beetle will live longer in your keeping than the more delicate fern web.

In powers of attraction, on the whole, the fern web has the advantage. In the Brav, the Mole, their tributary streams, and the double water which they form, I think the beetle equal to the fern web. On the streams of Exmoor, and I believe of Dartmoor, the fern web seems to be the more attractive. This may be from the abundance of the fern web natural to these parts, and their comparative scarcity in the immediate vicinity of the Bray, the Mole, and the double waters formed by their confluence. Thus, whilst in all the streams it equals, in some it excels the beetle as an allurement. I cannot allow that the fern web is at all superior to the beetle on the Bray; after much experience, I consider them equal in point 
of attraction; and since the beetle is more easily obtained, more tenacious of life, much harder, and more economical of time, and more general in application, I incline towards a preference to the beetle for general use. I am not sure, too, that the fern web is not the more uncertain of the two.

The rivers on which these beetles (I shall now drop the term fern web, being supposed to mean either) are so destructive, are any in which the main current is broken up into eddies and little sticklus; where, indeed, there is rapidity of water and richness in detail of stream; where you can stand, and at a glance see the exact spot that half-a-dozen good trout would each appropriate to himself as a choice feeding place. You will take trout with it in pools formed by the entire body of water-ay, and in the very centre of these pools; you would take more by the banks; or at the head of rapids, on either side of them, and most when the water is so broken up, that the trout are forced to select their peculiar and individual feeding holes. In all streams, it is necessary to keep in the water; and in large streams, by walking up the current, you can, when the waters get very low, generally find plenty of these dainty feeding spots of the large trout. Often, when bushes hang far out over the edge of the water, though there be scarce an appearance of movement in the water, you may, by a well-directed cast under the bushes and into very shallow water, turn out a fine old gormandizer who has been lurking in his secluded retirement under the 
shallow of the grateful branches, rubbing himself in the sandy or shingly bottom, and sucking in the flies which, from the shallowness of the stream, seem to fall directly into his open jaws. Shallow though the water, and trivial the current, if you throw directly up stream, and well under the bushes, you are sure of your fish.

It is often useful to flip your beetle under these bushes, by holding it in your left finger and thumb till your rod is well bent, and then suddenly releasing it; the rod, by its spring, will start the beetle straight as an arrow from the bow; don't fear a splash; I can assure you, if you are concealed, which, by throwing straight up stream, you must be, the splash, great though it be, will only wake up the trout and attract his attention. You cannot suppose that a cockchafer would tumble into the water from a tree, without a splash : your beetles are as large or larger, and the splash as natural. It is not weil to look on these beetles as something which the trout has only to see to insure his wanting to devour. With the more delicate May fly, one must ever remember that the bait is alone useful from its natural character to tempt the trout, and the more the bait is fairly exposed, and the more time as a general rule the trout has to catch it, the greater are your probabilities of taking the fish, provided the means or instruments of your offering are entirely concealed; hence you dap it in and out of the water in quiet still piaces, and even pull it up and down several times over 
the head of a trout before he takes it. And again, from the delicate nature of the fly you are prevented throwing it into those little side spots and holes closely adjacent to rapid water, lest it should be caught instantly after alighting, and carried away into a current which immediately would wash it off the hook; and whether the fish could or could not catch the fly in such a spot, you are unable to keep it on your hook; and if the fish were successful, in all probability he would seize the fly after the force of the water had separated it from the hook.

The powers of the beetle as a bait combine the qualities to a certain extent of the natural fly, and of such baits as seem to me to act rather by exciting and stimulating the trout to destruction of helpless and intrusive victims. Respecting its powers depending on qualities we trust to in the delicate fly, as the May $\mathrm{fly}$, viz. deception, the beetle is very far inferior to it-a few experiments will prove it: go to a weir pool, conceal yourself well, use your "dapping tackle" and be as cautious and careful as you please, bob, dap, do what you will, you will catch very few trout or more probably none with the beetle; similarly use in the same spot the May fly, and you will be sure to catch trout which your beetle had failed to tempt. As a living insect to dap with, as that word dap is commonly understood, and as the May fly is fished with, the beetle is next to useless; I say next to useless because, though I admit that some trout may in that way be taken 
by it, many more would be taken by the May or other fly. But when we consider its powers as an excitant to the trout, and the command we have over it in our employment of it as such, we shall find it almost unequalled, and were it not for the peculiarity of caprice connected with the trout in taking it, no bait could be compared with it on this head. The comparison between it and the May fly here ceases, the latter being, as before said, inapplicable in this respect, and wholly limited in its principle to deliberate deception.As to whether deliberate deception is more powerful in operating in one's favour, than the stimulus of excitement to destroy, must depend on the particular stream we apply the one or the other; some streams-slow, clear, and deep-can only be worked on the principle of deception, here the May fly has the advantage in an enormous degree -others rapid and lively, of various depth and surface, broken up and divided by stones or rocks, at one time expanding into a broad, shallow, rippling, gently flowing pool, at another restricted, by containing banks to narrower and deeper course, here partially overhung by bushes, and there absolutely concealed by trees; take for example the Bray, the Mole, their tributary streams and their combined waters, the Barle, or Exe on the Moor, and you have pictured to your mind, what in delineation my pen may fail to trace -on all and each of these the principle of excitement or bullying can be powerfully relied on. In some of these, nay most, the deception of the 
May fly is available, for the water varies so much as to afford abundance of scope for the use of both; but in this variety we find opportunity for either principle, and of the two I may here decidedly state that of deception alone is far inferior to the other I have designated excitement. I must admit that though the reliance on that of excitement is what I most confidently recommen , it will require some practical experience to bring conviction home to the mind of the fisherman, and at the first trial he will be led to think pure deception superior, and for the reason that it is easier at first to catch trout, especially large ones, by the May fly than by the beetle, if the stream is equally applicable to both; perseverance and energy will soon, however, bring sport to the fisherman, and sooner or later he will discover the truth of the assertion that on streams equally applicable to both, the beetle is by far the superior mode of fishing.

To use the beetle we must adopt a particular style of fishing: I have described the rod, collad, and hook, and the putting on of the beetles themselves; I further said you must wade the water. I had better have said you must walk up stream through the water. If the river be of sufficient size to permic it, I walk up through the water and fish the sides under the bushes, behind the stones, and in the little eddies and currents directly above. This is very easily done, and it is a most killing way of fishing, especially where. the banks are very bushy, and hence the water by 
them concealed, is but little disturbed by such as fish only from the bank. In this way, late in the season, I have had excellent sport in the double waters, when the waters had long been too low to attract the fishermen to their banks, save an occasional one or two, who for exercise (I should imagine not fishing) have made their appearance in the evening, to whip the water, with long lines and collar, little flies and fine fishing. It has seemed occasionally that thése midnight wanderers have been pleasea with their success, and actually have now and then caught a dozen or so-certainly, I will admit, a greater number than they could have caught by day. But how often have I thought, if to these would-be fishermen such satisfaction is afforded by their ideas of fishing, how great would be their delight could they open their eyes and with clear vision see the whole system of fishing! How truly enchanted would they be with the true sport of fishing!-sport, when a man goes forth boldly and defies the finny tribes in open day and glorious sunshine, confident to engage with them on their own terms, and careful only to discover he is entering the contest armed with rightly selected weapons, with whose full powers he is so familiar and confident, that he feels certain of victory: nor has he long to wait; he advances and attacks, conquers, and again renews in different ground, with different tactics, his contest, so surely to be rewarded by gratifying success. Ah! who can enter into the spirit of the sport of fishing, but he who is born a 
fisherman? The passion of sport is a constitutional quality, innate in us, neither acquired by education, nor begotten of success in the pursuit. It is a pleasurable excitement, which hangs in one's mind, amongst fancy and imagination, but it is firmly linked on the other side to the realities of the stimulus, the thing exciting, and the occupation engaging, to whose acquaintance by familiarity does it the more highly respond, and with which it becomes more fondly attached; an acquaintance, too, which, begun early when first perceived in most rudimentary outline, develops itself in enchanting fulness and thrilling effect through one's entire nature. I must not dwell longer on the sport of fishing; I have already disclosed myself as an enthusiast-kind reader, think me not a fanatic on the subject. Do you indulge ever in following our poets through their worlds of imagination? have you permitted your fancy to conjure up in sweetest pictures their ideal sketches,- - to exist with them awhile in the elysium whose shadowy outline their wild imagination has traced, for you with your mind's own operation to fill up in detail, and make it the more sensible, the more real to. your delusion? If so, try whether within you is the spirit of appreciation of sport: leave your poets ; take nature for your book; view her beauties, admire her splendour, breathe her exhilarating air, and go in and amongst her realities; then if you have the power to appreciate sport, you will find yourself dwelling in a natural elysium, surrounded by beauties real 
and substantial, yours, ay your own so far as they are really worth, for who can draw from them more pleasure than you? no one; they are yours to enjoy, revel in and delight, and your enjoyment of them is carried by this passion of sport far beyond the ordinary pleasurable feelings engendered by the gratification of taste. Others as observers of beauty may appreciate picturesque scenery as highly as you, but the animating influence of the passion of sport produces within you emotions of a most delicious character, and renders the mind more sensitive to the poetry of nature.

You as a fisherman in these hills arid dales of pleasure are existing under the charm of sport, and under the influence of its enchantrnent can appreciate in a highly exalted degree the beauties and harmony of creation, as displayed to you in your piscatorial rambles, and should rejoice that you possess a means of affording yourself such peculiar gratification-such extraordinary delight as your occupation is capable of bestowing.

Pardon, kind reader, my wandering from the subject of the beetle, and charitably regard the feelings which a remembrance of " those hills, my native hills, o'er which so oft I've roamed," have excited within me: truly do they prove the twofold value of innocent pleasure; first, the direct effect produced on our sensations at the time, and the enjoyment therefrom; secondly, the sweet impression left on the memory, on which fair picture the mind most wonderfully can concen- 
trate itself, and should any particular be at all fading, most vividly will the main features indelibly impressed, recall every minutix of detail, hallow the whole with a siveet fascination, and be to us a present ecstasy of past enjoyment.

$\mathrm{Ah}$ ! reader, brother Devonian, your sweet garden is indeed a Paradise; grander magnificence of country we may know, but give me your sweet little dales and hillocks, your little brooks and furze bushes, your homely air and welcome, joyous, happy aspect, in preference to the austere snowy ranges, the frowning mountains, and the pompous state of majestic rivers, vast plains, and impenetrable forests - the whole so reserved, so distant, so difficult of intimate acquaintance, demanding such laborious toil even to approach their presence, that you feel amongst what is uncongenial, unfriendly, overwhelming, and exclusive. Ay, but the little stream is dancing, the music of the falls is heard; we must be off to our sport, and retrace our devious course to where we began to digress.

This mode of fishing with the beetle on the middle-sized streams, as the double water, is destructive and exciting-thus walking up through the centre of the stream and fishing against it, your line and collar together should not exceed the length of the rod, indeed if your collar is the length I have recommended you will have no line out-sometimes you will want a little greater length to reach some good fish, but this rarely happens, and never should be done with the idea 
of keeping further away from your fish; the only circumstance which can warrant your letting out a greater length of line and collar than that of your rod is, when nearer approach is impossible from depth of water or other obstacle, and you must either put out line or not fish the spot at all. In all cases, if in the water, walk boldly up to' the spot, so as to command it with your collar's length; and provided you are in the stream, no matter how low it be, or how bright the day, you will never disturb the most watchful trout if you approach him in the proper manner.-This requires some practice to gain full confidence, but when you have caught a trout or two so close above your legs that you could have kicked him, you will understand the value of placing yourself in such a position. The manner of throwing the beetle is over-hand like the artificial fly, or underhand, or by the half-turn as you would cast a worm, or by flipping-each must be used as the particular spot you want to fish may require; but always throw boldly over-hand when you are able. When the beetle has alighted on the water, you must not pull too hard on the line, but just let that part of the collar which is out of water be a little slack, so that the beetle may sink a little beneath the surface of the water-keep it so by moving your rod at a pace depending on, and proportionate to, the rapidity of the stream, and be sure to keep the point of your rod well up, and have no bagging or hanging of the collar in the water. There should be no more gut in the water 
than is just sufficient to allow the beetle to be beneath the surface, or none at all, if the beetle floats on the surface. The trout does not usually rise if he means to take the beetle and you are using it properly, but you can see him dart at it, and then turn round, by which movement he will expose the lighter colour of his side or belly; this is your time-into him instantly by a wrist movement; you cannot be too quick, but it must, so far as the strike is concerned, be simply a wrist movement. You may, if you think the opportunity favourable, follow instantly this wrist movement for the strike, by a lifting of the arm, which is better done from the shoulder than the elbow, and so raise your fish out of the water and land him. Never attempt to do so by the strike; if you do, you will hear your line and collar twang, and either they or your rod will be snapped. Remember that the trout is usually under, not on the surface of the water, and that he has turned, and is going in a direction opposed to that in which you are pulling; consequently other forces are acting against you over and beyond the mere weight and muscles of the trout. Since you are in the water, you generally, after striking the fish, have to play him down till you can handle him; but if the strike was properly done, and the trout meant to take the beetle, you are almost sure of him, owing to the firm hold given by the large hook. A little landing-net, with a handle one or two feet long, with a loop of thread to attach it to your cuat's button-hole, will be useful-it 
should be small and light, and just serviceable as it were to scoop up your fish, instead of having to get your hand on him. Thus wading up stream in the North of Devon, when the waters are very low in June or July, you may kill a great many fish and of good size for the water, certainly far above the average size you could kill at the best of times on the same stream with the artificial fly - and at the time we are alluding to, the most able fisherman would be able to show but a comparatively miserable dish to that you with the beetle can make sure of after a little practice. Here then on such streams as the double waters, the Mole, Taw (in some parts), as well as on the Barle and Exe, near to, and on the Moor-is clearly acknowled ged the immense superiority of the beetle over the artificial $\mathrm{fly}$, excepting from the general rule those precarious days which we would forewarn you of, when the trout are not disposed, nor can they be excited, to run at the beetle.

Of course, in this mode of fishing with the beetle, we get over a great deal of water in the space of a few hours, - since, as I have said, we have but particular spots here and there to fish; - and it does not do to potter about too long' with the beetle. Try your water as closely as you possibly can; - let not a nook or stone escape your attempt; -let that attempt be made in a perfect manner ; but if not, say in the second or perhaps third cast, successful, go on, do not hang back on the old water;-you ought to make sure of your fish the first throw. To stand still flogging away at the 
same spot with the beetle, in the way some fishermen flog a pool with the artificial fly, is useless, senseless, and an extravagant waste of time. On some brooks great sport may be had;-and it is astonishing to see good big fish, half or threequarters of a pound each, rush out of little, bright, shallow, sandy rapids, at a time when from the lowness of the water and despicable appearance of the brook you would at first perhaps imagine it could not hold a fish bigger than a minnow. I think for early lessons in fishing with the beutle, these small brooks are most instructive, because they teach one the value of hunting out for every individual fish;-they make us more carefully scrutinize and examine, and lead us to understand practically that it is not always the grandest, deepest-looking spot which holds the biggest feeding trout. They make us early know to what kinds of places the best fish repair to feed, and force on our conviction the necessity of throwing with precision and boldness,-make us artful in approaching a fish, and of so working each little pool we may meet, that at the end of our work we are sure we have so done it, that each throw we made left open to us some new and undisturbed spot, till we had taken in the most advantageous succession all the throws to be had out of the place. They also best instruct us in the most proper manner of working the beetle when it is in the water, and of the exact value of throwing boldly and concealing ourselves. At the end of each day we shall have taken away with us a 
picture in our minds, plainly delineating the feeding places of the trout. Now, this picture kept before us, will be of the utmost service when we come to the bigger stream, in wading which, we must similarly look about us for each feeding place; nor is it difficult to discover them if we remember what we learned on the brook, which in point of fact is but the miniature of the detail of available water to the fisherman on the big stream. 'Think, then, you are but fishing the feeding spots you saw in the brook; these in the big stream are more scattered, more widely separated, and combined with other kinds of water, yet they will be found if looked for-and must be found if you would have sport. A good fisherman may glean much instruction by an occasional day on a brook. It always seemed to open my eyes to some new feature, to give me new hints for future application, and improve me in the art of fishing even more than a day on big. streams. I can strongly recommend every fisherman to pay an occasional visit to a rapid brook, for instruction-it is a point of discipline in the education of a young fisherman absolutely necessary, if he wishes ever to bring his art to a certainty. Throughout the entire course of the Bray the beetle kills well ; the little Bray indeed is especially adapted to it-I need say no more, after having urged the importance of throwing each time for some particular fish your mind can perceive lying in some exact spot. On the Moor the beetle kills well, but when the water is very 
low and bright, as a general rule, little only can be relied on in sport above Lanaker bridge; the river above that bridge when very low, as it commonly is in June and July, runs thin and poor, and has none of the rich detail of the brooklet fishing, but long flats, with white glaring stones at the bottom, shallow water often for a long distance almost entirely still; and though here and there you do find a spot suitable to sport, yet you have so far to go between each little place, so much toil and labour, so great a loss of time, that really it is not worth fishing when the water is very low and bright. If there be a moderate quantity of water, I would say, even just too little to allow you to do much with the artificial fly, you will get good sport. But there is better fishing and the fish are larger below Lanaker bridge; indeed, between Dulverton and that bridge the entire water is admirably adapted to beetle-fish. ing. One peculiarity I may mention, and it may be taken cum grano salis; still I have made the observation, and as I write only what I have observed it may be worth a little consideration-'tis this: wherever a stream flows long through heavy dense woods, whose trees overhang and overshadow the entire water for any considerable distance, I find the beetle to be the worst of baits, - as a general rule. The place seems too sombre, too gloomy for so gay and animated a style as beetle-fishing. The fish themselves which you generally catch with a beetle are bright fat-sided fellows, with rich golden spots; in these very 
shady retired places in deep woods the fish are dark, mean skulkers, the very opposite of the lovers of the beetle. On the Barle below Dulverton, on the Exe, and on the Taw, the beetle is good, and in such places as are rich in detail, much execution may be done.

In fishing with the beetle you must not be satisfied with large numbers only, you must have superior size; and if on a good day, in the same water, you are only killing fish of the same size as your neighbour with the artificial fly, take it off and use another bait, provided you are equally skilled in all the various ways of fishing, and you should not rest satisfied till you are master of them all.

Now I have endeavoured to make the reader despise all ideas of finikin pottering dapping with the beetle. I have tried to make him use it boldly and throw it determinedly, and altogether perhaps he may think it is a clumsy, bungling way of fishing - not so, however; the bait is clumsy, I admit, but the mode of fishing requires particular skill, and for great success, much knowledge of the habits of the trout and considerable experience will alone enable a fisherman to use the beetle to its full powers of killing. My own mind, however, has always been disinclined to beetle-fishing. To me it is of all the modes of fishing I shall describe (excepting the minnow, with which it is on an equality) the least pleasurable to the fisherman; for as soon as he has learnt the precise feeding spots of the trout, and 
the proper mode of working in them, which artificial fly-fishing in the manner I practise teaches, he has little else to acquire from the beetle. At first the novelty is agreeable, but soon a certain tameness in its use palls on one ; there is a sameness, a want of variety about it, which places it infinitely inferior in point of spirit to the artificial fly or the worm. 


\section{CHAPTER VII.}

FISHING WITH THE MAGGOT.

The mag'ot by itself, simply on a bare hook, is not a mode of fishing I can at all recommend to the Devonian; it will kill fish, but there are very many means far superior in every way to it, nor do I know that it is on North Devon waters capable of taking fish when other means iail. I can therefore only give you my experience that it is not worth your consideration, with the view of preventing disappointment and loss of time, should you be ever thinking of trying it. But the maggot may be made useful on North Devon streams when put on an artificial fly. I feel now on this head to labour under a difficulty which I am even fearful of not being able with my pen rightly to overcome - it is to convey to the reader's mind a just estimate of the power of the maggot as a bait. I know full well that with the generality of fishermen in North Devon, the maggot stuck on a fly is regarded with a mysterious feeling, as if it were irresistible bait; it is thought by many that you have but to put on a maggot in hot weather and 
the trout will be sure to come at it. I confess that for many years I over-estimated the value of the maggot, and seldom or never ventured on the small streams (as the Bray, \&c.) without a goodly store of them by me, which I almost invariably fished with on my stretcher fly, when the waters were very low in bright summer weather. I used to be successful, and attributed my success to the maggot. And well can I recall the meeting of brother fishermen after many a day's sport, when they had been viewing and admiring the trout I had killed; one perhaps would say, I suppose you must have used the maggot, or you would not have killed such numbers and such fine fish as those? This was always said with a sort of knowing smile of facetiousness, and I admit that I myself believed that the secret of my success was in the maggot.- It chanced one very bright morning, in the month of July, when the Bray was low, that on opening my maggot tin to put on the highly prized maggot, I discovered the tin to be empty; the lid as I had galloped along to my fishing ground had opened and all my maggots were lost; I had not one, and my disappointment was extreme. I was a long distance from home, and had no other bait to use. I thought I should not be able to obtain any sport whatever; still as my rod and the collar with the large flies I always used with the maggot on it were now ready, I determined to make the best of a bad business, and exert myself a little to see if it were possible to take trout with large flies tied on No. 7 
Adlington hooks, made rough and gaudy. I went to work (I need scarcely say that I did not fish down stream or with a long line), and was delighted and astonished to see the trout run at my big flies; and thatevening my brother fishermen were wrong, though I am afraid not undeceived in their ideas of my maggot-fishing. This day's sport led me afterwards to try again, and the result of many years' close observation has been to convince me of my early follies, and teach me that as a general rule a good gaudy fly without a maggot is as destructive on a small rapid river as any fly with a maggot, provided the thy be used in a proper manner; this my experience tells me is a general rule,-and under its guidance of late years I have very seldom found it necessary or advantageous to use the maggot on small rapid streams in low water and bright weather. Generally I have had maggots by me-seldom have I used them, and I might probably have just as well left them at home, for any great advantage they ever proved to me. This over-estimate of the value of the maggot I speak of in a comparative sense; I do not mean to say that by experience I found the maggot less killing, on the contrary, my power with it increased-but that I found I had undervalued the power of the artificial fly. I had neglected it at a time when I ought to have earnestly studied the art of using it, and subsequently when I did so, I learnt the relative importance of the art and instrument. My flies were the same, the river the same, but my art of using those self-same flies 
had so improved, that whereas at first I could do very little with them, and less than I could have done with fine flies and fine tackle, subsequently when I discovered how to use them, they equalled the maggot and immensely surpassed the finest and best tied flies, the most natural imitations of the insect on the water that could be obtained.

The maggot, however, is not to be wholly despised-it has its utility, and does add, under certain circumstances, to the exciting power of the fly. These circumstances depend on the particular kind of water principally. If the water be sufficiently rapid for the artificial $\mathrm{fly}$, I do not think the maggot improves the fly; but if the water be such, that in regarding it you would say - What inviting spots these would be if there were only a little more body of water to improve their richness! such, that feeding places are abundant and good for the trout, but the water scarce deep enough, or rapid enough to render the fly certain of killing, - in such water, probably you will find that the difficulties you have to overcome with the fly are so great, that the numbers taken (and especially the size of your fish) do not come up to what your ideas will tell you the river is capable of affording. In such places the maggot is an excellent appendage to the fly - not altering the character of the fly in the manner of its usage, but adding to it a something which before you felt was deficient, making what was insipid and too tame, at once exciting and irresistible to the trout. I hold that it does not alter the style of fishing, because the 
only style which would be applicable to the artificial fly under the same circumstances is that which must be adopted for the maggot in low water and bright weather: I mean strictly up-stream fishing, with short line. Fishermen in North Devon, who frequent the double waters or the Taw, when the water is low and bright are accustomed to put on a maggot to their stretcher fly, and they place their confidence or chance of sport in the maggot only, and think very highly indeed of the bait. I am inclined to think that they erroneously refer their success to the maggot, whereas it is to their altered mode of fishing, of which, however, they are unconscious and inconsiderate. Accustomed to these rivers in spring when there is plenty of water, and not too much sun, they practise, and very properly, fine fishing as would be commonly adopted in large trout streams, viz. fishing down stream, floating their flies along the surface of the water, and patiently flogging the entire breadth of some rippling, undulating pool, and showing off to the general congregation of trout their deceptive imitations of the natural fly. When however the rivers become very low, such spring pools are converted into standing water, still and shallow, in which the artificial fly, however well made, will not kill trout on a bright summer day; neither will the fly and maggot; but the remaining spots available to the fisherman are rapids, which in spring: formed the heads of the favourite trout pools. The big stream has resolved itself into something 
like the similitude of the little rapid brook, only that in the big stream the killing spots are further distant from one another. Now the fisherman, failing in the still water with the maggot, is driven to the rapids; in fishing these down streams, he discovers that the maggot on the fly makes such a clumsy appearance, and causes such an eddy of water on either side of it from the opposition afforded to the current, that he is obliged to throw either directly up stream, or at least with a considerable obliquity in that direction. Here then he makes an approach to the style I recommend for small stream fishing in bright water. $\mathrm{He}$ meets with success when thus fishing with the maggot, and attributes the cause simply to the maggot, because the maggot is the only difference he has made in his bait; true, but had he not put on a maggot, in what manner would he have fished these rapids in the bright summer months? Why, in the same manner as he would have fished the pools in spring, down stream, with long line, and a long collar floating about over the surface of the water. Now, however, he is fishing up stream with a short line; and this is the main source of his success. It may please his imagination to refer it to the maggot, and so give him greater confidence in its usage ; but unconsciously to himself he has altered entirely his system, and now is working with a conspicuous object, thrown immediately over the trout, rendered lively by the force of water and the direction of his cast, which stimulates the trout to rush at it. $\mathrm{He}$ is thus 
acting on the principle of excitement to the fish, and no longer on that of pure deception, which he properly relied on for spring fishing. The whole or main cause of his success, I say, is in the altered style of his fishing, and not in the alteration simply of his bait. Now, if instead of the artificial with a maggot attached, any bright-coloured fly be used, which will be equally conspicuous or more so-and provided this faney $\mathrm{fly}$ be worked in a lively manner, as it should be on a small stream, it would fully equal any fly with the maggot as regards its killing power. I state this from no fanciful hypothesis. I have practically proved it on large streams, both by comparison, when both agents were used by myself, and also by trying the powers of the gaudy fancy fly in my way of using it, against many a skilful and experienced fisherman of the larger streams, with a maggot. This is practically true then, that in these rapids, on large as on small streams, in bright water, the fancy and conspicuous fly will equal the imitative fly with a maggot attached; but we must not forget that big streams, when the water begins to fail, are not divided only into rapids and still water, there is much intermediate water where fish lie to feed-neither still nor can it be said to be rapid.- It is too shallow and too bright for the artificial fly used however skilfully as an imitation of the natural fly at any particular time the trout may be taking; it is not rapid enough for the fancy fly, which in such a place would be so long exposed, that it would scare the fish; but 
it may do very well for the maggot. Here, then, is the advantage it has; and in many a little shallow, scarce rippling spot, with perhaps shingly or sandy bottom and overhung by bushes, you may get your maggot well under the bush, and take a good trout from an apparently very insignificant-looking little spot. In such places it seems that the maggot itself is the attraction, but certainly a large fly and gaudy hackle increase its killing powers - and the small imitation fly with a maggot is inferior in every way to the maggot attached to the large bright gaudy-hackled fancy fly.

From what I have said, maggot-fishing resolves itself into one style only, the type of which is the way the gaudy fly must be used on a small rapid stream, and a few words will describe the principal points requiring attention. As to the maggots themselves, the larger they are the better; they should be bred in liver, and allowed to remain some days in bran, from which they should daily be taken and transferred to a clean quantity of the same. If the weather be very hot, it is well to put a layer of moist sand at the bottom of the bran,- this keeps the whole cool, and prevents the maggot turning so soon to the chrysalis form, as it otherwise would do. The bran makes the maggots clean and tough, and improves their colour. With a maggot, two flies can only be used to advantage on any stream whatever; - some have urged that one is enough on brooks - two, in my opinion, are bettier. The bob fly picks up a stray fish here and 
there, though I do not consider this of much importance, as it is to the stretcher fly we must look for our success. The real use of the bob fly is to steady the stretcher in the water; it aids the fisherman to work the stretcher fly, which, if used alone, will be found so light and unmanageable in the water, that however carefully you may make your casts, it will continually be washed away from the exact spot where the fish should take it, and be carried away by the current in such a manner that no trout can capture it; the bob fly prevents this by receiving the force of the current against the pulling of your rod, and allowing a slight but highly advantageous delay to the stretcher, just so as to make it take a gentle sweep or curve from the side of the rapid, in the radius of the gut between it and the bob, which formed as it were a turning-point for it to work on. The value of these little trifles is better felt at the water's edge than conceived in reading about fishing in your house; -it is the attention to every little point relating to fishing which makes excellence in the art.

The collar may be made of six links of gut for a large, and four for a small stream. The distance between the stretcher and bob fly never more than three links - for a small stream, two-and a brook, one. The gut must be very strong. Of the flies themselves, whatever our choice may be, it should be guided with these views-that the stretcher is to be the fly we depend on for taking the fish, and as an auxiliary to it must the bob fly be regarded. 
'The stretcher I have employed with most success is tied on a No. 7 Adlington; body of hare's flax, that has been shaved off, and has a good red tinge in it, ribbed with gold twist: the fly should be made short, but bushy and thick; the shortness of the body allows plenty of roorn on the hook for the maggot, and will be found a considerable advantage. The hackle should either match precisely the colour of the hare's flax, or it may be a rustyred hackle. Another good fly is made with peacock's feather for body, or red cow's hair, in either case ribbed with gold twist, short in the body, and with a black-red hackle, of which there should be abundance on the hook. The peacock's feather I seldom use, because it so soon wears out, but it is an attractive fly. The fly I chiefly employ is the hare's flax. For the bob fly, any medium-sized fly may be used-something either of the blues or browns, as the fisherman may fancy. No more reed be said about the rod than that we can use our ordinary fly rod suitable to the size and description of stream. The particular method of using the maggot to its greatest advantage, differs in no great degree from the method I recommend for the artificial fly in bright weather on rapid small streams; and should we be induced to use it on the large streams, we must still keep in our mind the characters of small rapid streams, and pick out the suitable places resembling those on the smaller streams, calling on each particular fish, and not wasting our time in indiscriminate attempts. From what is said, it will be evident 
that although we may at times on large streams kill larger fish and more in number than we could with the artificial fly alone, yet, nevertheless, the smaller and more rapid streams are those, par excellence, which we should select for the maggot to do the greatest execution in low and bright water.

To put the maggot on the hook:-hold it between the fore-finger and thumb of your left hand, with its obtuse end uppermost; take the stretcher fly between your right fore-finger and thumb, enter its point in the centre of the obtuse end of the maggot, pass it down through its entire body, and bring it out at the extreme end or point forming the apex of which the obtuse end is the base of the cone which the maggot's figure naturally represents. 


\title{
CHAPTER VIII.
}

\author{
WORM-FISHING.
}

WorM-FISHING, as is by too many considered and practised, namely, either in still streams with a float, or in rapid ones when muddy; is, to say the least of it, but little worthy the attention of one pretending to be, or ever hoping to become, a fisherman. I scarce know a more pitiable object than a man standing by the water side fishing in tedious monotony the same spot, now making a throw upwards against the little current there may be-now patiently watching for the bob of the float to announce to him that a fish has come to his hook; forcibly does it recall the graphic, though not complimentary, description of such a man's rod, which is sufficiently well known to need no repetition. With all these anglers and their occupation, I can hold no fellowship; like them, I have been guilty of the folly, but it was not from choice, and I never could see anything in the occupation in any way coming up to one's ideas of sport. A stupid float is of itself a thing introduced into the art which is incompatible with any feeling of sport as understood by any man having 
a capacity for the appreciation of the passion. It is this feeling of tameness and monotony which attaches itself to the idea of the worm and float, which makes the first idea of worm-fishing so disagreeable and uncongenial to the soul of a $\mathrm{fly}$ fisherman. And if I could say no more to you than that by applying the same tedious art to trout fishing you would find it destructive, in disgust might you spurn my words, in justice call me a fisher for the pot, and not a fisherman worthy the title. Happily my acquaintance with wormfishing is so foreign to any float-fishing, or angling (so called), that they have but a' name in common, and I could heartily wish their titles were as dissimilar as is their mode of practice-they essentially differ in every way; so much so, that whereas the one is a low art, so restricted in principle as to be easily acquired, the other is so complicated and varied, requires such a full knowledge of the whole system of fishing to rightly guide us in its selection; such intimate acquaintance with the habits of the trout to apply it, and such practical skill in its usage to obtain success, that it is a rich field, captivating and gratifying to a fisherman,-and one beset with so many difficulties that few attempt it, and very few indeed carry it to its full perfection.

I could not consider any man a perfect disciple of our art, if he were not a good worm fisherman; he may be good with the artificial fly, natural fly, beetle, or minnow, but if he is not far advanced in the art of worm-fishing, I hold that man to be very 
limited in his education, and I would recommend him earnestly to pay attention, without further delay, to the subject; and when he begins to master the art, he will indeed rejoice that so rich, so pleasing, and animated abranch has been opened up to him, from which he will reap many fruits of pleasure. I have said I exclude all worm-fishing, when the float is capable of being used. For those who have taste to potter about a pond and catch muddy carp, \&c., or pull out a few trout in this way, books in abundance by men of experience may be found; they will, however, but little please the North Devonian, I am sure, and have nothing to do with my immediate subjects; and as regards fishing for trout in any stream rapid or slow, when the water is muddy as after sudden and violent rain, I consider such occupation but one degree remote from the poacher's practice of catching trout with night lines. For those who would practise this worm-fishing in muddy streams only, I have nothing to say, we are dissimilar in tastes; but for the fisherman who may chance some day to be caught in a thunderstorm, which suddenly makes the river very muddy, and would thus stop his occupation and drive him home, I will only say, the best thing he can do if the water is to remain all the day muddy is to go home ; but if he is determined to remain, he may fish on the same principles as those I shall lay down for worm-fishing on bright days and clear streams, and provided the water is not rising he mav fill his basket quickly. 
First, then, as to the worms. I recommend the little gilt-tail worm, which you may find in any dung-heap where decomposition has been going on for some time, but in which there is no very high degree of temperature present. The largest are usually found in pigs' dung; they should be lively and bright-coloured-they cannot well be mistaken, as the yellow about the tail and the place where they are found would distinguish them. These I think best, but if you run short of them, any other small worm may be used, and probably the difference in success would be inappreciable. One is apt to get bigoted to one particular idea, formed from habit or custom, and if the result or application of it is good, perhaps it is not unwise to adhere to it, rather than be wasting time and opportunity in experimentalizing with unknown and untried means. I have been in the habit of using the little gilt-tail worm, and believe it is at any rate as good a worm as can be used. I have always felt satisfied with it, and therefore had no desire to try the killing powers of other worms. But there is one condition, namely, the toughness of the worm, with which is combinedits liveliness, which will very materially aflect the success of the fisherman. To obtain these conditions, the worms must be kept in moss, -not the common green moss of the trees or hedge-rows, but the long, coarse, moist moss, which you may find abundantly in any bog in Devonshire, especially those small ones which are raised in a slightly rounded mound above the level 
of the adjacent land, and commonly known as dancing bogs, because on your getting on the eminence and jumping about, if you do not sink in, the crust moves up and down with your body. You will find the moist parts of such bogs covered with thick, coarse, white moss. This is to be kept just a little moist, and the worms often changed to fresh quantities. They will soon get fat and tough in texture, so that when on the hcok they wriggle and twist about and seldom break off, which worms not so kept are apt to do. So fond of this particular moss are worms, that I have repeatedly put a small quantity in the midst of a pot full of common green moss, in which many worms had been placed, and with great rapidity. every worm has found it out, and the whole of them have been aggregated together to participate in the rich succulence of the bog moss. I consider this moss a great boon to the worm fisherman, and of such practical importance to him as to merit his attention. As to oils and different drugs to entice fish, I can only say I never saw any reason to believe in their utility, and therefore have never tried them.

The hook I use is a No. 7 Adlington, or a corresponding size Limerick-I think, however, that the lateral twist of the Adlington is an advantage in worm-fishing. The hook is to be tied on with red silk, which should be fine, and well waxed; the splicing is only to extend far enough down the shank of the hook towards the bend, to give it the necessary degree of firmness required 
of it; it is well to end the splicing with several half-hitches, as the silk will fray in putting on the worm, and at last a twist or two will wear through, and so the hook will be suddenly loosened. Some silk ready waxed should always be carried by the fisherman in his pocket, and immediately he perceives the silk of his hook is wearing away he should remove the old silk and resplice the hook to the gut; this requires much attention, or certainly the fisherman will some day be much disappointed on hooking a good trout, to lose him by the splicing giving way. This has occurred to me several times, and I warn the reader to be on the look out. I have led the reader to suppose that he is to use gut on which to splice his hook; I, however, do not recommend gut to be used, but horsehair, which should be black, very stout and strong, smooth and long, rourd and shining. A couple of links to terminate the collar, the upper of course attached to gut, the lower having the hook on it. More horsehair may be used, or an entire collar of it employed, but with two links only, I think the advantages of the hair are sufficiently attained, while the strength of the gut is not wholly dispensed with. The advantages of horsehair over gut in worm-fishing are, its stiffness, whereby though it has been in water for hours it does not coil or twist up as gut, but always tends to keep, with determined resistance to weight, a straight line; this is of great importance, and much assists the fisherman in working his worm; and again, its texture does not fray 
and become rough and opaque by usage, which gut most inconveniently does-on the contrary, it retains, in spite of the contact of the worm and friction from various causes, its same bright, smooth, glistening appearance, and is thus much less easily seen when in the water. There are other little points of advantage, which in its application the fisherman will discover; I need not detain him with these. By using only two links of horsehair with some six or eight of gut, you will have a collar strong enough for all proper usage, and with which you may begin to fish without difficulty. A long collar of hair alone is rather a ticklish thing to deal with at first, though with practice it will answer perfectly well. The gut used above the horsehair does no harm, as it will be principally out of water, and is of course advantageous in point of strength. It is well to dye this gut by putting it in a little green tea, or ink and water. The entire length of the collar should be about two feet short of the rod used, and the end of the line should be free to run with the collar attached easily through the loop and rings of the rod. The rod itself, I think, need not be other than the ordinary fly rod you would select for the stream you may want to fish, provided you are wading; indeed I change often from the fly to the worm and vice versâ in the same day with the same rod. It is more convenient to have a second rod carried by a servant who can be trusted; it is always at hand, and economizes time considerably. For the larger streams, a light springy 
rod of holluw bamboo, with a split cane top, sixteen feet long, is required. If the water be high and very rapid, use from two to four small shot, one inch apart, the lowest eight inches from the hook-in bright weather, or when the waters are low, I use no shot. I consider at such times the shot a useless encumbrance, but when the water is very high and rapid it is useful to prevent the worm being too rapidly carried away by the stream, and to resist the action of the water upon the hair or gut between the hook and the rod.

Since the worm forms an article of diet in extensive use by the trout, and for which he seems to have an universal liking, it follows that as a bait for his destruction, its employment by the fisherman is of a very general character-indeed the worm may be used wherever there are trout; at the same time, since there are difficulties to be overcome in its employment, we may expect to find some streams more favourable to our practical efforts than others would be; so also the particular conditions of a stream may favour or oppose our attempts. So that whilst we admit the worm to be an universal bait for trout, we yet are conscious of certain circumstances which will very materially affect our success in its usage, and modify our manner of working with it. The most convenient way of carrying the worms when fishing is to have a bag six or eight inches long, made of brown holland, with a tape to close it; in this bag some moss should be put for them, and it may be carried in the basket. A small 
bag like a pocket, with a hole or loop so as to fasten it to the button of one's waistcoat, is very useful; in this little pouch we can put just as many worms as may serve to go on with for a time, whilst the others are well protected in the larger bag-for worms will not bear much handling or knocking about, and the fisherman does well to take great care of them and keep them as lively as possible.

Any of the North Devon streams are good for the worm-the Bray particularly so-on the Moor streams especially between Dulverton and Withypool, or the latter and Lanaker Bridge, good sport may always be had whenever there is enough water in the river to form little rapids and stickles. The best time for the worm is very early of a morning-the earlier the better, three or four a.m.-you cannot be too early; a little practice will soon teach the value of an hour before six a.m. As a general rule, trout are sure to take the worm well in these early hours, and you may with a little skill make pretty sure of the biggest trout in any pool or stickle you may fish. Late of an evening the worm is also taken well; but though we may kill many trout even throughout the entire day, experience teaches that one hour before breakfast is worth two after. The season of the year to use the worm, is whenever trout may be legitimately taken; doubtless trout might be killed with the worm all the year round, but no fisherman would destroy a trout not in condition; and for North Devon streams 
the season would ordinarily include the time between the first of February and first of September. If the weather be cold and the winter long, there is not much to be done in most of the streams till March; but the Exe is an early river, and affords excellent sport in February, when the trout are usually in good condition.

To put the worm on the hook:-hold the worm between your left fore-finger and thumb, keeping the head uppermost; take the hook between your right fore-finger and thumb, enter the point at the very apex of the head, pass it down through the body till you come to the knot, which you will find in all those little gilt-tail worms ; through the middle of this thickened and tough substance pass out the point, and push the worm up till it lies on the shank of the hook, so that from one side of the shank will be the tail of the worm wriggling and twisting about, and on the other, the bend and point of the hook uncovered and exposed; you will thus have rather less than onehalf of the worm on the hook, the rest free and unfixed. So also the shank of your hook is covered with that portion of the worm which is transfixed, but the bend and all beyond it is perfectly bare and uncovered by worm. This keeps only the smaller portion of the worm in an unnatural and stiff position, the larger portion being free to twist and turn about in the water, so that the entire worm resembles very closely in appearance an ordinary worm as it would float, or be washed down the water. By bringing the 
hook out through the knot, you obtain a thicker and tougher tissue to resist the action of the hook, which in other parts is apt to cut and tear the worm.

The worm, though so universal a bait, is not to be relied on absolutely as the best at all times; it will, any day, some time or other, kill trout, and many too; but there are other baits which at particular times will kill more, so that no keen sportsman will rest satisfied with restricting himself to the worm, and excluding all other means. When the trout are taking the worm well, there is no mode of fishing so destructive, and perhaps at such times none more pleasing; but they will not always take the worm well, and sometimes will not take it at all. It 'requires much experience accurately to estimate the relative advantages of particular methods of fishing at any given time-the perfection of this calculation is the highest triumph the fisherman can acquire. It can only be attained by extensive knowledge, for which the fisherman has to toil with patient perseverance through years of experience, and bear with numerous disappointments in his daily pursuit, but if patiently persevered after, it will ultimately be obtained; and the confidence it inspires, the boldness it insures, and the sweet reward of perpetual, unremitting sport it brings, are indeed enjoyments to encourage and stimulate us in our exertions, though those have necessarily to be protracted over a lengthened period of time. I can mention a few circumstances which may 
assist to bring the fisherman to a right conclusion as to whether or no the trout are taking the worm sufficiently well to warrant his persevering with it; but it is not possible definitely to lay down precise rules on the subject-the circumstances are too varying, too complicated to admit of an exact deduction. I need but allude to the different degrees of skill of different fishermen; though this ought to be deducible to what is definable, it is not so, I am aware, because every man who takes a rod in hand has the assurance to designate himself a fisherman-hence the various degrees of perfection of men in our ranks. Again, the destructive power of other baits at the time in question, as well as the fisher's skill in using them, should be determined before a comparison can be made between any of them. But of this I am sure, that in each individual case, a fisherman will, if a man of experience, be readily able to form a very correct opinion on the subject, and when found, the trial will bring his conclusions at once to a practical demonstration, than which nothing can be more satisfactory.

As a preamble to such rules as I can give respecting the propriety of selection and perseverance with the worm, I will briefly describe what has seemed to me the best ways of using the worm.

The fisherman should, whenever practicable, be in the water; the reasons for this have already been given in speaking of fishing with the beetle. He should walk up stream, and carefully select 
every little hole and eddy which would afford a convenient place for the trout to find and secure to himself food. Having determined on this particular spot, and the line being just so long that the worm can he held in the left hand conveniently, the rod should be held horizontally, and made to take a short curve in a downward direction, from right to left, till the right hand has advanced as far as the left side; then with a sudden movement, the rod kept still horizontal, the hand should take an upward curve and be brought back again smartly to the right side, and by inclining the top of the rod towards the spot where you desire your worm to fall, you will accurately pitch it with gentleness and precision into the place you determined on, and of course situated directly or obliquely above you. As soon as it is in the water, you must take care not to let your collar bag, but by a gentle traction on the worm, maintain an even tension on the collar; the degree of force required depends on the rapidity and depth of stream. In all cases the worm should be made to traverse the water in the same direction, at the same depth, and with the same degree of rapidity that a worm would observe if unattached and left free to the natural forces of the water ; this is perhaps the most important point in worm-fishing. A little reflection will guide one to a correct practice. If after the worm has entered the water, you allow your collar to be slack, clearly the worm cannot assume a natural movement; the collar itself resists the 
force of the water, which will cause it to assume a bend or curve, the centre of which is the point on which the forces are acting most powerfully; the direction of the forces depends principally on your position; but as at one end of the curve the line is attached and resists the force of the water, and at the other terminating in the worm it is free, the tendency would be for the ends to approximate; but as that one which is free can alone move, the effect is that the worm is drawn upwards towards the surface, and often contrary to the direction of the current itself; now this movement is entirely unnatural, that is, it is a movement which can only be given the worm by some artificial agency; to this the trout is unaccustomed, and he will not take the worm under such circumstances. Again, if after the worm has entered the water, you keep up too great a tension, clearly you introduce an artificial force to act on the worm, whose course and direction consequently must be unnatural ; and as a result, the trout will equally refuse it. So you must steer the middle course, and whilst by gentle traction you prevent your tackle producing unnatural effects in delaying the worm, you yet must study to make the worm swim freely down the stream as much like a worm free and unattached as is possible.

The worm may be allowed to swim down past you till it is washed to the surface below, when another cast may be again tried. Besides the cast I have described, you can of course throw 
under-hand, as it is called, that is, just bring the rod from the horizontal to the vertical position, and allow the worm to swing out, or flip the worm by holding it in the left hand and pulling till the rod is bent, as I described before; but, as a general rule, it is not well to throw over-hand, as you would with a fly, lest you flick off your worm or send it into the water with a much disturbing splash. Should you be fishing a pool whose entire breadth forms a gentle rippling current, you may throw above and float the worr: down till it is washed to the surface below you, commencing usually by fishing the side or bank nearest you, and continuously casting further and further off, till, by a succession of casts and swims, you are sure the entire breadth has been properly traversed by the worm. These kinds of places you will often fish with best advantage from the bank, simply because you cannot get mto the water without spoiling some good feeding spot; still whenever practicable it is advantageous to be in the water. Now, in looking out for your spots of selection, remember what I have so often repeated-that feeding trout of good size usually lie in very insignificant-looking places as regards depth and breadth of water, and you must learn to pick out all the feeding fish-you will kill more with the worm in these little spots than you will, generally speaking, in the grander, deeper, and larger pools.

Let us suppose that you have selected an appropriate spot, and cast your worm properly, and 
are now swimming it down the stream in a natural manner-further, that you have a bite-your line is stopped, the collar quivers and shakes, it moves obliquely towards the spot your worm first pitched in-What are you to do? Whenever in swimming your worm the collar stops, drop the top of your rod quickly, but only through a short space; your collar will bag and curve, and if a stone should have stopped the worm, most probably it will rise and be washed over and past it. If a fish stopped it, you have removed all tension and given freedom to the worm to be moved about, which, unless the fish holds it firmly, it will assuredly be; but if he were simply playing with it, from the increased movement given it by your dropping the top of your rod, it will be quickly removed from him, and he, fearful of losing it, more quickly dashes at it and swallows it; if, on the contrary, he swallowed it, or took it in his mouth when the collar first stopped, by giving slackness to the line, you allow the trout to walk off with his prey, which in any case he is certain to do as soon as he has made sure of it; now then is your time, the instant you see your collar beginning to move in one direct course, into him sharp-give a sharp wrist movement, just enough to jerk the hook into his mouth, and then play him out. When trout are taking well, you find your collar quietly stop, then immediately move away-there is no mistake in such a case-drop for an instant your top, and then strike quickly. On the other hand, when they are not taking the 
worm well, you see and feel a rapid succession of little jerks and twitches; there is a deal of fuss about it, the collar goes first one way and then another, but this is trifling and does not mean business-you must drop the rod and wait till the collar moves in one determined direction, or until the humbug of twitching ceases, when on looking at your worm, you will find its tail bitten off close up to the hook. If you strike whilst the lively commotion is taking place, you will perhaps just prick your trout-you will not take one in a hundred, and your pricked trout will not bite again in a hurry. If, however, he has eaten the tail of the worm without your striking, he may think it so nice as to desire more of the same sort; so you put on another worm and try again, and very often you will thus kill your fish. To the beginner, this lively movement is so exciting, and seems to indicate such determination on the part of the trout, that he cannot resist striking - the result is always the same-tail of worm gone-fish pricked or not, as chance may bebut seldom or never taken. Often you may see the trout come towards your worm with a rush from his lurking place-in this case the instant you see the trout turn in the water, strike. A trout that you can see dart sharply at your worm from his lurking spot, and then suddenly turn, is one that will do his best to take the worm, and you are almost sure of catching him. The most common error, with learners of worm-fishing, is striking too quickly. Now at any time that 
you are using the worm, should you witness the twitching and jerking of the collar to recur frequently with different trout, you had better change, and continue no longer with the worm. Again, if gou have the tails of three or four worms in succession bitten off without capturing the trout, delay no longer, some other mode may be adopted superior in killing powers to the worm. If, on the contrary, every, or nearly every fish that comes to you, exhibits a quiet manner in his mode of stopping the worm, and then runs with it in his mouth back to his lurking place, or seizing the worm with greedy avidity, darts off in a determined course, you will do best to persevere with the worm, which, under such conditions, is the most killing bait you can use.

I have already said that I usually begin in the early morning with the worm, and I persevere with it till I find I am losing the tails of many worms, getting many bites from small fish, and killing very fuw big ones; I then usually try the artificial $\mathrm{fly}$ - if that is killing fish up to my ideas of the number and size the river is capable of affording, I continue with it; if, on the contrary, the numbers are too few, or the size too small, I then try another and another mode, taking care to give each a fair and patient trial. Towards the afternoon I come back again very often to the worm, if the minnow is nut killing: well. It has seemed to me that the middle of the day has usually afforded the least sport with the worm-this is a conviction to be accepted 
only in a general sense, and should by no means deter the fisherman from fair trial at that time if circumstances require it. He must remember that the worm is a very general food to the trout, but that at times we can employ other means for his destruction, which are superior to it; as to what those occasions are, the fisherman nuust learn for himself by patient and persevering practice, aided, I trust, by what will be found in different parts of this book. As far as the rivers are concerned, the best condition is plenty of water in the river-with richness of tint-what indeed would be thought best for the artificial fly; but the worm is powerfully destructive in low and bright water: the only necessary condition of water for the destructive power of the worm to be employed is that there be rapids and currents, with eddies, \&c. A perfectly still water in bright weather is not that to which worm-fishing is adapted. It is said by some that the best time for killing trout with the worm is in very bright weather and low water; this I deny, and I can only explain the mistake in this way:-often in very low and bright water fishing, one has most excellent sport, and can kill more fish with the worm than with perhaps any other bait.-I will, for the sake of argument, admit that in such cases the worm kills more than any other; well, but it byno means follows, because in low water the worm shows superiority to other baits, that therefore the worm kills more fish in low water than it does when the rivers are of moderate height; on the 
contrary, more fish may be taken with the worm when the river is moderately full than when very low, cateris paribus, and this must be so from the very character of its usage. It kills so powerfully by picking out the trout from those numerous little spots they select to feed in apart from larger currents and pools, but the number of these little feeding spots decrease in the same ratio as the water subsides. There are then much fewer fishing spots in low water than in full streamthe field for labour decreases, and with it its rewards. Indeed, this argument will apply pret'y generally to all the modes of fishing I am azquainted with, and it is obvious enough to require no further comment. 


\section{CHAPTER IX.}

FISHING WITH THE MINNOW.

The most useful rod for fishing with the minnow is constructed of hollow bamboo-in length, eighteen feet; very light in hand; having rings all through of large size, and placed throughout at shorter intervals than one usually sees them on-the so-called trolling rods. I prefer a top joint of split cane, with much more action in it than the top of a trolling rod ordinarily has. For small streams, a rod of sixteen or even fourteen feet will be long enough. And for very small and bushy streams, in which one has to wade through the water, fourteen feet is the most convenient length. The above rods can be used with equal advantage either for the worm or the minnow. The length most convenient to any particular stream depends on its size, and on the amount of bushes growing over it. On large streams, the longest rod is requisite; but on smaller, the bushes may form such impediments to the use of the long rod, that the shorter one may be more easily and freely worked. These remarks apply equally both to worm and minnow 
fishing. I commonly use the same rod for both. The line should be of platted silk, steeped in oil.

Fishermen use the natural or the artificial minnow-some only the former, and others both. The natural minnow has, in my opinion, greatly the superiority in killing powers; but it has the disadvantage of the buther of carrying the minnows themselves, and of frequently putting them on the hooks. As to the particular tackle to be used, I shall leave the fisherman chiefly to please himself from the fishing-tackle shops, merely enumerating what have appeared to me the most essential points on the subject; and those apply equally to the natural and artificial minnow. When the water is low and bright, the artificial minnow should be small. It should be so made that it will spin the instant it is in the water ; its own weight should suffice; it must be heavy towards the head, so that if it be cast from one and dropped in any little spot, by a sort of dragging sweep, it will come head-foremost into the water and with great rapidity spin immediately, instead of tumbling first to the bottom like a bar of lead, and then wabbling about. Again, in its spinning, it should revolve in a straight line, not roll, or assume a cork-screw sort of motion, and its revolutions should be rapid. Working a minnow in a little rapid stream, and working him in a large dull one, are totally different practices. On the rapid stream the majority of the trout, and the largest trout are not caught in the big pools and stickles; on the contrary, the killing spots are 
such as I indicated in speaking of the worm, which, in its usage, the minnow closely resembles. Here again the fisherman must learn to pick out his individual trout; but these little feeding spots are so small that the fisherman has much difficulty in spinning his minnow in them, and he knows that unless it does spin he will frighten away the fish, and certainly not capture them; and to be successful, he must be quick and make the minnow spin as it enters the water, which is often so shallow that there is scarce any distance for it to sink ; on the contrary, it swims away just under the surface, and is often in and out of the water again in the brief distance of two or three feet. How differently does the minnow act in a large, deep, quiet pool! Here it is thrown out, allowed to sink, and then spin about down, or across the pool, till some fish is hooked. When the water is excessively low and bright, the spots in which the feeding trout are lying are so small, that it is very difficnlt so to work the artificial minnow as to deceive the trout, and many a place will be met with in which we cannot work it in such a style as to warrant hopes of success, in which it is obvious indeed that the staring deception will simply frighten the trout. On the other hand, from the same spot, the natural minnow will surely kill the fish, because, though perhaps its spinning in such spots may be by no means perfect, yet, nevertheless, it being a natural minnow is sufficient to make the trout rush at it. It amounts to this in question of relative value of 
the natural and artificial minnow :- when each or either can be worked equally well, and the trout are feeding well on the minnow, their killing powers are practically almost equal. Where the artificial minnow cannot be worked perfectly well, it will not kill at all; but in such places the natural minnow, though imperfectly spinning, or working in such a way as will not answer for the artificial minnow, may yet be made sufficiently stimulating and exciting to the trout for him to come at it and be captured. Therefore, on the whole, the natural minnow is much the superior of the two, and its superiority is most apparent in very low and bright water. When the water is pretty full and at all coloured, if using the artificial bait, I think a larger sized one should be used, and I then prefer one of bright colour, which will be highly conspicuous as it spins along.

If one goes to such a shop as that of Mr. Farlow's, in the Strand, and looks over his collections of artificial minnows, or kill-devils, one will be able to form some idea of the various fancies of fishermen. Here one can see minnows of endless varieties, each of which are pretty equally in demand by their several admirers.

The minnow, which I prefer for the North Devon streams, is made of horn, and is partially translucent. I get it from Mr. Farlow, or Mr. Holyroyd, of Gracechurch Street; it has a triplet at the tail, another at the head, and a third in the middle, and though I sometimes append more hooks, I find generally that the spinning of the 
minnow is impaired by the addition of any hooks - to those it originally has when it comes from the maker's hands.

As a general rule, I think that these kill-devils, or artificial minnows, are not sufficiently heavily armed as to hooks. In some I find a want of proper arming at the head, in others at the tail, and too frequently the spinning of the bait has been more attended to than the surety of hooking the fish that may run at it. Again, in some of these baits, the hooks are tied down and firmly fixed so close to the minnow itself, that though they may prick a trout running at it, they yet will not readily enter so deeply as to gain a sure hold in the fish. I like to have a triplet at the head of the bait, as I have seen that trout very frequently dash at this part of their prey, and if the bait will spin well with it, I put on a triplet tied to a piece of fine gut, long enough to let it extend from two to three inches beyond the tail triplet; this is of no service when the trout are taking well, but when they are running often and stopping just short of the bait, I think it occasionally pays out some of these fish for want of proper resolution.

As these artificial baits can be procured at a low rate from either of the fishing-tackle makers I have mentioned, I need not detain the reader longer in considering them.

As regards the best tackle for the natural minnow, perhapsnone exceeds the following:-first, a single lip hook, having attached to it by means of a short 
piece of knitting silk, a small piece of lead about an inch and a quarter long, tapered to an obtuse point at one end, the other rounded off and of the size of a crow's quill. This lip hook should be tied on a piece of gut separate from the trace, in such a manner as to form a very small loop at either end of the splicing of the silk on the hook ; through these loops the trace is passed, so that the lip hook is movable up or down the trace. Next follow in nearly equal distances attached to the trace itself, three triplets, and from the last of them, at a distance of two or three inches, may be appended a fourth triplet.

The minnow is thus put on:-first, open its mouth and thrust down its gullet the lead, and then hook the lip hook through the upper and lower jaw to keep them both closed. Now hitch one of the hooks of the upper triplet by the side of the cheek; next bend the minnow slightly, so as to make its tail curved, and when in this position hitch one of the hooks of the third triplet immediately above the tail; and lastly, stick in the second triplet about the middle of the fish, from the tail of which the end hooks will be freely pendent at a distance of two or three inches. This drawing up of the tail of the minnow by the third triplet, makes it spin. It should not be very much curved; a very little turn will suffice.

I like a swivel pretty close to the minnow, and a second at the distance of one or two links of gut from the first. The entire collar need not exceed four or six links of gut in length. The 
end triplet is useful to pick up stragglers; and many fish that have not pluck enough to go at the minnow heartily, but keep following after it, will be caught, which, without it, would escape altogether.

The tackle sold by Mr. Farlow, which has the spinning part of the artificial minnow, with a lead spill for insertion into the minnow itself, is another excellent arrangement for spinning the natural bait.

The minnow is decidedly a very killing bait, and, as a rule, it will beat any other bait I am acquainted with in point of size of trout. It is, too, a pretty general bait-from the biggest and broadest stream to the smallest brook, the minnow is destructive. The season of the year extends from about the middle of April to the end of the season. I think very early in the year the minnow is not of much use: the fish at this time being too sickly and feeble to be out in the feeding spots, take their food in too quiet a manner for the minnow, but a well-conditioned trout can seldom resist the tempting presence of a spinning minnow. Trout take the minnow well of a morning, and often continue to do so all day, even to late of an evening: but it is by no means a bait we can depend on to kill well, or better than others throughout a day; indeed it is a very precarious and uncertain bait. If the trout are taking it well, that is to say, if the trout are taking it in the small feeding spots, and taking it with a hearty and determined will, resolutely making their dash and catching hold of it lustily 
-if these trout are of large size, and good number, then persevere. There is no bait at all equal to it for large fish when it is killing well. If, on the contrary, you find that you have spun through some really good, though small feeding spots, and from these have made no trout run, you had better change immediately; delay in such a case is loss of trout. If again you make some trout run from the best places, but these neither many nor of good size; or if they come on in a half-resolute manner, and get hitched only by the stern triplet, change; - such half-and-half work will not do; they must come with a will or not at all-under either of these circumstances if you persevere with the minnow you will take but very few trout, these of no considerable size, and you will assuredly spoil much good water, from which by other means you would derive good sport.

The particular period of the day when I have found the minnow beat any other bait you can use, is in the afternoon. I by no means say that the afternoon is the period of the day when of all others the trout take the minnow best, but when of all baits he very often prefers the minnow,and it is a period of the day when of all others it is most difficult to kill good-sized trout;-so the minnow comes in most advantageously; and often have I, after giving up all other baits as almost useless, or only capable of killing little fish, put on a minnow, and immediately began to kill large trout, which I can tell you make a good topper to your second basket, for your first ought o 2 
to have been full hours before. You will sometimes be out when for the whole day the minnow is the best killing bait, but those days are rare; they are mostly met with when the rivers have a fair body of water in them and are rich in colour. More often you find that for some time the trout take the minnow greedily, and gradually they get sickly over it, when you have to change, and sometimes there is scarce a part of the day in which the minnow will not be beaten by some other bait.

In spinning the minnow, the particular points to acquire are, first-to be certain of your pitch, so as to be able to put your. minnow at any time exactly where you wish; and secondly-to make him spin as he goes into the water; he must begin this the instant his shoulders are wet, and having begun, he must continue to spin, straight, and rapidly. To effect the first, practice alone can avail; as to the latter, as a general rule one should strive to spin directly, obliquely, or in a curve down stream, and mainly because of the advantages of the position you yourself occupy as regards concealment; and avoid spinning up stream for the opposite reason, as also that it is too unnatural a movement and is apt to scare the trout. By spinning directly across the stream, you often get a fine fish; you just pitch out the minnow with precision and pull straight towards you, and perhaps before the minnow has spun one foot you have your trout. I like this cast, and kill usually a large number of fish by it. In spinning down stream, when your minnow has 
gone as far as you are able or willing to spin him, reverse very rapidly the direction of the movement of your rod; your minnow in course suddenly turns round and runs up stream as hard as he can go. Now, it often happens just at the moment when you reverse your rod's direction and make the minnow dart up stream, that a trout has been watching the minnow, but has not had resolution enough to run at him;-the sudden dart the minnow has finally made has settled the question, and fearful that he will lose his prey, he makes a dart and gets the hooks into him.

In spinning the minnow, always keep the line in the left hand, and should you, at any time, see a trout swimming on behind the bait as though he could not quite make up his mind to go in at it boldly, just give a good jerk on the line, so that the minnow will dart suddenly and with increased velocity, and you will find that the trout will rush into him greedily. Again, if in spinning, your rod is brought to, by a tree or bush, so that you can no further move it in the direction requisite to continue the spinning as before of the minnow, you may vet make him continue to spin correctly by pulling on the line with the left hand. Always keep this left hand on the alert, and be ready to use it promptly. You will pick up a lot of trout by the dextrous working of the minnow, even when your rod cannot be moved. If you see a fish following your minnow, you must work him along briskly, in whatever way you can most advantageously do so, just as if he were trying to run 
away from the trout; but on no account let him stop still in the water, for the moment he stops and ceases to spin, the besitating trout will determine on not taking him, and will swim away from him.

The fisherman will readily hit on all these and many other plans of manœurring his minnow, which will follow to him as a matter of course, from the consideration of the simple principles on which he is working. If I might mention what has appeared to me the most common error of fishermen as regards the spinning minnow, it is in supposing that the large and grand pools are the particular spots of all others best adapted to the minnow-hence they go on from one pool to another, fishing these, and little or nothing else. It is true, I grant, in these large pools you may often take a good fish or two; your doing so, however, is a matter of verygreat uncertainty; whereas I am certain, as regards rapid streams, that those grand pools are not the most sport-giving places for the minnow ; on the contrary, the best fish and the greatest number of them are to be caught by looking out closely for them in every little hole or hover, every little sly, lurking, and feeding spot. The trout are not only lying in these choice places, but are eager for food, and will be assuredly taken by the minnow. To depend on these spots for sport is almost to insure it; to confide in the deeper and larger pools, often few and far between, is to rest our trust on an apparently grander support of which early disappointment will prove its unworthiness. 


\section{CHAPTER X.}

CONCLUDING REMARKS.

I HAVE now almost exhausted my stock of knowledge of the art of fishing small and rapid trout streams. I have earnestly endeavoured to trace the principles on which the practice of fishing should be based, and have set forth so much of the art itself as has sufficed to afford me great success. With all the faults of the foregoing pages, I am confident, nevertheless, that there is embodied in one part or another, matter of much value to a fisherman. I place every confidence of the usefulness of my writings on the feeling of having openly, honestly, and candidly, without any reservation whatever, written all that I believe to be of any value from the stock of knowledge which practical experience has given me. That I have fallen short of my primary desire, I am equally sure. I found as I progressed with my undertaking that difficulties increased on me rapidly-and amongst all my perplexities none was greater than the task of endeavouring so to explain myself that those uninitiated would be able to understand me and follow my instructions, 
and the more educated fisherman be not too long delayed over simples, nor too much wearied by lengthened details, often so nearly allied to each other, as to appear almost repetitions of former descriptions.

As it is possible that this book may fall into the hands of a stranger to the North of Devon, who may be desirous of enjoying a few days' fishing in our rivers, and who may have by him a well-stocked book of flies, and yet be doubtful which to select for employment, or who may wish to purchase flies from local makers, and be uncertain which to buy, I now append a list of the flies which the local residents chiefly use, or rather I should have said, a list of flies, which I have myself chiefly relied on, selected from the collections of flies used by the Fishers of North Devon. From this list I have omitted many very excel. lent flies, which many good fishermen use on North Devon streams, and have altogether passed over the ordinary shop flies, which are made as correct imitations of the natural insect, such as the varieties of blue duns, quilled blues, the whirling dun, half-stone fly, brown flies, black gnat, iron blues, drakes, \&c., \&c.- - with respect to which I have only to say that the list is far more comprehensive than the collection I trouble myself to tie for my own use; and as regards the flies made to imitate the natural fly, if the fisherman has them by him he may use them with much success at their appropriate seasons. My experience, as hereinbefore stated, inclines me strongly 
in favour of the hackle fly if tied with really good hackles. I have no doubt that if my fancy flies be compared with the imitations of the natural insect, the fisherman will detect some more or less near resemblance to them; by so doing, perhaps his fancy may be pleased, and his confidence in them thereby more strongly engrafted. Whether or not the trout find out any such similitude, I really do not know; but. of this I am positive, that they will take in the rapids of North Devon, my bright hackled fancy flies better than the best imitations of the natural fly I have ever tried, and I have repeatedly made the experiment with the very best Town-made flies. It is well to have the flies tied of different sizes. On a bright day, in down-stream fishing, in quiet water, the fly cannot be too small, so that it can hook a fish, nor the gut too fine, so that it will hold one when hooked; but in up-stream fishing, in bright weather, you want a large conspicuous fly. Also, in rough windy weather, or when there is a little colour in the water, the larger sizes are preferable, particularly on the larger streams. As a general rule, the flies used in the North of Devon are considerably larger than those employed in other counties. The fisherman must judge for himself as to the size required. I affix, as a guide in his choice, the sizes I have been in the habit of using. On some of our streams, small flies are advantageous; I have therefore in the "list" entered the number of hook for each fly, though in point of fact, it is the peculiarity of 
the day and the water, and not so much the special month which determines the size of fly that should be used when we are selecting from fancy hackle flies. 


\section{EXPLANATION OF ABBREVIATIONS, \&c.,} IN THE FOLLOWING

\section{LIST OF ARTIFICIAL FLIES.}

B means the body of the fly.

$\mathrm{H}$, hackle.

W " the wing for the fly.

$\mathrm{R}$, ribbed with.

N.B.-Whenever hare's flax is mentioned, the ends shaved off as before directed are intended to be understood, unless otherwise specially stated.

Directions concerning the making up of flies will be found at page $5 \tilde{5}$ et seq.

Attention is directed to page 70 .

The hooks used are Messrs. Hutchinson's, of Kendal, Westmoreland, and of their Kirby bend.

The silk used in tying these flies should be of a straw colour.

The yellow dye alluded to is a strong solution of turmeric, in which a lump of alum has been dissolved, and in which the furs are boiled for some minutes. 


\section{F E B R U A R Y. \\ No. I. Size, No. 7.}

B. Equal parts of fox's and squirrel's fur, from the back.

H. Rusty brownish blue.

No. II. Size, No. 7 or 6.

B. Equal parts.-House-rat's and light brown sable's fur, or fur taken from the tail of the brown sable alone.

H. Silvery speckled brown.

$$
\text { No. III. Size, No. } 7 \text { or } 6 .
$$

B. (a) Dark peacock's harl. R. gold twist, or

(b) Cow's hair of a purple tint. R .gold twist.

H. Black red.

No. IV.

B. Equal parts of hare's flax dyed yellow, waterrat's fur undyed, and of rabbit's flax undyed. R. straw-coloured silk.

H. Smoky blue.

N.B.-This is a greenish-coloured body. This fly may be made up lighter or darker, both in body and in hackle.

\section{No. V.}

B. The same as No. 2. R. gold twist.

H. As positively brown or drab-coloured, as can be got. 
No. VI. Size, No. 7 to 5 .

B. Equal parts of brown bullock's hair and of the ends of squirrel's fur. R. gold twist.

W. Pheasant, or

H. Bluish red.

No. VII. Size, No. 6 or 5 .

B. The black flax from a rabbit's tail, some flax from the eyelid, ditto from the back, all from a skin dyed in the yellow dye.

W. Thrush, or

H. Blue to match the body. ,

\section{No. VIII. Size, No. 7 to 5 .}

B. Finest cow's hair, such as you can pick out of a wren's nest. R. straw-coloured silk.

H. Dark rusty blue.

\section{A R C H.}

The above will all kill, particrularly No. $2 \& 5$. No. IX. Size, No. 7 to 5 .

B. Hare's flax, and water-rat's fur mixed. R. straw-coloured silk.

H. Very rusty blue, inclining to a brown, not to a red.

No. X. Size, No. 6.

B. Light claret-coloured silk.

H. Smoky blue. 
No. XI. Size, No. 5 or 4 .

B. Yellow mohair, and the roots of the flax from a hare's back, dyed in the yellow dye.

H. Light smoky blue.

No. XII. Size, No. 7 or 6.

B. Red cow's hair.

H. Lightish blue.

W. Woodcock.

No. XIII.

B. Red fur of a fox.

H. Blood red.

W. Under feather of a woodcock's wing.

No. XIV. Size, No. 6 or 5 .

B. The dark smoky feather of a heron.

H. Of similar colour.

No. XV. Size, No. 7 or 6.

B. The reddest part of a fox's brush, flax from the neck of a hare, and also some from the same part dyed yellow, in equal parts. $R$. straw-coloured silk conspicuously.

W. Woodcock's-pick out the body for leg's or feet-or put on

H. A light rusty red. 
No. XVI. Size, No. 7 or 6 .

B. Bright red bullock's hair, flax from hare's neck, dyed yellow, and some from the reddest part of a fox's brush. Pick out the body for legs.

W. Woodeock's.

No. XVII. Size, No. 7 to 5 .

B. Yellow silk, slightly waxed.

H. Red.

W. Thrush.

No. XVIII. Size, No. 6 to 4 .

B. From the back of a water-rat.

H. Black red.

No. XIX. Size, No. 6 to 4 .

B. Lightest part of the roots of the fur of a fox, taken from the back. R. straw-coloured silk conspicuously. Two tails taken from a blue hackle.

H. Two turns of a light blue.

W. Starling.

No. XX. Size, No. 7 or 6 .

B. Equal parts, cow's hair, hare's flax, and fox's fur, put on abundantly and then picked out, so as to stick out roughly.

W. Woodcock. 


\section{A P R I L.}

The foregoing flies will kill in this month. The greenish-bodied flies should be made lighter as the season advanees.

No. XXI. Size, No. 7 to 5 .

B. Reddish fox's fur and fur from a grey cat. Pick out the body to make the legs.

W. Bluish pheasant's feather.

No. XXII. Size, No. 5 or 4.

B. Equal parts of the fur of a rabbit's skin dyed yellow, and of one in natural colour. $R$. silver twist.

H. Light silvery blue.

No. XXIII. Size, No. 5 or 4.

B. Rabbit's fur. R. straw-coloured silk.

H. Two turns of a silvery blue.

W. Thrush.

\section{No. XXIV. Size, No. 6 to 4 .}

B. Equal parts of the fur from the back of a fox, and of the roots of the fur from the back of a hare's skin, dyed yellow. R. strawcoloured silk.

H. Light silvery blue. 
No. XXV. Size, No. 7 to 4.

B. House-rat. R. silver twist.

H. Highly speckled or grizzled blue.

No. XXVI. Size, No.

B. Peacock's tail. R. silver twist.

H. Rusty blue.

No. XXVII. Size, No. 7 or 5.

B. Hare's flax. R. gold twist.

H. Dark rusty red.

No. XXVIII. Size, No. 6 to 4 .

B. Hare's ear, mixed with a little dark squirrel's fur.

H. Dark rusty blue.

No. XXIX. Size, No. 5.

B. Hare's ear.

H. Dark brown.

W. Dark part of a pbeasant's wing.

No. XXX. Size, No. 5 or 4.

B. Dark squirrel. R. straw-coloured silk.

H. Lightish rusty blue.

No. XXXI. Size, No, 6 to 4.

B. Fur pulled out from the forehead of an old fox. R. gold twist.

H. Bluish red. 
No. XXXII. Size, No. 5 or 4.

B. Equal parts from the ear of a hare, of a nutural colour, and from one dyed yellow.

$\mathrm{R}$. bright yellow silk.

II. Dark rusty red.

\section{A Y.}

In this month the May flies, and small. winged blues of the shops, may be used with advantage on the larger streams:

No. XXXIII. Size, No. 7 or 6.

B. Equal parts, hare's flax, natural and ditto, - dyed yellow. R. gold twist.

H. Yellow spangled red.

No. XXXIV. Size, No. 7 or 6.

B. Flax from a very young leveret, shaved as the hare's flax. R. silver twist.

H. Spangled silvery blue, or spangled blue ginger.

\section{J U N E.}

The flies here below given are for upstream fishing in very low and bright water. No. XXXV. Size, No. 7 or rarely 6.

B. Hare's flax dyed yellow. R. gold twist. H. The most brilliant yellowish red obtainable. 


\section{No. XXXVI. Size, No. 7 or rarely 6 .}

B. Bright yellow worsted, bound over lightly with strong yellow silk of the same colour as the worsted.

H. The bright yellow red hackle from a bantam cock.

No. XXXVII. Size, No. 7 or rarely 6 .

B. Bright red worsted: R. gold twist.

H. The same as in No. 36 .

No. XXXVIII. Size, No. 7 or rarely 6.

B. Dark blood orange. R. gold twist.

H. Black.

In making all the flies from No. 33 to No. 38 inclusive, put on the hackle in abundance, so as to make the fly very bushy.

The numbers in the Table following refer to the flies in the foregoing list, so that any one can readily understand the flies which are used throughout the year on the different streams in the North of Devon. 
212

\begin{tabular}{|c|c|c|c|c|c|c|c|}
\hline 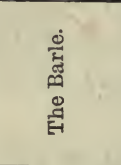 & $\begin{array}{l}+1 \\
\text { ला } \\
-\infty\end{array}$ & 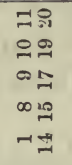 & 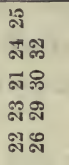 & $\begin{array}{l}\text { ลิ } \\
\text { ส } \\
\text { ลี } \\
\text { ลี }\end{array}$ & \begin{tabular}{l} 
Nิ \\
$\infty$ \\
o \\
\multirow{1}{1}{} \\
$\infty$ \\
$\infty$
\end{tabular} & 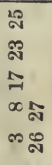 & 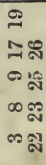 \\
\hline 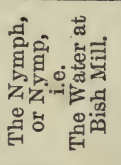 & $\begin{array}{l}\infty \\
\infty \\
\infty\end{array}$ & 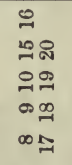 & 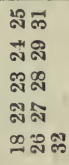 & $\begin{array}{l}\text { N } \\
\text { ลิ } \\
\text { Nิ } \\
\infty \\
\stackrel{1}{=}\end{array}$ & $\begin{array}{l}\infty \\
\text { న } \\
\text { సิ } \\
\infty \\
\text { N } \\
\text { నิ }\end{array}$ & $\begin{array}{l}\text { มิ } \\
\text { Aิ } \\
\text { ลิ } \\
\text { เึ }\end{array}$ & $\begin{array}{l}\text { के } \\
\text { Nे } \\
\text { के } \\
\text { ลे } \\
\text { क }\end{array}$ \\
\hline 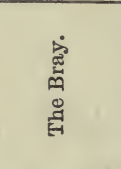 & $\begin{array}{l}\qquad 0 \\
+\infty \\
\infty \\
\infty\end{array}$ & 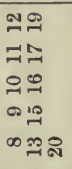 & 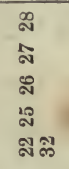 & 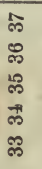 & 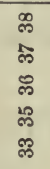 & 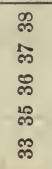 & $\begin{array}{l}\text { ले } \\
\text { ले } \\
\text { ले }\end{array}$ \\
\hline 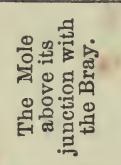 & $\begin{array}{l}0 \\
40 \\
+\infty \\
\sim \infty \\
-\infty\end{array}$ & 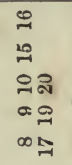 & 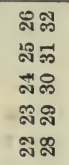 & $\begin{array}{l}\text { సิ } \\
\text { สิ } \\
\text { ลี } \\
\text { สี }\end{array}$ & $\begin{array}{l}\text { N } \\
\text { ก } \\
\text { N1 } \\
\infty \\
\infty\end{array}$ & 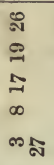 & 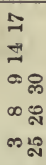 \\
\hline 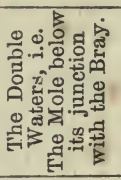 & $\begin{array}{l}\text { मी } \\
\text { का } \\
\text { का } \\
-\infty\end{array}$ & $\begin{array}{l}0 \\
0 \\
0 \\
0 \% \\
09 \\
09 \\
\infty \pi\end{array}$ & 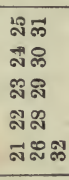 & $\begin{array}{l}\text { ลิ } \\
\text { สึ } \\
\text { ลี } \\
\text { ลี }\end{array}$ & 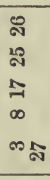 & 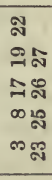 & 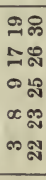 \\
\hline $\begin{array}{l}\text { Eे } \\
\text { E्म } \\
\text { E् }\end{array}$ & $\begin{array}{l}\infty \\
m \infty \\
m \infty \\
\infty\end{array}$ & 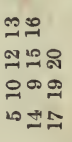 & 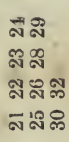 & $\begin{array}{l}\text { ๙ } \\
\text { สู }\end{array}$ & 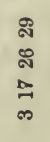 & 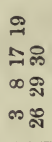 & \\
\hline 害 & 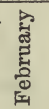 & 혈 & 㻤 & : & $\dot{\Xi}$ & $\dot{\vec{B}} \overrightarrow{\dot{B}}$ & 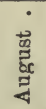 \\
\hline
\end{tabular}



RETURN TO the circulation desk of any University of California Library or to the

NORTHERN REGIONAL LIBRARY FACILITY Bldg. 400, Richmond Field Station University of California Richmond, CA 94804-4698

ALL BOOKS MAY BE RECALLED AFTER 7 DAYS 2-month loans may be renewed by calling (415) 642-6233

1 -year loans may be recharged by bringing books to NRLF

Renewals and recharges may be made 4 days prior to due date

DUE AS STAMPED BELOW

\section{AUG 31989}

SENT ON ILL

SEP 141994

U. C. BERKELEY 
YA 01256 
